\title{
UM MODELO DE AVALIAÇÃO DE NOVAS TECNOLOGIAS: O CASO DO SISTEMA DE CANA CRUA
}

\author{
MIGUEL SANTAELLA
}

Engenheiro Agrônomo

Orientador: Prof. Dr. Fernando Curi Peres

\begin{abstract}
Dissertação apresentada à Escola Superior de Agricultura "Luiz de Queiroz", da Universidade de São Paulo, para obtenção do título de Mestre em Agronomia, Área de concentração: Economia Agrária.
\end{abstract}

PIRACICABA

Estado de São Paulo -Brasil

Fevereiro - 1995 
CATALOGAÇÃO NA PUBLICAÇÃO

DIVISÃO DE BIBLIOTECA E DOCUMENTAÇÃO - CAMPUS "LUIZ DE QUEIROZ"/USP

Santaella. Miguel

Um modelo de avaliação de novas tecnologias: o caso do sistema de cana crua. Piracicaba, 1995.

$89 p$.

Diss. (Mestre) - ESALQ

Bibliografia.

1. Cana-de-açúcar - Colheita - Tecnologia 2. Cana-de-açúcar Produção Modelo Linear 3. Modelo matemático 4. Simulação automatizada I. Escola Superior de Agricultura Luiz de Queiroz, Piracicaba 


\title{
UM MODELO DE AVALIAÇÃO DE NOVAS TECNOLOGIAS: O CASO DO SISTEMA DE CANA CRUA
}

\author{
MIGUEL SANTAELLA
}

Aprovada em: 25.08 .95

Comissão julgadora:

Prof. Dr. Fernando Curi Peres

ESALQ/USP

Prof. Dra. Heloisa Lee Burnquist ESALQ/USP

Dr. Jorge Alberto Gonçalves da Silva COPERSUCAR

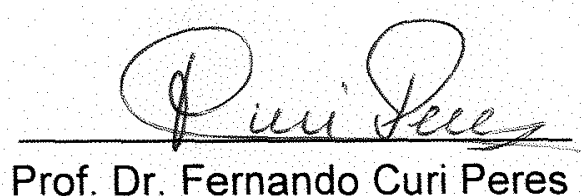

Orientador 


\section{INDICE ANALITICO}

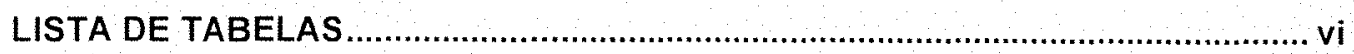

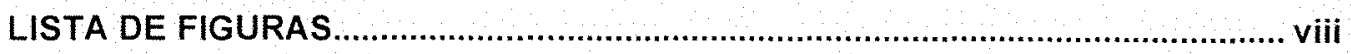

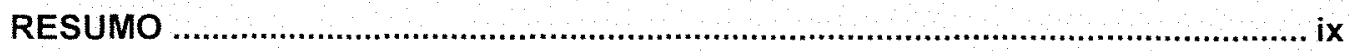

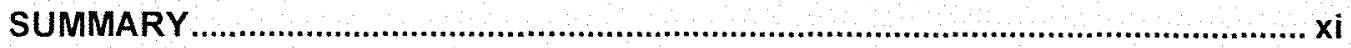

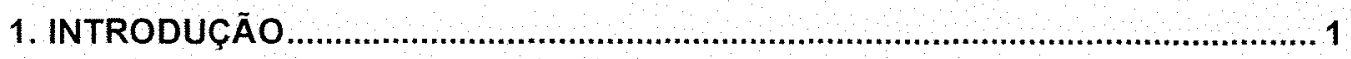

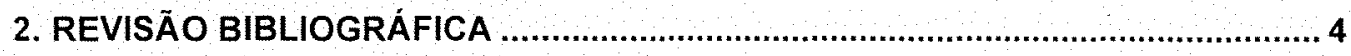

2.1. EFEITO DA QUEIMA NA QUALIDADE TECNOLOGICA DA MATERIA-PRIMA _............. 4

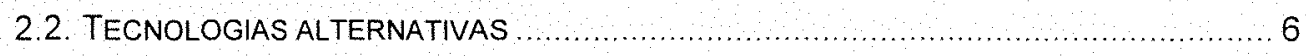

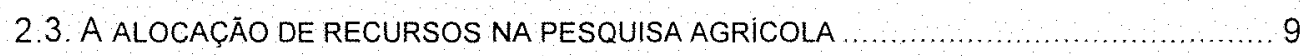

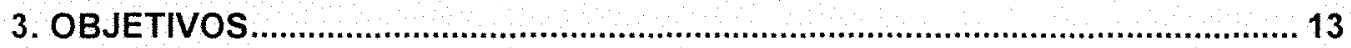

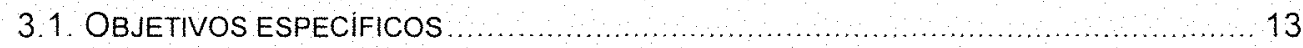

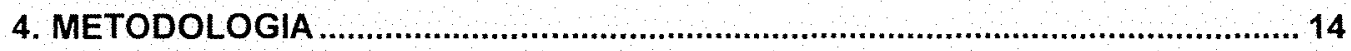

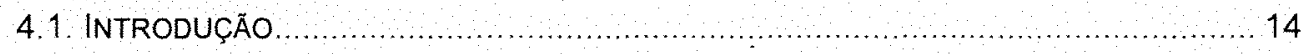

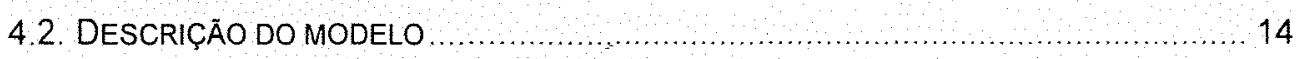

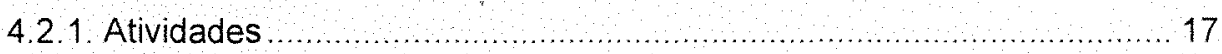

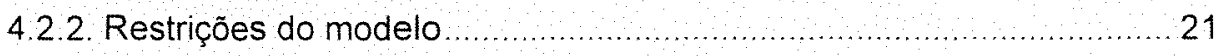

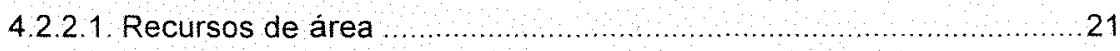

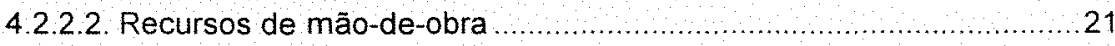

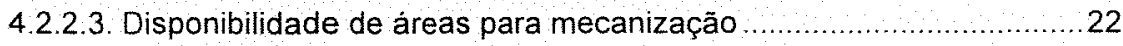

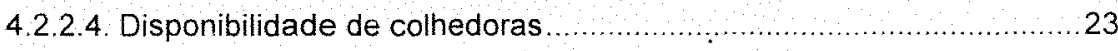




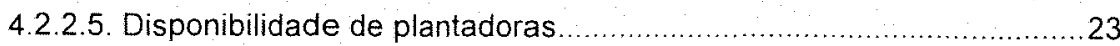

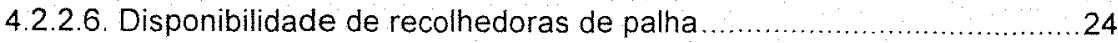

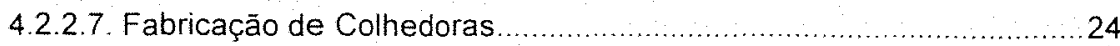

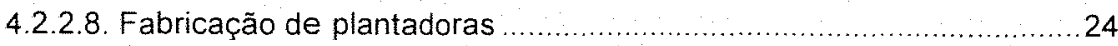

4.2. 2.9. Fabricação de recolhedoras de palha

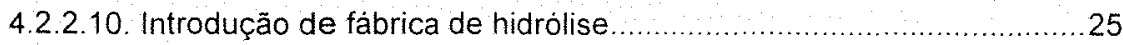

4.2.2.11. Introdução de fábrica de cogeração de energia elétrica ...............25

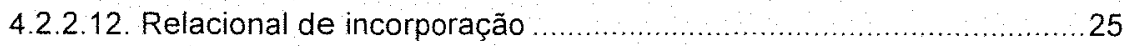

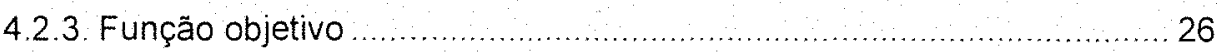

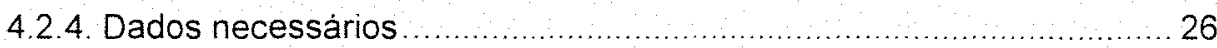

4.2.5. Descrição matemática do modelo .......................................... 31

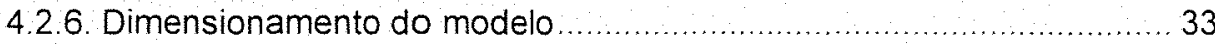

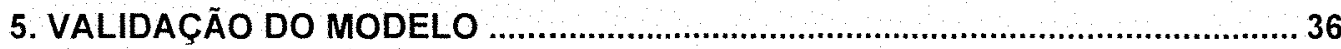

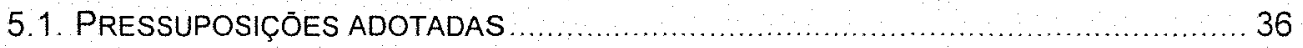

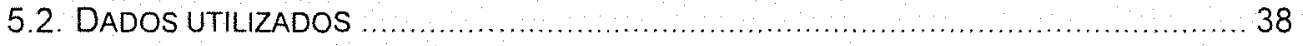

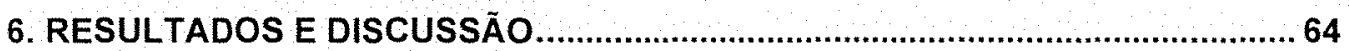

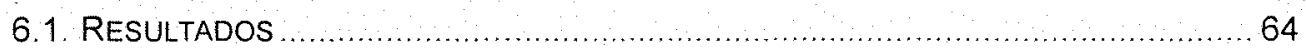

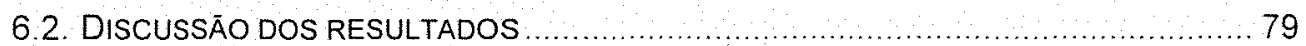

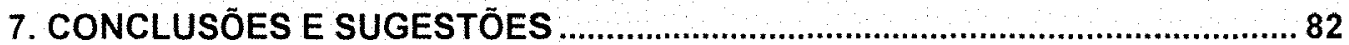

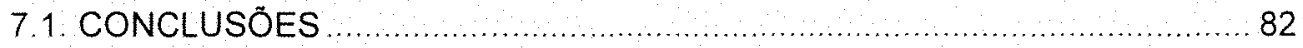

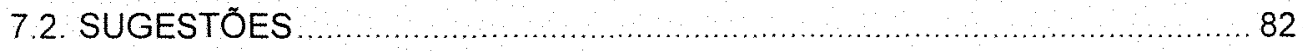

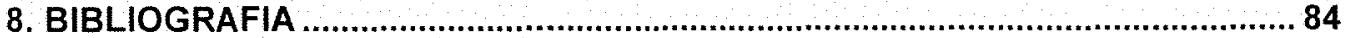




\section{LISTA DE TABELAS}

TABELA 1: ATIVIDADES UTILIZADAS PELAS DIVERSAS POLITICAS DO MODELO E SUA RESPECTIVA UNIDADE.

TABELA 2: ATIVIDADES UTILIZADAS PELAS DIVERSAS POLITICAS DO MODELO E SUA RESPECTIVA UNIDADE

TABELA 3 : INFORMAÇÕES NECESSÁRIAS PARA O CALCULO DA FUNÇÃO OBJETIVO E PARA O PREENCHIMENTO DOS COEFICIENTES DAS RESTRIÇŌES

TABELA 4 EQUIPAMENTOS E PRODUTOS COM POSSIBILIDADE DE COMPRA E/OU VENDA AO LONGO DO HORIZONTE DE PLANEJAMENTO E SUAS RESPECTIVAS UNIDADES 30

TABELA 5 : INFORMAÇOEES NECESSARIAS PARA PREENCHIMENTO DOS "RHS" 30

TABELA 6: ATIVIDADES UTILIZADAS PELAS DIVERSAS POLITICAS DO MODELOE SEU RESPECTIVO CUSTO 39

TABELA 7 : PREÇO DE COMPRA E/OU VENDA DE EQUIPAMENTOS E PRODUTOS UTILIZADOS AO LONGO DO HORIZONTE DE PLANEJAMENTO.

TABELA 8: VALORES UTILIZADOS PARA O CÁLCULO DA FUNÇÃO OBJETIVO E PARA O PREENCHIMENTO DOS COEFICIENTES DAS RESTRIÇŌES

TABELA 9 : VALORES UTILIZADOS PARA PREENCHIMENTO DOS "RHS". 44

TABELA 10 : PRODUTIVIDADES E CARACTERISTICAS TECNOLOGICAS ADOTADAS PARA CANA QUEIMADA PARA TODO O HORIZONTE DE PLANEJAMENTO 46

TABELA 11 : PRODUTIVIDADES E CARACTERISTICAS TECNOLOGICAS ADOTADAS PARA CANA CRUA PARA TODO O HORIZONTE DE PLANEJAMENTO.

TABELA 12 DIVISÃO DA AREA COM CANA DE AÇÚCAR NO ESTADO DE SÃO PAULO EM BLOCOS DE ACORDO COM A EXPECTATIVA DE FERTILIDADE, DECLIVIDADE, DISTÂNCIA E ESTAGIO DE CORTE DISTANACIA E ESTAGIO DE CORTE. 
TABELA 13: ÁREA ALOCADA PELO MODELO PARA CADA POLITICA ADOTADA NOS LOCAIS COM DECLIVIDADE ACIMA DE $8 \%$.

TABELA 14 : ÁREA ALOCADA PELO MODELOO PARA CADA UMA DAS POLITICAS ADOTADAS PARA OS LOCAIS COM DECLIVIDADE MENOR OU IGUAL A $8 \%$

TABELA 15 :AREA ALOCADA PELO MODELO PARA CADA UMA DAS POLITICAS ADOTADAS PARA OS LOCAIS COM DECLIVIDADE MENOR OU IGUAL A $8 \%$ E DISTÂNCIA MENOR OU IGUAL A 10 $\mathrm{KM}$. 70

TABELA 16 : AREA ALOCADA PELO MODELO PARA CADA UMA DAS POLITICAS ADOTADAS PARA OS LOCAIS COM DECLIVIDADE MENOR OU IGUAL A $8 \%$ E DISTÂNCIA MAIOR QUE $10 \mathrm{KME}$ MENOR OU IGUAL A $20 \mathrm{KM}$

TABELA 17 : AREA ALOCADA PELO MODELO PARA CADA UMA DAS POLITICAS ADOTADAS PARA OS LOCAIS COM DECLIVIDADE MENOR OU IGUAL A $8 \%$ E DISTANNCIA MAIOR QUE $20 \mathrm{KM} \mathrm{E}$ MENOR OU IGUAL A $30 \mathrm{KM}$

TABELA 18 : ÁREA ALOCADA PELO MODELO PARA CADA UMA DAS POLITICAS ADOTADAS PARA OS LOCAIS COM DECLIVIDADE MENOR OU IGUAL A $8 \%$ E DISTÂNCIA MAIOR QUE $30 \mathrm{KM} \ldots .76$ 


\section{LISTA DE FIGURAS}

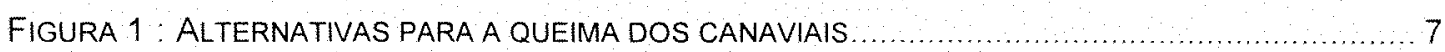




\title{
UM MODELO DE AVALIAÇÃO DE NOVAS TECNOLOGIAS: O CASO DO SISTEMA DE CANA CRUA
}

\author{
Autor: Miguel Santaella \\ Orientador: Prof. Dr. Fernando Curi Peres
}

\section{RESUMO}

Este trabalho visou desenvolver um modelo matemático que viesse a auxiliar os centros de pesquisa a direcionar as suas pesquisas voltadas à eliminação ou redução das queimadas dos canaviais.

Para tanto foi criado um modelo de otimização que utiliza a metodologia de programação linear. O modelo procura simular o processo de produção da agro-indústria da cana-de-açúcar e permite analisar o efeito da introdução de novas tecnologias num horizonte de 16 anos. As principais variáveis analisadas pelo modelo são os custos de produção, a utilização de mão-de-obra, a disponibilidade de máquinas, o destino alocado para a palha de cana que deixaria de ser queimada no campo e os efeitos na produtividade agrícola e na qualidade da matéria-prima que chega à industria. Cada nova tecnologia a ser estudada pode ter um efeito sobre uma ou mais destas variáveis, deixando o modelo livre para mostrar as consequências de sua implantação ou o potencial de utilização para esta tecnologia. 
Para validar o modelo foi realizada uma simulação que não considera a introdução de nenhuma nova tecnologia nem a variação das eficiências operacionais ou custos de produção durante o horizonte de planejamento. Esta simulação serve de parâmetro de comparação para qualquer outra que venha a ser realizada. Visando agilizar a realização de novas simulações foi desenvolvido um programa de computador que gera a matriz do modelo no formato MPSX. 


\title{
AN EVALUATION MODEL FOR NEW TECHNOLOGIES: THE CASE OF HARVESTING NON-BURNED SUGARCANE
}

\author{
Author: Miguel Santaella \\ Adviser: Prof Dr. Fernando Curi Peres
}

\section{SUMMARY}

An optimization mathematical model was built to help research institutions evaluate alternative technologies aimed at eliminating the routine of burning sugar-cane fields before harvest. In building the model, linear programming was utilized. The model describes the present sugar-cane production process and allows simulation of other technologies to be tested. It covers a 16 year planning horizon. Among the most important variables considered are the costs of production, labor requirements, and machinery availability. The destination of the trash, when fields are not burned before harvesting, is taken into account. Also, the consequent effect on both soil fertility and on the quality of raw material taken to destilaries and sugar mills is considered. New technologies can be tested by the model and their effects on each variable can be evaluated.

To validate de model, it was run without introducing any new technology or variations on costs of production for the planning horizon. Results of any desired simulation can be compared to this basic run. To 
expedite the simulation process a software that generates a MPSX linear programming matrix was produced. 


\section{INTRODUÇÃO}

A queima da palha de cana anteriormente ao corte é uma prática bastante utilizada no Brasil e no mundo. A queima prévia visa a eliminação da palha e folhas secas facilitando o corte manual ou mecanico da cana.

Os principais motivos da queima prévia do canavial para corte manual são apontadas por FERNANDES(1988), BASSINELO(1988), MACEDO(1991), RÍPOLI(1990) e outros como sendo: a)Segurança do Trabalhador a queima prévia evita os cortes por folhas, elimina o "Joçal" (pequenos pêlos de sílica urticantes das folhas de cana), diminui o risco de acidentes com animais peçonhentos, aumenta a visibilidade para o cortador evitando acidentes com o facão e elimina o risco de incêndio acidental quando do corte, b)Capacidade de Corte: a capacidade do corte cai de cerca de $9 \mathrm{t}$ cana/dia homem na cana queimada para 2 a $3 \mathrm{t}$ cana/dia homem na cana crua (cana sem queimar); c)Eliminação de impurezas com a queima prévia consegue-se levar cerca de $20 \%$ a menos de impureza vegetal (folhas, palmito, etc.) e mineral (terra, pedras, etc.) para a usina; d)exigencia dos trabalhadores: os contratos de trabalho com os sindicatos dos cortadores de cana exigem que a cana seja queimada antes do corte. 
Os mesmos autores apontam os seguintes motivos para a queima do canavial para corte mecânico: a)eliminação de impurezas: cerca de $32 \%$ a menos de impurezas vegetais e minerais são levadas para a indústria quando se realiza a queima prévia; b)consumo e capacidade operacional: o consumo específico (l/t cana) é cerca de $51 \%$ maior e a capacidade operacional (t cana/h) é cerca de $30 \%$ menor quando não se queima a cana antes do corte; c)perdas quando se corta cana crua tem-se um aumento de cerca de $65 \%$ na perda de cana no campo (cana que deixa de ser levada à usina).

Apesar dessas aparentes vantagens, existem diversos trabalhos que apontam os problemas causados, à própria agro-indústria sucroalcooleira, pela queima do canavial antes do corte. 0 principal destes problemas parece ser a deterioração rápida da cana após a queima, tornando necessário o seu corte, carregamento transporte e processamento em menos de 48 horas, a fim de evitar perdas muito grandes de sacarose.

Nos últimos anos, pressões de ambientalistas e das populaçōes que vivem nas regiōes canavieiras vem forçando os centros de pesquisa a fornecer tecnologias alternativas a este processo. Muitos são os pesquisadores envolvidos no levantamento dos possiveis danos causados pela queima não só ao ambiente como também à saúde humana. KIRCHHOFF(1991) aponta o problema do ozônio produzido indiretamente 
pelas queimadas como um elemento que, em grandes concentrações, é tóxico para as pessoas e pode afetar o crescimento das plantas. Em seu trabalho encontrou concentrações 4 vezes maiores na época da queima do que na entre-safra da cana. Outros pesquisadores como MANSO(1991) citado por KIRCHHOFF(1991) apontam para o problema do particulado emitido pela queima, o "carvãozinho", como sendo um precursor de doenças respiratórias. Embora outros pesquisadores refutem essas teorias (HALL(1990),MACEDO(1991)), pode-se esperar que essas pressões devam continuar aumentando única e simplesmente pelo incômodo causado por essa fuligem às populações das áreas canavieiras.

Uma outra corrente de pesquisadores, está mais preocupada com o aproveitamento econômico da palha do que exclusivamente com o problema ambiental. Para eles, a queima da palha de cana é um desperdicio pois a palha poderia ser responsável por aproximadamente um terço de toda a energia potencialmente gerada em um canavial (RIPOLI(1990)). Esta palha poderia ainda ser utilizada na alimentação animal (AYALA(1987)) ou ser queimada nas caldeiras em substituição ao bagaço, liberando este último para uso mais nobre como a fabricação de papel, papelão, etc. (ATCHISON(1977)). 


\section{REVISÃO BIBLIOGRÁFICA}

Este capítulo foi dividido em 3 seções. A primeira delas apresenta uma comparação da qualidade tecnológica da matéria-prima nos sistemas de corte de cana crua e do corte de cana queimada. Na segunda são apresentadas as vantagens e desvantagens das alternativas tecnológicas que estão sendo desenvolvidas visando a eliminação da operação de queima. Na terceira e última seção são apresentados trabalhos realizados que visavam orientar o direcionamento de pesquisas agricolas.

\subsection{Efeito da queima na qualidade tecnológica da matéria-} prima

O efeito da queima na qualidade da cana-de-açúcar como matériaprima é talvez, o aspecto mais pesquisado quando se pensa em queima de cana. Mas, nem por isso, é o mais conhecido. Autores como NICKELL(1970) e ORSENIGO(1978) afirmam que, em estudos realizados, a produtividade da cana (t/ha) não diferiu entre cana cortada crua e cortada queimada. Os mesmos autores afirmam também haver um ganho na quantidade de açúcar teórico recuperável quando se faz a queima prévia.

Por outro lado, TURNER(1961), GASCHO(1972), WOOD(1973), REDMAN(1977), YOUNG(1983), FURLANI NETO(1989) e outros, mostram 
em seus trabalhos existir uma deterioração após o corte mais rápida e mais acentuada da cana queimada em relação à cana crua, provocando perda de peso e de qualidade tecnológica.

Apesar de existir uma aparente contradição nos trabalhos realizados, FOSTER e IVIN(1981) conseguiram explicar de uma maneira bastante clara - processo físico-químico a que a cana-de-açúcar é submetida quando queimada. Segundo eles os efeitos da queima variam muito de acordo com a intensidade do fogo e das condições de umidade do solo. Eles apontam a exụdação pelo colmo e a ejeção de fluido pela ruptura das células como os principais fatores causadores de perda de peso. Em algumas situaçōes, quando o fogo não é muito intenso e existe boa humidade no solo, a canade-açúcar pode readquirir seu peso anterior pela rápida absorção de água pelas raizes.

Esses mesmos autores esclarecem que existem perdas de açúcares durante a queima por destruição térmica da sacarose, perda de açúcar junto com o caldo exudado ou expelido na explosão das células com o calor Eles afirmam que, se o fogo for intenso, a perda de água pode ser muito maior, proporcionalmente, que a perda de açúcar fazendo com que a concentração de açúcar na cana (Pol \% cana) seja mais alta do que na cana crua. Isto, entretanto, não significa que a quantidade de açúcar por hectare (Kg de Pol 
por ha) seja maior pois a cana de açúcar pesaria menos, por perda de água, gerando uma quantidade total de açúcares menor.

\subsection{Tecnologias alternativas}

* Diversas alternativas vem sendo estudadas visando aproveitar a massa vegetal que deixa de ser queimada no sistema de cana crua. Um esquema simplificado das possiveis alternativas para utilização da palha é apresentado no Diagrama 1.

Alguns pesquisadores defendem a manutenção da palha no campo visando diminuir problemas de erosão, controlar plantas daninhas e aumentar a produtividade pela manutenção da umidade do solo. Em seu trabalho, SALLAWAY (1979) concluiu que o principal papel da manutenção da palha no campo seria o de diminuir a erosão. Para ele, a manutenção da palha no campo tem um efeito muito pequeno na produtividade agricola, podendo ser significante somente com o possivel aumento da matéria orgânica após muitos anos de cultivo. Quanto ao aparecimento de plantas daninhas, SALLAWAY (1979), assim como MATHUR e SAKSENA(1965) apontam para uma diminuição da infestação quando a palha é deixada no campo, podendo até mesmo ser eliminada a aplicação de herbicidas. 


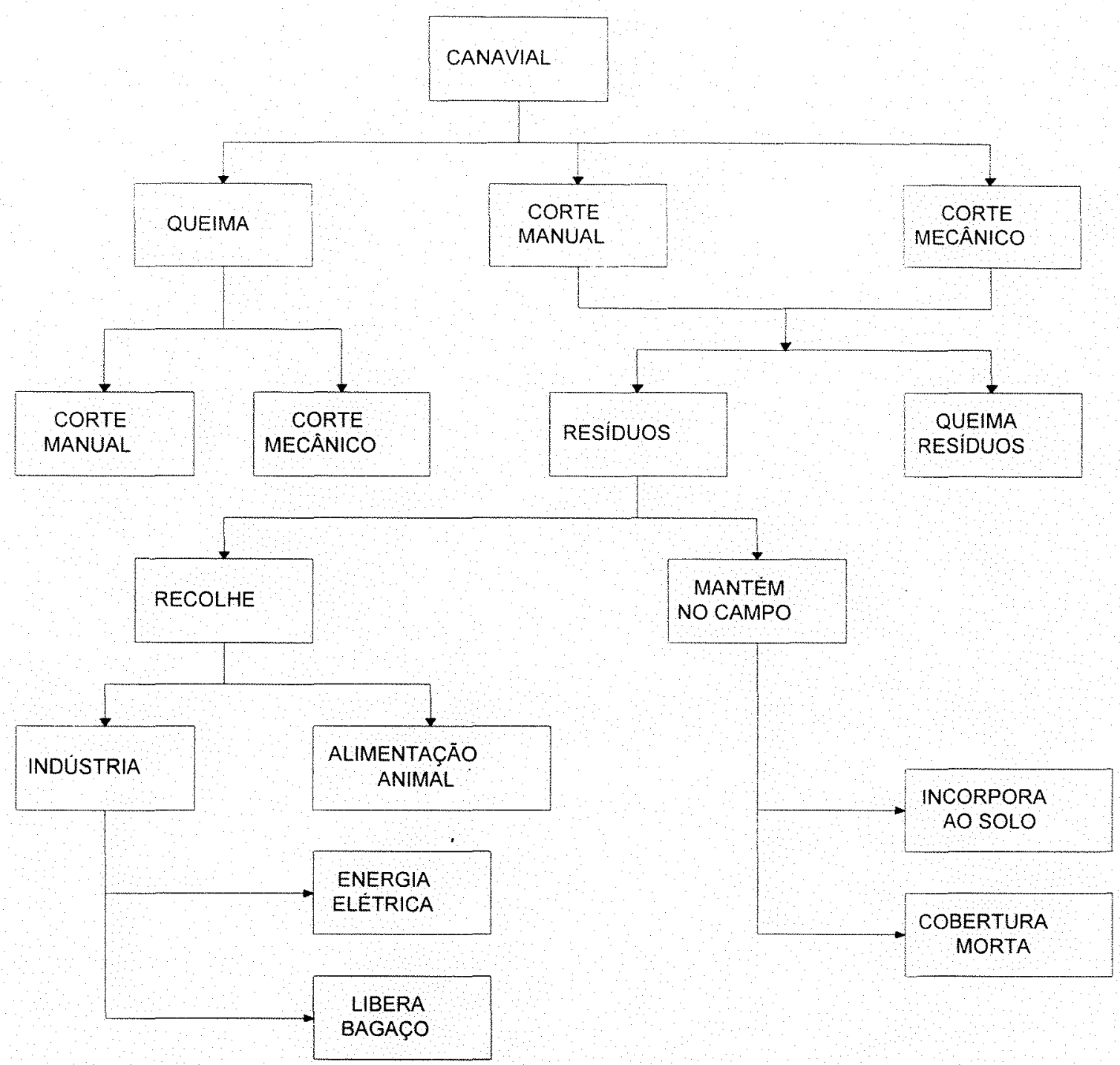

Figura 1 : Alternativas para a queima dos canaviais

Entretanto, a não queima do canavial pode trazer alguns problemas. Segundo DEGASPARI et alli (1973) a queima da cana ajuda no controle da broca da cana (Diatraea saccharalis) reduzindo drasticamente sua população sem contudo diminuir os seus inimigos naturais na mesma proporção. 
Um outro grupo de pesquisadores está procurando formas de aproveitar esta nova fonte de biomassa gerada pela eliminação da queima dos canaviais. Com esse pensamento, RiPOLI(1991) chamou a atenção para a quantidade de energia que é jogada fora a cada ano pela queimada. De acordo com seus cálculos um hectare de cana com produtividade média de 70 toneladas de cana produz cerca de 10 toneladas de palha e ponteiros que, se não fossem queimados, poderiam gerar aproximadamente 21000 MCal. Esses valores são bastante próximos dos valores obtidos por CETESB(1985) e AGUILLAR(1989).

Uma vez que é sabido que está sendo jogada fora uma grande quantidade de energia, é preciso estudar um meio de evitar esse desperdício. Este foi o objetivo de EILAND(1983), LOPEZ(1987), HOWE e SREESANGKOM(1990) e MOLINA(1991) ao fazerem levantamentos do custo de recolhimento, transporte e processamento da palha. Nestes trabalhos, os autores conseguem mostrar que, quase sempre, pode-se gerar mais energia do que é consumida no processo. Entretanto, isso infelizmente não garante a economicidade da alternativa pois a energia que é consumida está fundamentalmente na forma de óleo díesel e a que é gerada na forma de energia elétrica cuja política de preços difere substancialmente da anterior. 
Avançando ainda mais no sistema, ATCHISON(1977) apresenta diversas opções para a utilização do bagaço que seria liberado pela utilização nas caldeiras da palha recolhida no campo. Entre as diversas alternativas apontadas destacam-se a produção de papel e de papelão. Seguindo o mesmo raciocínio AYALA(1987) recomenda a utilização do bagaço ou da própria palha para a alimentação animal após sofrerem um processo de hidrólise.

Toda estas pesquisas são bastante interessantes mas não podemos esquecer que, no Brasil, cerca de $85 \%$ da cana produzida é cortada manualmente e que, segundo RíPOLI(1990), o rendimento de corte da mão de obra cai de quase 10 toneladas de cana por homem-dia para aproximadamente 3 toneladas. Este fator se torna ainda mais grave quando percebemos que somente cerca de $45 \%$ da área de cana no Estado de São Paulo seriam mecanizáveis com as colhedoras existentes hoje no mercado (TOLEDO(1991)). Pode-se perguntar como, com o nível atual de tecnologia disponivel, se conseguiria tornar as áreas não mecanizáveis viáveis economicamente se a queima dos canaviais fosse simplesmente proibida.

\subsection{A alocação de recursos na pesquisa agrícola}

Diversos estudos tem sido realizados visando definir uma metodologia para a alocação de recursos em pesquisa. A maior parte dos pesquisadores 
procurou avaliar os centros de pesquisa como um todo, direcionando o orçamento anual para as pesquisas com maior probabilidade de retorno. $\mathrm{A}$ grande divergência existente entre as diversas linhas de pesquisa está, justamente, na definição do que seja o retorno de uma pesquisa.

KALDOR(1971),PAULSEN(1971) e HEADY(1971) defendem que os possiveis efeitos colaterais de uma pesquisa que fossem prejudiciais à sociedade deveriam ser considerados como parte do custo social pago para chegar ao efeito positivo ou benéfico dessa mesma pesquisa. Neste caso, o gasto público em pesquisa é considerado como um investimento feito pela sociedade visando aumentar o seu bem estar geral. O problema neste tipo de enfoque é que para determinar as pesquisas a serem realizadas necessita-se de uma função de bem estar social que contemple todos os fatores envolvidos com os resultados diretos ou indiretos das possiveis pesquisas a serem realizadas. Esta função é, no mínimo, de muito difícil obtenção.

PETERSON(1971), EVENSON(1971) e outros defendem, por outro lado, que a pesquisa já demonstrou sua capacidade de acelerar o crescimento nacional dos Estados Unidos e que o sistema relativamente descentralizado e pluralista de órgãos de financiamento foi fundamental neste sucesso não devendo, portanto, ser modificado. Entretanto, este tipo 
de enfoque não maximiza a utilização dos recursos limitados aplicados à pesquisa.

Um terceiro ponto de vista, defendido por FISHEL(1971), PUTERBAUGH(1971) e MAHLSTEDE(1971), acredita que a utilização de uma metodologia mais formal e sistemática de fornecer informações às pessoas tomadoras de decisão poderia aperfeiçoar o sistema atualmente utilizado. TICHENOR e RUTTAN(1971) concluem que, seja qual for o critério utilizado para se alocar recursos em pesquisa, deve-se lembrar que estas metodologias precisam incentivar a criatividade pois dela depende a obtenção de resultados satisfatórios de pesquisas inovadoras.

Outros trabalhos procuraram analisar o direcionamento dado à pesquisa no passado e as consequências dessas decisões. Os trabalhos de GRILICHES(1964), que estudou os efeitos das despesas em pesquisa e educação na produção agrícola agregada, e o de AYER e SCHUH(1972), que avaliou o caso específico da pesquisa em algodão no Estado de São Paulo, são exemplos desses trabalhos. Este mesmo objetivo foi também seguido por HAYAMI e RUTTAN(1970a) em seu trabalho sobre o efeito dos preços dos fatores no desenvolvimento da agricultura nos Estados Unidos e no Japão, onde concluiram que as mudanças no "mix" de insumos utilizados no crescimento agrícola dos dois países estudados representavam um processo dinâmico de substituição de fatores de acordo com as mudanças 
nos preços relativos dos fatores. Esta conclusão é muito importante pois mostra que, se pretendemos decidir qual direcionamento deve ser dado à pesquisa, devemos ter uma boa previsão de como vão se comportar os preços dos fatores no horizonte de tempo analisado. Não devemos esquecer, entretanto, que, para obter os resultados almejados, devemos considerar também os preços relativos dos produtos e subprodutos, reais ou possiveis, que possam ser gerados pela tecnologia em análise.

Um outro conceito utilizado para direcionar pesquisas é o utilizado por PIZYSIEZNIG(1987) que procurou primeiramente modelar o sistema de produção da cultura com que ele trabalhou, no caso o cacau, para depois analisar o impacto que teria a introdução de novas tecnologias no sistema. A partir daí, por uma análise de sensibilidade ele procurou definir qual seria o melhor direcionamento de pesquisas futuras de modo a atingir os melhores resultados possíveis no sistema de produção. Este tipo de enfoque é bastante interessante quando se deseja analisar uma cultura ou um sistema produtivo especifico, ao invés de um centro de tecnologia ou toda a política de pesquisa de um pais. 


\section{OBJETIVOS}

O objetivo desta dissertação é auxiliar os centros de pesquisa na identificação das melhores linhas de pesquisa a serem seguidas para se chegar com maior rapidez e eficiência às melhores alternativas à queima de palha de cana através do desenvolvimento de um modelo matemático que simule o sistema agroindustrial da cana-de-açúcar.

\subsection{Objetivos específicos}

Pretende-se, neste trabalho, desenvolver um modelo de programação linear que permitirá a modelagem do sistema de produção de cana crua com a tecnologia disponivel hoje. Com este modelo ter-se-á condições de avaliar a relevância de cada fator de produção no atual estágio de tecnologia. Este modelo visa ser a ferramenta que permitirá aos órgãos de pesquisa a realização de análises de sensibilidade visando a identificação do melhor direcionamento para novos experimentos através de simulações com diversas expectativas de resposta das tecnologias em estudo. Conforme novas pesquisas sejam iniciadas pode-se incorporar atividades ao sistema para incluí-las nas avaliações. 


\section{METODOLOGIA}

\subsection{Introdução}

Este trabalho utilizará um modelo de programação matemática para avaliar a utilização de novas tecnologias de produção de cana-de-açúcar. Optou-se por esta abordagem pelas vantagens operacionais que ela traz como a mudança no "mix" de produtos ou nas relações estruturais. $\mathrm{O}$ modelo utilizado para representar o sistema de produção de cana-de-açúcar é um modelo simplificado que leva em consideração somente as atividades e restrições que diferem entre as diversas opções tecnológicas analisadas. Esta modelagem permite a inclusão de atividades elou restriçōes conforme novas tecnologias venham a ser estudadas.

\subsection{Descrição do modelo}

Foi adotado um horizonte de planejamento de 16 anos correspondente a dois ciclos de condução da cultura no ambiente de alta produção. Optouse por um horizonte de pelo menos dois ciclos da cultura para garantir que todas as tecnologias tenham tempo suficiente para serem implementadas. Todas as atividades foram definidas como ocorrendo dentro de um período de um ano e podem ser seqüenciais ou concomitantes. $O$ modelo permite 
que o pesquisador determine a duração de cada ciclo em cada ambiente e também o número de ambientes a serem utilizados. $O$ modelo adota um ciclo fixo de corte para cada um dos tipos de ambiente de produção considerados.

Cada ambiente de produção pode ser distribuido em qualquer número de faixas de distância da área agrícola até a usina. O modelo permite ainda que cada relação ambiente e distância seja distribuida em um número indeterminado de faixas de declividade. Para cada ambiente, faixa de distância e faixa de declividade assumiu-se a hipótese de que as áreas estariam uniformemente distribuidas entre os diversos estágios de corte adotados para aquele ambiente de produção.

O modelo visa avaliar a introdução de tecnologias na área atualmente plantada com cana-de-açúcar no Estado de São Paulo, não levando em consideração possíveis expansões ou diminuições dessa área. Deste modo está se considerando que o fator de produção terra já atingiu o seu limite máximo de utilização. Opcionalmente poder-se-ia utilizar uma curva de demanda por produtos finais como álcool, açúcar, bagaço, etc. Evitou-se utilizar este último enfoque neste trabalho devido à dificuldade existente em se conseguir uma previsão de demanda de longo prazo para estes produtos, principalmente o álcool. No presente modelo admitiu-se que toda a produção de cana será utilizada na fabricação de açúcar e álcool numa 
proporção fixa para cada ano do horizonte de planejamento. Esta proporção pode ser estipulada pelo pesquisador quando da realização da simulação.

De modo geral o modelo assume que toda a área de cana a ser analizada será dividida em blocos. Cada bloco representará a área de cana existente em um determinado ambiente de produção, uma faixa de distância média até a unidade industrial a que pertence, uma faixa de declividade e a um estágio de corte especifico. O modelo permite que cada um destes itens seja conforme o nivel de interesse ou conhecimento do pesquisador. Cada bloco será conduzido durante todo o horizonte de planejamento sendo que somente o estágio de corte sofrerá alteração de ano para ano, assumindo 0 valor estabelecido pela definição de ciclo de corte de cada ambiente de produção.

0 modelo exige que o pesquisador informe as produtividades e características tecnológicas (pol\%cana, pureza do caldo e fibra\%cana) para cada ambiente de produção e estágio de corte do ciclo definido para este ambiente. O modelo também necessita da informação da porcentagem de área já preparada para colheita mecanizada existente em cada bloco. Além disso, todos os valores estimados de rendimento de mão-de-obra, máquinas e valores de preços e custos precisam ser informados para cada nova atividade incluída no modelo. 


\subsubsection{Atividades}

Para cada bloco definido pelo pesquisador as seguintes politicas poderão ser adotadas a cada ano, dependendo do estágio de corte em que o bloco se encontrar:

\section{- Blocos em reforma:}

- Plantio manual com incorporação de palha;

- Plantio manual sem incorporação de palha;

- Plantio mecânico com incorporação de palha;

- Plantio mecânico sem incorporação de palha;

\section{- Blocos em estágios com corte:}

- Colheita manual de cana queimada;

- Colheita mecânica de cana queimada;

- Colheita manual de cana crua com recolhimento da palha e venda do excedente de bagaço;

- Colheita manual de cana crua com recolhimento da palha, hidrólise do bagaço excedente e venda do bagaço hidrolisado;

- Colheita manual de cana crua com recolhimento da palha, cogeração de energia e venda de energia elétrica excedente para a rede;

- Colheita manual de cana crua sem recolhimento de palha;

- Colheita mecânica de cana crua com recolhimento da palha e venda do excedente de bagaço; 
- Colheita mecânica de cana crua com recolhimento da palha, hidrólise do bagaço excedente e venda do bagaço hidrolisado;

- Colheita mecânica de cana crua com recolhimento da palha, cogeração de energia e venda de energia elétrica excedente para a rede;

- Colheita mecânica de cana crua sem recolhimento de palha.

Cada uma destas políticas representa um agrupamento de atividades que podem ou não serem realizadas a cada ano do horizonte de planejamento. Um custo ou receita está associado a cada atividade. 0 valor da função objetivo de uma determinada política em um determinado ano é o resultado da margem de contribuição da agroindústria da cana-de-açúcar calculada com os valores de custo elou receita às atividades formadoras desta politica neste ano. O modelo permite que cada atividade tenha um valor de custo ou receita diferenciado para cada ano permitindo, deste modo, a análise do efeito da variação dos custos de produção ou nos preços dos produtos ao longo do tempo no uso de tecnologia. Esta facilidade é importante porque é esperado que 0 custo de produção de uma determinada atividade decresça à medida em que uma nova tecnologia se torne mais difundida. As atividades adotadas nesta versão do modelo assim como a unidade em que são medidas são mostradas na Tabela 1. A forma de modelagem adotada permite que novas atividades e/ou políticas sejam 
incluídas tornando possível a rápida avaliação do potencial de uso de novas tecnologias no universo em estudo.

Tabela 1: Atividades utilizadas pelas diversas políticas do modelo e sua respectiva unidade.

\begin{tabular}{|c|c|}
\hline Atividade & Unidade \\
\hline Plantio manual & RS/ha \\
\hline Plantio mecanizado & $R \$ / h a$ \\
\hline Incorporação da palha ao solo & $\mathrm{R} \$ / \mathrm{ha}$ \\
\hline Queimar & $R \$ / h a$ \\
\hline Custo assistência social & $\mathrm{R} \$$ /dia homem \\
\hline Custos adicionais & $\mathrm{R} \$ / \mathrm{ha}$ \\
\hline Colheita mecanizada de cana queimada & $\mathrm{R} \$ / \mathrm{t}$ cana \\
\hline Colheita manual de cana queimada & $R \$ / t$ cana \\
\hline Colheita mecanizada de cana crua & $R \$ /$ t cana \\
\hline Colheita manual de cana crua & $R \$ / t$ cana \\
\hline $\begin{array}{l}\text { Carregamento de cana colhida crua } \\
\text { mecanicamente }\end{array}$ & $\mathrm{R} \$ / \mathrm{t}$ cana \\
\hline Carregamento de cana colhida crua manualmente & $R \$ / t$ cana \\
\hline $\begin{array}{l}\text { Carregamento de cana colhida queimada } \\
\text { mecanicamente }\end{array}$ & $\mathrm{R} \$ /$ t cana \\
\hline $\begin{array}{l}\text { Carregamento de cana colhida queimada } \\
\text { manualmente }\end{array}$ & $\mathrm{R} \$ / \mathrm{t}$ cana \\
\hline Transporte de cana colhida crua mecanicamente & $\mathrm{R} \$ /$ t cana \\
\hline Transporte de cana colhida crua manualmente & $\mathrm{R} \$ / \mathrm{t}$ cana \\
\hline $\begin{array}{l}\text { Transporte de cana colhida queimada } \\
\text { mecanicamente }\end{array}$ & $\mathrm{R} \$ / \mathrm{t}$ cana \\
\hline Transporte de cana colhida queimada manualmente & $\mathrm{R} \$ /$ t cana \\
\hline $\begin{array}{l}\text { Lavagem e Moagem de cana colhida crua } \\
\text { mecanicamente }\end{array}$ & $\mathrm{R} \$ /$ t cana \\
\hline $\begin{array}{l}\text { lavagem e Moagem de cana colhida crua } \\
\text { manualmente }\end{array}$ & $\mathrm{R} \$ / \mathrm{t}$ cana \\
\hline
\end{tabular}


Tabela 1 (cont.): Atividades utilizadas pelas diversas políticas do modelo e sua respectiva unidade.

\begin{tabular}{ll} 
Atividade & Unidade \\
lavagem e moagem de cana colhida queimada & $R S / t$ cana \\
mecanicamente & \\
lavagem e moagem de cana colhida queimada & $R \$ / t$ cana \\
manualmente & \\
Fabricação do Açúcar & $\mathrm{R} \$ / \mathrm{t}$ açúcar \\
Fabricação do Alcool & $\mathrm{R} \$ / \mathrm{m}^{3}$ de alcool \\
Recolhimento da palha & $\mathrm{R} \$ / \mathrm{t}$ palha \\
Limpeza e preparo da palha na usina & $\mathrm{R} \$ / \mathrm{t}$ palha \\
Cogeraçăo de energia elétrica & $\mathrm{R} \$ / \mathrm{KW}$ \\
Hidrólise do bagaço & $\mathrm{R} \$ / \mathrm{t}$ bagaço \\
Tratos culturais com palha & $\mathrm{R} \$ / \mathrm{ha}$ \\
Tratos culturais sem palha & $\mathrm{R} \$ / \mathrm{ha}$ \\
Venda do açúcar & $\mathrm{R} \$ / \mathrm{t}$ açúcar standard \\
Venda do álcool & $\mathrm{R} \$ / \mathrm{m}^{3}$ de álcool \\
Venda do bagaço & $\mathrm{R} \$ / \mathrm{t}$ bagaço \\
Venda da energia elétrica & $\mathrm{R} \$ / \mathrm{KW}$ \\
Venda do bagaço hidrolisado & $\mathrm{R} \$ / \mathrm{t}$ bagaço hidrolisado \\
Venda da torta de Filtro & $\mathrm{R} \$ / \mathrm{t}$ torta \\
Venda da vinhaça & $\mathrm{R} \$ / \mathrm{m}^{3}$ de vinhaça \\
\hline
\end{tabular}

Outras variáveis foram incluidas no modelo visando representar a entrada e saida de máquinas e equipamentos ao longo do horizonte de planejamento. Novamente o modelo permite o uso de valores diferenciados dos custos de compra e da receita das vendas das máquinas para cada ano. A descrição dos tipos de máquinas e equipamentos com possibilidade de compra e/ou venda é mostrada na Tabela 2. 
Tabela 2: Atividades utilizadas pelas diversas políticas do modelo e sua respectiva unidade.

\begin{tabular}{|c|c|c|}
\hline Equipamento & Unidade de compra ou Venda & Unidade de Processamento \\
\hline Colhedoras de cana queimada & $\mathrm{RS}$ & t de cana/dia \\
\hline Colhedoras de cana crua & RS & t de cana/dia \\
\hline Recolhedoras de palha & $R S$ & T.de palha/dia \\
\hline Plantadoras de cana & $R \$$ & ha/dia \\
\hline Fábrica de bagaço hidrolisado & $\mathrm{R} \$$ & tbagaço/dia \\
\hline Fábrica de cogeração de energia & $R S$ & tbagaço/dia \\
\hline
\end{tabular}

\subsubsection{Restrições do modelo}

\subsubsection{Recursos de área}

A área especificada para cada bloco definido no modelo deve ser totalmente utilizada a cada ano por uma ou várias políticas disponiveis para aquele bloco naquele ano. A unidade adotada para esta restrição é hectares.

\subsubsection{Recursos de mão-de-obra}

A mão-de-obra é um fator decisivo quando se analisa a possibilidade de se adotar o corte de cana crua no Estado de São Paulo. A disponibilidade de mão-de-obra para corte é considerada levando-se em conta que o mínimo de mão-de-obra a ser utilizado será aquele necessário para o plantio que, com a tecnologia disponivel atualmente, é um grande utilizador desse insumo. A utilização de mão-de-obra em um determinado ano deve ser menor ou igual à disponibilidade deste fator neste ano. Do 
mesmo modo, a utilização deste insumo para este mesmo ano deve ser maior ou igual à necessidade de mão-de-obra para plantio neste mesmo ano. Para se conseguir este relacionamento dividiu-se a necessidade de mão-de-obra em dois períodos: safra e entre-safra. Toda a mão-de-obra utilizada em atividades relacionadas ao plantio é alocada na entre-safra e, por outro lado, toda a mão-de-obra alocada em outras atividades é alocada na safra. A unidade adotada nestas restrições é "dias.homem".

\subsubsection{Disponibilidade de áreas para mecanização}

O desenho dos talhões precisa ser modificado para permitir a entrada de colheita mecanizada. A modificação deste traçado só pode ser feito quando do plantio. Portanto, a área disponível para colheita mecanizada deve ser obrigatoriamente menor ou igual a área existente já adequada para colheita mecânica mais a área de plantio do ano anterior das áreas com declividade aceitável. $\mathrm{A}$ declividade aceitável pode ser especificada no modelo podendo variar durante o horizonte de planejamento. Em um determinado ano, um bloco específico deve estar dentro ou fora desta declividade limite, não podendo estar parcialmente dentro. Do ponto de vista prático o pesquisador deve definir os intervalos das faixas de declividade de modo a garantir que os limites de declividade adotados para cada ano coincidam com os extremos das faixas de declividade. A unidade adotada nesta restrição é "hectares". 


\subsubsection{Disponibilidade de colhedoras}

Foi considerada uma restrição de disponibilidade máxima de colhedoras de cana criada pela capacidade limitada de produção das montadoras. A utilização de colhedoras em um determinado ano deverá ser menor ou igual a disponibilidade destas máquinas para aquele ano. Visto que muitas pesquisas vem sendo realizadas visando 0 aperfeiçoamento destas máquinas o rendimento e o custo de operação das mesmas colocado na função objetivo pode ser variável de ano para ano, refletindo a evolução tecnológica dos equipamentos. A unidade adotada para esta restrição é "dias.máquina".

\subsubsection{Disponibilidade de plantadoras}

Ainda não existem plantadoras de cana disponíveis no mercado mas muitas pesquisas no desenvolvimento deste implemento vêm sendo feitas. Por esta razão optou-se pela inclusão desta restrição para permitir a avaliação do impacto deste equipamento no sistema produtivo, principalmente com relação à utilização de mão-de-obra. A utilização de plantadoras a cada ano deverá ser menor ou igual à sua disponibilidade para aquele ano. Do mesmo modo que para as colhedoras o modelo permite a compra ou venda de plantadoras durante 0 horizonte de planejamento. A unidade adotada nesta restrição é "dias. máquina". 
4.2.2.6. Disponibilidade de recolhedoras de palha

Como acontece com as plantadoras ainda não existem recolhedoras de palha disponiveis no mercado mas muitas pesquisas no desenvolvimento deste implemento vem sendo feitas. Por esta razão optou-se pela inclusão de mais esta restrição. A utilização de recolhedoras de palha a cada ano deverá ser menor ou igual a sua disponibilidade para aquele ano. Do mesmo modo que para as colhedoras e plantadoras o modelo permite a compra ou venda de recolhedoras durante o horizonte de planejamento. A unidade adotada nesta restrição é "dias. máquina".

\subsubsection{Fabricação de Colhedoras}

O número de colhedoras de cana crua e queimada compradas a cada ano não pode ser maior do que a capacidade de fabricação anual destas máquinas. A capacidade de fabricação pode variar de ano para ano, assim como o seu custo de compra. Esta restrição atualiza a variável de compra de colhedoras que por sua vez aumenta a disponibilidade de colhedoras para corte de cana crua ou queimada para o ano em questão e para os seguintes. A unidade adotada nesta restrição é "número de máquinas".

\subsubsection{Fabricação de plantadoras}

A fabricação de plantadoras segue o mesmo princípio da fabricação de colhedoras. 
4.2.2.9. Fabricação de recolhedoras de palha

A fabricação de recolhedoras de palha também segue o mesmo princípio da fabricação de colhedoras e plantadoras.

\subsubsection{Introdução de fábrica de hidrólise}

A capacidade de produção de bagaço hidrolisado depende da disponibilidade atual de equipamentos para hidrólise do bagaço e da implantação de novos equipamentos. Esta restrição atualiza a variável inteira de introdução de novas fábricas de hidrólise. A unidade adotada nesta restrição é "t.de bagaço ".

4.2.2.11. Introdução de fábrica de cogeração de energia elétrica

A introdução de fábricas de cogeração de energia elétrica obedece às mesmas diretrizes da introdução de fábricas de hidrólise. A unidade adotada nesta restrição também é "t.de bagaço".

\subsubsection{Relacional de incorporação}

Esta restrição visa relacionar as políticas de plantio com incorporação de palha com a obrigatoriedade do bloco ter sido cortado como cana crua sem recolhimento de palha no ano anterior. 


\subsubsection{Função objetivo}

A função objetivo a ser maximizada medirá o valor presente líquido do fluxo de caixa gerado no horizonte de 16 anos que está sendo considerado. O modelo permite que se adote uma taxa de juros diferenciada para cada ano do horizonte de planejamento, sendo o valor presente liquido calculado para o ano 0 .

\subsubsection{Dados necessários}

O modelo necessita de uma série de informações para calcular a margem de contribuição a ser alocada na função objetivo, assim como de outras que irão determinar os coeficientes e os "Right Hand Side (RHS)" que serão colocados nas restrições. A Tabela 3 complementa a Tabela 1 , mostrando o restante das informações necessárias e suas respectivas unidades para o cálculo da função objetivo e coeficientes das restriçōes. Estas informações dizem respeito, principalmente, à eficiência dos equipamentos ou processos envolvidos em cada uma das atividades realizadas para cada política. A Tabela 4 mostra os ítens de preços e custos necessários para o cálculo da função objetivo. As informações necessárias para o preenchimento dos "RHS" das restrições são apontados na Tabela 5. 
Tabela 3 : Informações necessárias para o cálculo da função objetivo e para o preenchimento dos coeficientes das restrições

\begin{tabular}{|c|c|}
\hline Informação & Unidade \\
\hline Pol do bagaço & $\%$ do bagaço \\
\hline Pol da torta & $\%$ da torta \\
\hline Perda de pol na fabricação de açúcar & $\%$ da pol \\
\hline Perda de pol na fabricação de álcool & $\%$ da pol \\
\hline Pol da vinhaça & $\%$ da vinhaça \\
\hline Umidade do bagaço & $\%$ do bagaço \\
\hline Produção de torta & t.torta/tcana \\
\hline Fração usina/destilaria & pol para a Produção açúcar/Pol total \\
\hline Pol do melaço & $\%$ do melaço \\
\hline Produção de melaço & t melaço/t cana \\
\hline Produção de vinhaça & 1. vinhaça/l álcool \\
\hline Açucares redutores & t. Aç.red $/ \mathrm{t}$ pol \\
\hline Juros & $\%$ ao ano \\
\hline Perda pol moagem cana cortada crua mecanicamente & $\%$ de pol \\
\hline $\begin{array}{l}\text { Perda de pol na moagem de cana cortada crua } \\
\text { manualmente }\end{array}$ & $\%$ de pol \\
\hline $\begin{array}{l}\text { Perda de pol na moagem de cana cortada queimada } \\
\text { mecanicamente }\end{array}$ & $\%$ de pol \\
\hline $\begin{array}{l}\text { Perda de pol na moagem de cana cortada queimada } \\
\text { manualmente }\end{array}$ & $\%$ de pol \\
\hline $\begin{array}{l}\text { Perda de pol na lavagem de cana crua cortada } \\
\text { mecanicamente }\end{array}$ & $\%$ de pol \\
\hline $\begin{array}{l}\text { Perda de pol na lavagem de cana crua cortada } \\
\text { manualmente }\end{array}$ & $\%$ de pol \\
\hline $\begin{array}{l}\text { Perda de pol na lavagem de cana queimada cortada } \\
\text { mecanicamente }\end{array}$ & $\%$ de pol \\
\hline $\begin{array}{l}\text { Perda de pol na lavagem de cana queimada cortada } \\
\text { manualmente }\end{array}$ & $\%$ de pol \\
\hline
\end{tabular}


Tabela 3 (cont.): Informações necessárias para o cálculo da função objetivo e para o preenchimento dos coeficientes das restrições.

Informação

Perda de cana na lavoura com cana cortada crua

mecanicamente

Perda de cana na lavoura com cana cortada crua

manualmente

Perda de cana na lavoura com cana cortada queimada

mecanicamente

Perda de cana na lavoura com cana cortada queimada

manualmente

Perda de cana no corte com cana cortada crua

mecanicamente

Perda de cana no corte com cana cortada crua

manualmente

Perda de cana no corte com cana cortada queimada mecanicamente

Perda de cana no corte com cana cortada queimada

manualmente

Perda de cana no carregamento com cana cortada crua mecanicamente

Perda de cana no carregamento com cana cortada crua manualmente

Perda de cana no carregamento com cana cortada queimada mecanicamente

Perda de cana no carregamento com cana cortada queimada manualmente

Perda de cana no transporte com cana cortada crua mecanicamente

Perda de cana no transporte com cana cortada crua manualmente
Unidade

$\%$ de cana

$\%$ de cana

$\%$ de cana

$\%$ de cana

$\%$ de cana

$\%$ de cana

$\%$ de cana

$\%$ de cana

$\%$ de cana

$\%$ de cana

$\%$ de cana

$\%$ de cana

$\%$ de cana

$\%$ de cana 


\section{Tabela 3 (cont.): Informações necessárias para o cálculo da função objetivo e para o preenchimento dos coeficientes das restrições}

\begin{tabular}{|c|c|}
\hline Informação & Unidade \\
\hline $\begin{array}{l}\text { Perda de cana no transporte com cana cortada queimada } \\
\text { mecanicamente }\end{array}$ & $\%$ de cana \\
\hline $\begin{array}{l}\text { Perda de cana no transporte com cana cortada queimada } \\
\text { manualmente }\end{array}$ & $\%$ de cana \\
\hline Rendimento da produção de bagaço hidrolisado & t. bagaço hidrolisado/t. bagaço \\
\hline Rendimento da produção de energia elétrica & $\mathrm{Kw} / \mathrm{t}$ bagaço \\
\hline Exigência de fibra para processamento & $\%$ de fibra minima \\
\hline $\begin{array}{l}\text { Rendimento da mão-de-obra no corte manual de cana } \\
\text { queimada }\end{array}$ & tdia homem \\
\hline $\begin{array}{l}\text { Rendimento da mão-de-obra no corte manual de cana } \\
\text { crua }\end{array}$ & tdia.homem \\
\hline $\begin{array}{l}\text { Rendimento da mão-de-obra no corte mecânico de cana } \\
\text { queimada }\end{array}$ & t/dia.homem \\
\hline $\begin{array}{l}\text { Rendimento da mão-de-obra no corte mecânico de cana } \\
\text { crua }\end{array}$ & t/dia homem \\
\hline Rendimento da mão-de-obra no plantio manual & t/dia.homem \\
\hline Rendimento da mão-de-obra no plantio mecânico & tdia.homem \\
\hline Rendimento da máquina no plantio mecânico & tdia máquina \\
\hline $\begin{array}{l}\text { Rendimento da máquina no corte mecânico de cana } \\
\text { queimada }\end{array}$ & t/dia máquina \\
\hline Rendimento da máquina no corte mecânico de cana crua & t/dia máquina \\
\hline Rendimento da máquina no recolhimento de palha & tdia máquina \\
\hline $\begin{array}{l}\text { Rendimento da mão-de-obra no recolhimento mecânico } \\
\text { de palha }\end{array}$ & t/dia homem \\
\hline Rendimento da mão-de-obra na queima do canavial & haldia.homem \\
\hline $\begin{array}{l}\text { Capacidade de processamento de uma fábrica de bagaço } \\
\text { hidrolisado }\end{array}$ & t de bagaço/dia \\
\hline $\begin{array}{l}\text { Capacidade de processamento de uma fábrica de } \\
\text { cogeração }\end{array}$ & t de bagaço/dia \\
\hline
\end{tabular}


Tabela 4: Equipamentos e produtos com possibilidade de compra elou venda ao longo do horizonte de planejamento e suas respectivas unidades

\begin{tabular}{ll} 
Equipamento & Unidade \\
\hline Colhedoras de cana queimada & $R \$$ \\
Colhedoras de cana crua & $R \$$ \\
Recolhedoras de palha & $R \$$ \\
Plantadoras de cana & $R \$$ \\
Fábrica de bagaço hidrolisado & $R \$$ \\
Fábrica de cogeração de energia & $R \$$ \\
Preço do açúcar & $R \$ / t$ açúcar standard \\
Preço do álcool & $R \$ / m^{3}$ de álcool \\
Preço do bagaço & $R \$ / t$ bagaço \\
Preço da energia elétrica & $R \$ / K W$ \\
Preço do bagaço hidrolisado & $R \$ / t$ bagaço hidrolisado \\
Preço da Torta de Filtro & $R \$ / t$ torta \\
Preço da Vinhaça & $R \$ / \mathrm{m}^{3}$ de vinhaça \\
\hline
\end{tabular}

Tabela 5 : Informações necessárias para preenchimento dos "RHS"

\begin{tabular}{l|l}
\hline İtem & Unidade \\
\hline Disponibilidade de mão-de-obra na safra & Homems \\
\hline Disponibilidade de colhedoras de cana queimada & Máquinas \\
disponibilidade de colhedoras de cana crua & Máquinas \\
disponibilidade de plantadoras & Máquinas \\
Disponibilidade de recolhedoras de palha & Máquinas \\
Capacidade de fabricação de colhedoras de cana queimada & Máquinas/ano \\
Capacidade de fabricação de colhedoras de cana crua & Máquinas/ano \\
Capacidade de fabricação de plantadoras & Máquinas/ano \\
Capacidade de fabricação de recolhedoras de palha & Máquinas/ano \\
Disponibilidade de mão-de-obra na entre-safra & Homems
\end{tabular}




\subsubsection{Descrição matemática do modelo}

A terminologia adotada para formulação do modelo matemático é mostrada a seguir.

$\boldsymbol{n}=$ número de anos do horizonte de planejamento;

$N=$ número de blocos homogêneos (no mesmo ambiente, na mesma faixa de distância e no mesmo estágio de corte);

$T i j=$ número de tecnologias diferentes definidas para o bloco i no ano $j$

$\boldsymbol{A} \boldsymbol{i}=$ Área em hectares do bloco homogêneo $\boldsymbol{i}$;

$\boldsymbol{M} \boldsymbol{k j}$ = número de máquinas colhedoras disponiveis para a tecnologia $\boldsymbol{k}$ no ano $j$

Oj = número de máquinas plantadoras disponiveis no ano $j$;

$D i j=$ área disponivel para colheita mecânica no bloco i no ano $j$;

$L i j=$ área disponível para plantio mecânico no bloco i no ano $j$;

$R i k j=$ número de colhedoras necessárias para colher um hectare no bloco homogêneo $\boldsymbol{i}$, com a tecnologia $\boldsymbol{k}$ no ano $\boldsymbol{j}$;

$P i j=$ número de plantadoras necessárias para plantar um hectare no bloco homogêneo $i$, no ano $j$; 
$B j=$ mão-de-obra disponivel (homens dia) no ano $j$;

Eikj = número de homens dia necessárias para cortar um hectare no bloco i na tecnologia $\boldsymbol{k}$ no ano $\boldsymbol{j}$;

$Q j=$ mão-de-obra necessária para plantio de cana no ano $j$;

$X i k j=$ Área em hectares do bloco homogêneo $i$ conduzido pela tecnologia $\boldsymbol{k}$ no ano $\boldsymbol{j}$

Cikj $=$ valor presente líquido, por hectare, do bloco homogêneo $\boldsymbol{i}$ utilizando a tecnologia $k$ no ano $j$;

O modelo matemático pode ser descrito da seguinte maneira:

$$
(\max ) Z=\sum_{i=1}^{X} \sum_{k=1}^{T} \sum_{j=1}^{n} C_{i k j} * X_{i k j}
$$

Sujeito às seguintes restriçōes para cada um dos anos de planejamento:

Disponibilidade de área dos blocos homogêneos:

$$
\sum_{k=1}^{T} X_{i k j}=A_{i j}
$$

Disponibilidade de área para mecanização:

$$
\sum_{i=1}^{N}\left(X_{i k i} * R_{i k j}\right) \leq M_{i j}
$$


Disponibilidade de mão-de-obra:

$$
\begin{aligned}
& \sum_{i=1}^{N}\left(X_{i k j} * E_{i k j}\right) \leq B_{j} \\
& \sum_{i=1}^{N}\left(X_{i k j} * E_{i k j}\right) \geq Q_{i}
\end{aligned}
$$

Disponibilidade de colhedoras:

$$
\sum_{i=1}^{N} \sum_{k=1}^{T}\left(X_{i k j} * R_{i k j}\right) \leq M_{k i}
$$

Restrição de declividade:

$$
\begin{aligned}
& \sum_{i=1}^{N}\left(X_{i k i}\right) \leq D_{i} \\
& \sum_{i=1}^{N}\left(X_{i k i}\right) \leq L_{i}
\end{aligned}
$$

Disponibilidade de plantadoras:

$$
\sum_{i=1}^{N}\left(X_{i k j} * P_{i k j}\right) \leq O_{j}
$$

\subsubsection{Dimensionamento do modelo}

A dimensão da matriz de programação linear definida pelo modelo descrito pode ser obtida segundo as equações descritas a seguir. 
-Número de variáveis:

$\left(N *\left(P *\left(\frac{1}{E}\right)+C *\left(\frac{(E-1)}{E}\right)\right)+2 * M\right) * A$

onde:

$\boldsymbol{N}=$ número de blocos definidos;

$P=$ número de políticas definidas para plantio;

$\mathbf{C}=$ número de politicas definidas para corte;

$E=$ número de estagios de corte médio definido para os ambientes;

$A=$ número de anos do horizonte de planejamento;

$M=$ número de tipos de máquina definido.

-Número de restrições:

Área: $N^{*} A$;

Mão-de-obra na safra: $A$;

Mão-de-obra no plantio: $A$;

Disponibilidade de máquinas : $M^{*} A$;

Disponibilidade para mecanização: $N{ }^{*} A$;

Fabricação de Máquinas: $M{ }^{*} A$;

Introdução de fábricas: $F^{*} A$; 
Relacional de incorporação: $\left(\frac{N}{E}\right) * A$;

Total de restrições: $A *\left(2+2 * M+F+N *\left(\frac{2 * E+1}{E}\right)\right)$

onde:

$N=$ número de blocos definidos;

$M=$ número de tipos de máquina definido;

$F=$ número de tipos de fábrica definido;

$E=$ número de estágios de corte médios definidos para os ambientes;

$A=$ número de anos do horizonte de planejamento. 


\section{VALIDAÇÃO DO MODELO}

\subsection{Pressuposições adotadas}

Para validar o modelo foi realizada uma simulação procurando avaliar a evolução do sistema produtivo atual do Estado de São Paulo, sem a implantação de nenhuma tecnologia alternativa em estudo. Para tanto a disponibilidade de máquinas ainda não existentes comercialmente está sendo determinada como zero para todo o horizonte de planejamento. Do mesmo modo os preços e custos utilizados assim como os rendimentos operacionais não se alteram durante o horizonte de planejamento.

Para representar o Estado de São Paulo foram adotados três tipos de ambiente de produção. $O$ ambiente de produção 1 englobaria as áreas de alta expectativa de produção e teriam um ciclo de colheita representado por um ano sem colheita denominado de plantio e 7 anos consecutivos de corte quando então o ciclo se repetiria. $O$ ambiente de produção 2 representaria as áreas de expectativa média de produção e teria um ciclo representativo de um ano de plantio seguido de 5 anos de corte. Finalmente, o ambiente de produção 3 representaria as áreas de baixa expectativa de produção e teria um ciclo de um ano de plantio e 4 anos de corte. 
Cada ambiente de produção foi distribuído dentro de 6 faixas de distância da área agrícola até a usina, a saber: de 0 a $10 \mathrm{Km}$; de 10 a 20 $\mathrm{Km}$; de 20 a $30 \mathrm{Km}$; de 30 a $40 \mathrm{Km}$; de 40 a $50 \mathrm{Km}$; e de $50 \mathrm{Km}$ a $60 \mathrm{Km}$. Para cada conjunto de ambiente e faixa de distância alocou-se a área representativa de 4 faixas de declividade. Estas faixas de declividade foram definidas de acordo com a expectativa de adaptação do funcionamento das colhedoras. As faixas definidas foram: $\leq 8 \%$; $>8 \%$ e $\leq 13 \%$; $>13 \%$ e $\leq 20 \%$; e $>20 \%$. Para cada faixa de distância e ambiente assumiu-se a hipótese de que as áreas estariam uniformemente distribuidas entre os diversos estágios de corte adotados para aquele ambiente de produção. A cada conjunto de ambiente, faixa de distância, faixa de declividade e estágio damos o nome de bloco. Foram determinadas produtividades e características tecnológicas para cana queimada e para cana crua a cada estágio de corte em cada tipo de ambiente.

Como ponto inicial será considerada a situação que consiste em $80 \%$ da área de corte sendo colhida manualmente a cana queimada e $20 \%$ da área de corte sendo colhida mecanicamente a cana queimada. 


\subsection{Dados utilizados}

Os dados de produtividade, pol, fibra, e pureza foram retirados dos recenseamentos feitos pelo Centro de Tecnologia Copersucar de 1989 a 1993 junto às usinas e destilarias do Estado de São Paulo. Este censo abrange cerca de 500 mil hectares por ano. As expectativas de rendimento operacional e retorno econômico foram feitos com base nos levantamentos feitos pelo Centro de Tecnologia Copersucar junto às unidades cooperadas. Os preços e custos utilizados estão em Reais de outubro/94.

Para 0 ano inicial de planejamento serão utilizados os seguintes valores para as atividades conforme mostra a Tabela 6. Algumas observações devem ser feitas com relação aos custos calculados. Primeiramente, o custo de corte manual leva em consideração um rendimento médio de 9 toneladas de cana por homem por dia para a cana queimada e 3 toneladas de cana por homem por dia para a cana colhida sem queimar. Em segundo lugar, o custo de tratos culturais com palha engloba um custo mais alto das operações mecânicas e a redução do custo de aplicação de herbicidas. E, finalmente, que o custo de lavagem e moagem é um pouco mais elevado na cana crua colhida mecanicamente devido à maior quantidade de impurezas vegetais existentes neste sistema. 
Os preços de compra ou venda de equipamentos e produtos utilizados para o horizonte de planejamento serão os apresentados na Tabela 7.

\section{Tabela 6 : Atividades utilizadas pelas diversas políticas do modelo e seu respectivo custo.}

\begin{tabular}{|c|c|c|}
\hline Atividade & Valor & Unidade \\
\hline Plantio manual & 800.00 & $\mathrm{R} \$ / \mathrm{ha}$ \\
\hline Plantio mecanizado & 750.00 & $\mathrm{R} \$ / \mathrm{ha}$ \\
\hline Incorporação da palha ao solo & 20.00 & $\mathrm{R} \$ / \mathrm{ha}$ \\
\hline Queimar & 0.50 & $\mathrm{R} \$ / \mathrm{ha}$ \\
\hline Assistência social & 1.00 & $\mathrm{R} \$$ /dia.homem \\
\hline Atividades adicionais & 0.00 & $\mathrm{R} \$ / \mathrm{ha}$ \\
\hline Colheita mecanizada de cana queimada & 2.0 & $\mathrm{R} \$ / \mathrm{t}$ cana \\
\hline Colheita manual de cana queimada & 1.76 & $R \$ / t$ cana \\
\hline Colheita mecanizada de cana crua & 32 & $\mathrm{R} \$ / \mathrm{t}$ cana \\
\hline Colheita manual de cana crua & 4.3 & $R S / t$ cana \\
\hline Carregamento de cana colhida crua mecanicamente & 0.00 & $R \$ / t$ cana \\
\hline Carregamento de cana colhida crua manualmente & 0.70 & $\mathrm{R} \$ / \mathrm{t}$ cana \\
\hline $\begin{array}{l}\text { Carregamento de cana colhida queimada } \\
\text { mecanicamente }\end{array}$ & 0.00 & $R \$ / t$ cana \\
\hline $\begin{array}{l}\text { Carregamento de cana colhida queimada } \\
\text { manualmente }\end{array}$ & 0.56 & $R \$ / t$ cana \\
\hline Transporte de cana colhida crua mecanicamente & 0.08 & $\mathrm{R} \$ / \mathrm{t}$ cana $\mathrm{km}$ \\
\hline Transporte de cana colhida crua manualmente & 0.04 & $\mathrm{R} \$ / \mathrm{t}$ cana $\mathrm{km}$ \\
\hline $\begin{array}{l}\text { Transporte de cana colhida queimada } \\
\text { mecanicamente }\end{array}$ & 0.06 & $\mathrm{R} \$ / \mathrm{t}$ cana $\mathrm{km}$ \\
\hline Transporte de cana colhida queimada manualmente & 0.05 & $\mathrm{R} \$ / \mathrm{t}$ cana $\mathrm{km}$ \\
\hline $\begin{array}{l}\text { Lavagem e Moagem de cana colhida crua } \\
\text { mecanicamente }\end{array}$ & 1.30 & $\mathrm{R} S / \mathrm{t}$ cana \\
\hline $\begin{array}{l}\text { Lavagem e Moagem de cana colhida crua } \\
\text { manualmente }\end{array}$ & 100 & $\mathrm{R} \$ /$ t cana \\
\hline $\begin{array}{l}\text { Lavagem e moagem de cana colhida queimada } \\
\text { mecanicamente }\end{array}$ & 120 & $\mathrm{R} \$ / \mathrm{t}$ cana \\
\hline
\end{tabular}


Tabela 6 (cont.): Atividades utilizadas pelas diversas politicas do modelo e seu respectivo custo.

\begin{tabular}{|c|c|c|}
\hline Atividade & Valor & Unidade \\
\hline Lavagem e moagem de cana colhida queimada & 110 & $\mathrm{R} \$ / \mathrm{t}$ cana \\
\hline \multicolumn{3}{|l|}{ manualmente } \\
\hline Fabricação do Açúcar & 56.00 & $\mathrm{R} \$ / \mathrm{t}$ açúcar \\
\hline Fabricação do Álcool & 84.00 & $\mathrm{RS} / \mathrm{m}^{3}$ de álcool \\
\hline Recolhimento da palha & 20.00 & $\mathrm{R} \$ / \mathrm{t}$ palha \\
\hline Limpeza e preparo da palha na usina & 3.00 & R\$/t palha \\
\hline Cogeração de energia elétrica & 25.00 & $\mathrm{R} \$ / \mathrm{MW}$.h \\
\hline Hidrólise do bagaço & 5.00 & $R \$ / t$ bagaço \\
\hline Tratos culturais com palha & 200.00 & $\mathrm{R} \$ / \mathrm{ha}$ \\
\hline Tratos culturais sem palha & $265: 00$ & $\mathrm{R} \$$ /ha \\
\hline
\end{tabular}

Tabela 7 : Preço de compra elou venda de equipamentos e produtos utilizados ao longo do horizonte de planejamento.

\begin{tabular}{|c|c|c|c|}
\hline Equipamento & Compra & Venda & Unidade \\
\hline Colhedoras de cana queimada & 150000.00 & 20000.00 & $\mathrm{R} \$$ \\
\hline Colhedoras de cana crua & 20000000 & 20000.00 & $R \$$ \\
\hline Recolhedoras de palha & 50000.00 & 10000.00 & $\mathrm{R} \$$ \\
\hline Plantadoras de cana & 100000.00 & 15000.00 & $R \$$ \\
\hline Fábrica de bagaço hidrolisado & 500000.00 & & $R \$$ \\
\hline Fábrica de cogeração de energia & 8000000.00 & & $\mathrm{RS}$ \\
\hline Preçn do açúcar & & 153.00 & $\mathrm{R} \$ /$ t açúcar standard \\
\hline Preçc $-\mathrm{s}$ álcool & & 238.00 & $\mathrm{R} \$ / \mathrm{m}^{3}$ de álcool \\
\hline Preço do bagaço & & 6.00 & $\mathrm{R} \$ /$ t bagaço \\
\hline Preço da energia elétrica & & 14.00 & $\mathrm{R} \$ / \mathrm{MW} \cdot \mathrm{h}$ \\
\hline \multirow[t]{2}{*}{ Preço do bagaço hidrolisado } & & 15.00 & $\mathrm{R} \$ /$ t bagaço \\
\hline & & & hidrolisado \\
\hline Preço da Torta de Filtro & & 0.00 & $\mathrm{R} \$ / \mathrm{t}$ torta \\
\hline Preço da Vinhaça & & 0.00 & $\mathrm{R} \$ / \mathrm{m}^{3}$ de vinhaça \\
\hline
\end{tabular}


Os rendimentos agrícolas e industriais adotados para cada atividade são mostrados na Tabela 8 . Estes rendimentos irão determinar os coeficientes a serem utilizados nas restrições. A Tabela 9 mostra os valores adotados como disponibilidade de mão-de-obra e máquinas que serão utilizados nos "RHS" das restrições.

Tabela 8: Valores utilizados para o cálculo da função objetivo e para o preenchimento dos coeficientes das restrições.

\begin{tabular}{|c|c|c|}
\hline Informação & Valor & Unidade \\
\hline Pol do bagaço & 3.0 & $\%$ do bagaço \\
\hline Pol da torta & 0.7 & $\%$ da torta \\
\hline Perda de pol na fabricação de açúcar & 2.5 & $\%$ da pol \\
\hline Perda de pol na fabricação de álcool & 10 & $\%$ da pol \\
\hline Pol da vinhaça & 0.35 & $\%$ da vinhaça \\
\hline Umidade do bagaço & 50.0 & $\%$ do bagaço \\
\hline Produção de torta & 04 & ttorta/t.cana \\
\hline Fração usina/destilaria & 0.33 & $\begin{array}{l}\text { pol para a Produção açucar } / \mathrm{Pol} \\
\text { total }\end{array}$ \\
\hline Pol do melaço & 39.45 & $\%$ do melaço \\
\hline Produção de melaço & 0.3942 & t melaço/t cana \\
\hline Produção de vinhaça & 13.0 & I. vinhaçall álcool \\
\hline Açucares redutores & 0.05 & $t$ Acred.tt pol \\
\hline Juros & 12.0 & $\%$ ao ano \\
\hline $\begin{array}{l}\text { Perda pol moagem cana cortada crua } \\
\text { mecanicamente }\end{array}$ & 0.01 & $\%$ de pol \\
\hline $\begin{array}{l}\text { Perda de pol na moagem de cana cortada } \\
\text { crua manualmente }\end{array}$ & 0.01 & $\%$ de pol \\
\hline $\begin{array}{l}\text { Perda de pol na moagem de cana cortada } \\
\text { queimada mecanicamente }\end{array}$ & 0.01 & $\%$ de pol \\
\hline $\begin{array}{l}\text { Perda de pol na moagem de cana cortada } \\
\text { queimada manualmente }\end{array}$ & 0.01 & $\%$ de pol \\
\hline
\end{tabular}


Tabela 8 (cont.): Valores utilizados para o cálculo da função objetivo e para o preenchimento dos coeficientes das restrições.

\begin{tabular}{|c|c|c|}
\hline Informação & Valor & Unidade \\
\hline $\begin{array}{l}\text { Perda de pol na lavagem de cana crua } \\
\text { cortada mecanicamente }\end{array}$ & 1.99 & $\%$ de pol \\
\hline $\begin{array}{l}\text { Perda de pol na lavagem de cana crua } \\
\text { cortada manualmente }\end{array}$ & 1.99 & $\%$ de pol \\
\hline $\begin{array}{l}\text { Perda de pol na lavagem de cana } \\
\text { queimada cortada mecanicamente }\end{array}$ & 1.99 & $\%$ de pol \\
\hline $\begin{array}{l}\text { Perda de pol na lavagem de cana } \\
\text { queimada cortada manualmente }\end{array}$ & 1.99 & $\%$ de pol \\
\hline $\begin{array}{l}\text { Perda de cana na lavoura com cana } \\
\text { cortada crua mecanicamente }\end{array}$ & 0.0 & $\%$ de cana \\
\hline $\begin{array}{l}\text { Perda de cana na lavoura com cana } \\
\text { cortada crua manualmente }\end{array}$ & 0.0 & $\%$ de cana \\
\hline $\begin{array}{l}\text { Perda de cana na lavoura com cana } \\
\text { cortada queimada mecanicamente }\end{array}$ & 0.0 & $\%$ de cana \\
\hline $\begin{array}{l}\text { Perda de cana na lavoura com cana } \\
\text { cortada queimada manualmente }\end{array}$ & 0.0 & $\%$ de cana \\
\hline $\begin{array}{l}\text { Perda de cana no corte com cana cortada } \\
\text { crua mecanicamente }\end{array}$ & 0.0 & $\%$ de cana \\
\hline $\begin{array}{l}\text { Perda de cana no corte com cana cortada } \\
\text { crua manualmente }\end{array}$ & 0.0 & $\%$ de cana \\
\hline $\begin{array}{l}\text { Perda de cana no corte com cana cortada } \\
\text { queimada mecanicamente }\end{array}$ & 0.0 & $\%$ de cana \\
\hline $\begin{array}{l}\text { Perda de cana no corte com cana cortada } \\
\text { queimada manualmente }\end{array}$ & 0.0 & $\%$ de cana \\
\hline $\begin{array}{l}\text { Perda de cana no carregamento com cana } \\
\text { cortada crua mecanicamente }\end{array}$ & 0.0 & $\%$ de cana \\
\hline $\begin{array}{l}\text { Perda de cana no carregamento com cana } \\
\text { cortada crua manualmente }\end{array}$ & 0.0 & $\%$ de cana \\
\hline
\end{tabular}


Tabela 8 (cont.): Valores utilizados para o cálculo da função objetivo e para o preenchimento dos coeficientes das restrições.

\begin{tabular}{|c|c|c|}
\hline Informação & Valor & Unidade \\
\hline $\begin{array}{l}\text { Perda de cana no carregamento com cana } \\
\text { cortada queimada mecanicamente }\end{array}$ & 0.0 & $\%$ de cana \\
\hline $\begin{array}{l}\text { Perda de cana no carregamento com cana } \\
\text { cortada queimada manualmente }\end{array}$ & 0.0 & $\%$ de cana \\
\hline $\begin{array}{l}\text { Perda de cana no transporte com cana } \\
\text { cortada crua mecanicamente }\end{array}$ & 0.0 & $\%$ de cana \\
\hline $\begin{array}{l}\text { Perda de cana no transporte com cana } \\
\text { cortada crua manualmente }\end{array}$ & 0.0 & $\%$ de cana \\
\hline $\begin{array}{l}\text { Perda de cana no transporte com cana } \\
\text { cortada queimada mecanicamente }\end{array}$ & 0.0 & $\%$ de cana \\
\hline $\begin{array}{l}\text { Perda de cana no transporte com cana } \\
\text { cortada queimada manualmente }\end{array}$ & 0.0 & $\%$ de cana \\
\hline $\begin{array}{l}\text { Rendimento da produção de bagaço } \\
\text { hidrolisado }\end{array}$ & 0.7 & t.bagaço hidrolisado/t. bagaço \\
\hline $\begin{array}{l}\text { Rendimento da produção de energia } \\
\text { elétrica }\end{array}$ & 0.5 & MW/t.bagaço \\
\hline Exigência de fibra para processamento & 12.0 & $\%$ de fibra minima \\
\hline $\begin{array}{l}\text { Rendimento da mão-de-obra no corte } \\
\text { manual de cana queimada }\end{array}$ & 9.0 & t/dia.homem \\
\hline $\begin{array}{l}\text { Rendimento da mão-de-obra no corte } \\
\text { manual de cana crua }\end{array}$ & 3.0 & t/dia.homem \\
\hline $\begin{array}{l}\text { Rendimento da mão-de-obra no corte } \\
\text { mecânico de cana queimada }\end{array}$ & 150.0 & tdia.homem \\
\hline $\begin{array}{l}\text { Rendimento da mão-de-obra no corte } \\
\text { mecânico de cana crua }\end{array}$ & 100.0 & tdia.homem \\
\hline $\begin{array}{l}\text { Rendimento da mão-de-obra no plantio } \\
\text { manual }\end{array}$ & 0.1 & haldia.homem \\
\hline $\begin{array}{l}\text { Rendimento da mão-de-obra no plantio } \\
\text { mecânico }\end{array}$ & 0.8 & ha/dia.homem \\
\hline
\end{tabular}


Tabela 8 (cont.): Valores utilizados para o cálculo da função objetivo e para o preenchimento dos coeficientes das restrições.

\begin{tabular}{|c|c|c|}
\hline Informação & Valor & Unidade \\
\hline $\begin{array}{l}\text { Rendimento da máquina no plantio } \\
\text { mecanico }\end{array}$ & 3.6 & ha/dia máquina \\
\hline $\begin{array}{l}\text { Rendimento da máquina no corte } \\
\text { mecánico de cana queimada }\end{array}$ & 450 & t/dia maquina \\
\hline $\begin{array}{l}\text { Rendimento da máquina no corte } \\
\text { mecanico de cana crua }\end{array}$ & 300 & tddia máquina \\
\hline $\begin{array}{l}\text { Rendimento da máquina no recolhimento } \\
\text { de palha }\end{array}$ & 400 & tdia máquina \\
\hline $\begin{array}{l}\text { Rendimento da mão-de-obra no } \\
\text { recolhimento mecanico de palha }\end{array}$ & 100 & t/dia.homem \\
\hline $\begin{array}{l}\text { Rendimento da mão-de-obra na queima } \\
\text { do canavial }\end{array}$ & 20 & ha/dia.homem \\
\hline $\begin{array}{l}\text { Capacidade de processamento de uma } \\
\text { fábrica de bagaço hidrolisado }\end{array}$ & 500 & t. de bagaço/dia \\
\hline $\begin{array}{l}\text { Capacidade de processamento de uma } \\
\text { fábrica de cogeração }\end{array}$ & 2000000 & t. de bagaço/dia \\
\hline
\end{tabular}

Tabela 9 : Valores utilizados para preenchimento dos "RHS".

\begin{tabular}{llll}
\hline Item & Valor & Unidade \\
\hline Disponibilidade de mão-de-obra na safra & 100000 & Homems \\
Disponibilidade de colhedoras de cana queimada & 300 & Máquinas \\
disponibilidade de colhedoras de cana crua & 20 & Máquinas \\
disponibilidade de plantadoras & 0 & Máquinas \\
Disponibilidade de recolhedoras de palha & 0 & 0 & Máquinas \\
Capacidade de fabricação de colhedoras de cana queimada & 50 & Máquinas/ano \\
Capacidade de fabricação de colhedoras de cana crua & 20 & Máquinas/ano \\
Capacidade de fabricação de plantadoras & 0 & Máquinas/ano \\
Capacidade de fabricação de recolhedoras de palha & 0 & Máquinas/ano \\
Disponibilidade de mão-de-obra na entre-safra & 100000 & Homens \\
\hline
\end{tabular}


Para cada ambiente e estágio de corte foram definidos produtividades e características tecnológicas médias para cana colhida crua e cana colhida queimada. Os valores estimados para estes fatores são mostrados na Tabela 10 e Tabela 11. A produtividade utilizada é ligeiramente maior para a cana crua devido à perda de água provocada pela queima do canavial. Além disto, a pol\%cana da cana crua ainda está sendo considerada maior do que a da cana queimada pelo fato da queima provocar a exudação de grande quantidade de sacarose. Finalmente, a Tabela 12 mostra uma listagem da área de cana do Estado de São Paulo, e sua respectiva produção, subdividida em blocos definidos para a simulação assim como a sua respectiva área e produção de cana. 
Tabela 10: Produtividades e características tecnológicas adotadas para cana queimada para todo $o$ horizonte de planejamento.

\begin{tabular}{|c|c|c|c|c|c|}
\hline Fertilidade & Estágio & t.cana/ha & Pol\%cana & Fibra & Pureza \\
\hline Alta & Plantio & & & & \\
\hline Alta & Corte 1 & 121 & 14.5 & 13.2 & 88 \\
\hline Alta & Corte2 & 105 & 14.1 & 13.0 & 88 \\
\hline Alta & Corte 3 & 92 & 14.1 & 13.0 & 88 \\
\hline Alta & Corte 4 & 85 & 14.1 & 13.0 & 88 \\
\hline Alta & Corte 5 & 80 & 14.1 & 13.0 & 88 \\
\hline Alta & Corte 6 & 75 & 14.1 & 13.0 & 88 \\
\hline Alta & Corte 7 & 68 & 141 & 13.0 & 88 \\
\hline Média & Plantio & & & & \\
\hline Média & Corte 1 & 105 & 144 & 13.3 & 86 \\
\hline Média & Corte 2 & 88 & 140 & 13.2 & 86 \\
\hline Média & Corte 3 & 79 & 14.0 & 132 & 86 \\
\hline Média & Corte 4 & 70 & 14.0 & 13.2 & 86 \\
\hline Média & Corte 5 & 59 & 14.0 & 132 & 86 \\
\hline Baixa & Plantio & & & & \\
\hline Baixa & Corte 1 & 89 & 14.4 & 13.5 & 84 \\
\hline Baixa & Corte 2 & 70 & 13.9 & 13.4 & 84 \\
\hline Baixa & Corte 3 & 58 & 13.9 & 13.4 & 84 \\
\hline Baixa & Corte 4 & 47 & 13.9 & 13.4 & 84 \\
\hline
\end{tabular}


Tabela 11: Produtividades e características tecnológicas adotadas para cana crua para todo o horizonte de planejamento.

\begin{tabular}{|c|c|c|c|c|c|}
\hline Fertilidade & Estágio & T.cana/ha & Pol\%cana & Fibra & Pureza \\
\hline Alta & Plantio & & & & \\
\hline Alta & Corte 1 & 125 & 14.7 & 13.2 & 88 \\
\hline Alta & Corte2 & 108 & 14.3 & 13.0 & 88 \\
\hline Alta & Corte 3 & 96 & 14.3 & 13.0 & 88 \\
\hline Alta & Corte 4 & 88 & 14,3 & 13.0 & 88 \\
\hline Alta & Corte 5 & 83 & 14.3 & 13.0 & 88 \\
\hline Alta & Corte 6 & 77 & 14.3 & 13.0 & 88 \\
\hline Alta & Corte 7 & 70 & 14.3 & 130 & 88 \\
\hline Média & Plantio & & & & \\
\hline Média & Corte 1 & 108 & 14.6 & 13.3 & 86 \\
\hline Média & Corte 2 & 91 & 142 & 13.2 & 86 \\
\hline Média & Corte 3 & 82 & 142 & 13.2 & 86 \\
\hline Média & Corte 4 & 72 & 142 & 132 & 86 \\
\hline Média & Corte 5 & 61 & 142 & 13.2 & 86 \\
\hline Baixa & Plantio & & & & \\
\hline Baixa & Corte 1 & 92 & 14.5 & 13.5 & 84 \\
\hline Baixa & Corte 2 & 73 & 140 & 13.4 & 84 \\
\hline Baixa & Corte 3 & 60 & 14.0 & 13.4 & 84 \\
\hline Baixa & Corte 4 & 49 & 14.0 & 13.4 & 84 \\
\hline
\end{tabular}


Tabela 12: Divisão da área com cana de açúcar no Estado de São Paulo em blocos de acordo com a expectativa de fertilidade, declividade, distância e estágio de corte distância e estágio de corte.

\begin{tabular}{|c|c|c|c|c|c|c|}
\hline$B L O C O$ & ÁREA & $\%$ MECAN & DECLIVIDADE & DISTÂNCIA & ESTÁGIO & FERTILID. \\
\hline 0001 & 18102.15 & 38 & $<=8 \%$ & $D E 00 \mathrm{~A}<10 \mathrm{KM}$ & PLANTIO & ALTA \\
\hline 0002 & 21151.35 & 38 & $<=8 \%$ & $D E 10 A<20 \mathrm{kM}$ & PLANTIO & ALTA \\
\hline 0003 & 7053.75 & 38 & $<=8 \%$ & $D E 20 \mathrm{~A}<30 \mathrm{KM}$ & PLANTIO & ALTA \\
\hline 0004 & 1742.4 & 38 & $<=8 \%$ & DE $30 \mathrm{~A}<40 \mathrm{KM}$ & PLANTIO & ALTA \\
\hline 0005 & 1450.35 & 38 & $<=8 \%$ & $\mathrm{DE} 40 \mathrm{~A}<50 \mathrm{KM}$ & PLANTIO & ALTA \\
\hline 0007 & 2011.35 & & $>8 \% A<=13 \%$ & DE $00 \mathrm{~A}<10 \mathrm{kM}$ & PLANTIO & ALTA \\
\hline 0008 & 2350.15 & & $>8 \% \mathrm{~A}<=13 \%$ & $D E 10 \mathrm{~A}<20 \mathrm{kM}$ & PLANTIO & ALTA \\
\hline 0009 & 783.75 & & $>8 \% A<=13 \%$ & $D E 20 A<30 \mathrm{kM}$ & PLANTIO & ALTA \\
\hline 0010 & 193.6 & & $>8 \% A<=13 \%$ & $D E 30 \mathrm{~A}<40 \mathrm{KM}$ & PLANTIO & ALTA \\
\hline 0011 & 161.15 & & $>8 \%$ A $<=13 \%$ & DE $40 \mathrm{~A}<50 \mathrm{KM}$ & PLANTIO & ALTA \\
\hline 0013 & 2011.35 & & $>13 \% A<=20 \%$ & $D E 00 A<10 \mathrm{KM}$ & PLANTIO & ALTA \\
\hline 0014 & 2350.15 & & $>13 \% A<=20 \%$ & $D E 10 A<20 \mathrm{kM}$ & PLANTIO & ALTA \\
\hline 0015 & 783.75 & & $>13 \% A<=20 \%$ & $D E 20 \mathrm{~A}<30 \mathrm{KM}$ & PLANTIO & ALTA \\
\hline 0016 & 1936 & & $>13 \% A<=20 \%$ & $D E 30 \mathrm{~A}<40 \mathrm{KM}$ & PLANTIO & ALTA \\
\hline 0017 & 161.15 & & $>13 \% \mathrm{~A}<=20 \%$ & $\mathrm{DE} 40 \mathrm{~A}<50 \mathrm{KM}$ & PLANTIO & ALTA \\
\hline 0019 & 1508.51 & & $>20 \%$ & $D E 00 A<10 \mathrm{KM}$ & PLANTIO & ALTA \\
\hline 0020 & 1762.61 & & $>20 \%$ & $D E 10 A<20 \mathrm{KM}$ & PLANTIO & ALTA \\
\hline 0021 & 58781 & & $>20 \%$ & $D E 20 \mathrm{~A}<30 \mathrm{KM}$ & PLANTIO & ALTA \\
\hline 0022 & 145.2 & & $>20 \%$ & $D E 30 \mathrm{~A}<40 \mathrm{KM}$ & PLANTIO & ALTA \\
\hline 0023 & 120.86 & & $>20 \%$ & $\mathrm{DE} 40 \mathrm{~A}<50 \mathrm{KM}$ & PLANTIO & ALTA \\
\hline 0025 & 18102.15 & 38 & $<=8 \%$ & $\mathrm{DE} 00 \mathrm{~A}<10 \mathrm{KM}$ & CORTE 1 & ALTA \\
\hline 0026 & 21151.35 & 38 & $<=8 \%$ & $D E 10 A<20 \mathrm{KM}$ & CORTE 1 & ALTA \\
\hline 0027 & 7053.75 & 38 & $<=8 \%$ & DE $20 \mathrm{~A}<30 \mathrm{KM}$ & CORTE 1 & ALTA \\
\hline 0028 & 1742.4 & 38 & $<=8 \%$ & DE $30 \mathrm{~A}<40 \mathrm{KM}$ & CORTE 1 & ALTA \\
\hline 0029 & 1450.35 & 38 & $<=8 \%$ & $D E 40 A<50 \mathrm{KM}$ & CORTE 1 & ALTA \\
\hline 0031 & 201135 & & $>8 \% \mathrm{~A}<=13 \%$ & $D E 00 A<10 \mathrm{kM}$ & CORTE 1 & ALTA \\
\hline
\end{tabular}


Tabela 12 (cont.): Divisão da área com cana de açúcar no Estado de São Paulo em blocos de acordo com a expectativa de fertilidade, declividade, distância e estágio de corte distância e estágio de corte.

\begin{tabular}{|c|c|c|c|c|c|}
\hline BLOCO & ÁREA & \%MECAN. & DECLIVIDADE & DISTÂNCIA & ESTÁGIO FERTILID \\
\hline 0032 & 235015 & & $>8 \% A<=13 \%$ & $D E 10 A<20 \mathrm{KM}$ & CORTE 1 ALTA \\
\hline 0033 & 783.75 & & $>8 \% \mathrm{~A}<=13 \%$ & $D E 20 A<30 \mathrm{kM}$ & CORTE 1 ALTA \\
\hline 0034 & 193.6 & & $>8 \% A<=13 \%$ & $D E 30 \mathrm{~A}<40 \mathrm{kM}$ & CORTE 1 ALTA \\
\hline 0035 & 16115 & & $>8 \% A<=13 \%$ & $D E 40 A<50 \mathrm{KM}$ & CORTE 1 ALTA \\
\hline 0037 & 2011.35 & & $>13 \% A<=20 \%$ & $D E 00 A<10 \mathrm{KM}$ & CORTE 1 ALTA \\
\hline 0038 & 235015 & & $>13 \% \mathrm{~A}<=20 \%$ & DE $10 \mathrm{~A}<20 \mathrm{KM}$ & CORTE 1 ALTA \\
\hline 0039 & 783.75 & & $>13 \% A<=20 \%$ & $D E 20 A<30 \mathrm{KM}$ & CORTE 1 ALTA \\
\hline 0040 & 193.6 & & $>13 \% \mathrm{~A}<=20 \%$ & DE $30 \mathrm{~A}<40 \mathrm{KM}$ & CORTE 1 ALTA \\
\hline 0041 & 161.15 & & $>13 \% \mathrm{~A}<=20 \%$ & $D E 40 A<50 \mathrm{KM}$ & CORTE 1 ALTA \\
\hline 0043 & 1508.51 & & $>20 \%$ & $D E 00 A<10 \mathrm{KM}$ & CORTE 1 ALTA \\
\hline 0044 & 1762.61 & & $>20 \%$ & $D E 10 A<20 \mathrm{KM}$ & CORTE 1 ALTA \\
\hline 0045 & 587.81 & & $>20 \%$ & $\mathrm{DE} 20 \mathrm{~A}<30 \mathrm{KM}$ & CORTE 1 ALTA \\
\hline 0046 & 145.2 & & $>20 \%$ & DE $30 \mathrm{~A}<40 \mathrm{KM}$ & CORTE 1 ALTA \\
\hline 0047 & 120.86 & & $>20 \%$ & $D E 40 \mathrm{~A}<50 \mathrm{KM}$ & CORTE 1 ALTA \\
\hline 0049 & 18102.15 & 38 & $<=8 \%$ & DE $00 \mathrm{~A}<10 \mathrm{kM}$ & CORTE 2 ALTA \\
\hline 0050 & 2115135 & 38 & $<=8 \%$ & $D E 10 A<20 \mathrm{KM}$ & CORTE 2 ALTA \\
\hline 0051 & 705375 & 38 & $<=8 \%$ & DE $20 \mathrm{~A}<30 \mathrm{KM}$ & CORTE 2 ALTA \\
\hline 0052 & 1742.4 & 38 & $<=8 \%$ & $\mathrm{DE} 30 \mathrm{~A}<40 \mathrm{KM}$ & CORTE 2 ALTA \\
\hline 0053 & 1450.35 & 38 & $<=8 \%$ & DE $40 \mathrm{~A}<50 \mathrm{KM}$ & CORTE 2 ALTA \\
\hline 0055 & 201135 & & $>8 \% A<=13 \%$ & $D E 00 A<10 \mathrm{kM}$ & CORTE 2 ALTA \\
\hline 0056 & 235015 & & $>8 \% A<=13 \%$ & $\mathrm{DE} 10 \mathrm{~A}<20 \mathrm{kM}$ & CORTE 2 ALTA \\
\hline 0057 & 783.75 & & $>8 \% A<=13 \%$ & $D E 20 A<30 \mathrm{kM}$ & CORTE 2 ALTA \\
\hline 0058 & 193.6 & & $>8 \% A<=13 \%$ & $\mathrm{DE} 30 \mathrm{~A}<40 \mathrm{kM}$ & CORTE 2 ALTA \\
\hline 0059 & 161.15 & & $>8 \% A<=13 \%$ & $\mathrm{DE} 40 \mathrm{~A}<50 \mathrm{KM}$ & CORTE 2 ALTA \\
\hline 0061 & 201135 & & $>13 \% A<=20 \%$ & $D E 00 \mathrm{~A}<10 \mathrm{KM}$ & CORTE 2 ALTA \\
\hline 0062 & 2350.15 & & $>13 \% A<=20 \%$ & $D E 10 A<20 \mathrm{KM}$ & CORTE 2 ALTA \\
\hline 0063 & 783.75 & & $>13 \% \mathrm{~A}<=20 \%$ & $D E 20 \mathrm{~A}<30 \mathrm{KM}$ & CORTE 2 ALTA \\
\hline
\end{tabular}


Tabela 12 (cont.): Divisão da área com cana de açúcar no Estado de São Paulo em blocos de acordo com a expectativa de fertilidade, declividade, distância e estágio de corte distância e estágio de corte.

\begin{tabular}{|c|c|c|c|c|c|}
\hline BLOCO & AREA & $\% M E C A N$ & DECLIVIDADE & DISTANCIA & ESTÁGIO FERTILID \\
\hline 0064 & 193.6 & & $>13 \% A<=20 \%$ & $D E 30 \mathrm{~A}<40 \mathrm{kM}$ & CORTE 2 ALTA \\
\hline 0065 & 161.15 & & $>13 \% A<=20 \%$ & DE $40 \mathrm{~A}<50 \mathrm{KM}$ & CORTE 2 ALTA \\
\hline 0067 & 1508.51 & & $>20 \%$ & $D E 00 \mathrm{~A}<10 \mathrm{KM}$ & CORTE 2 ALTA \\
\hline 0068 & 1762.61 & & $>20 \%$ & DE $10 \mathrm{~A}<20 \mathrm{KM}$ & CORTE 2 ALTA \\
\hline 0069 & 587.81 & & $>20 \%$ & DE $20 \mathrm{~A}<30 \mathrm{KM}$ & CORTE 2 ALTA \\
\hline 0070 & 145.2 & & $>20 \%$ & $D E 30 \mathrm{~A}<40 \mathrm{KM}$ & CORTE 2 ALTA \\
\hline 0071 & 120.86 & & $>20 \%$ & $D E 40 A<50 \mathrm{KM}$ & CORTE 2 ALTA \\
\hline 0073 & 18102.15 & 38 & $<=8 \%$ & $D E 00 \mathrm{~A}<10 \mathrm{KM}$ & CORTE 3 ALTA \\
\hline 0074 & 2115135 & 38 & $<=8 \%$ & $D E 10 A<20 \mathrm{KM}$ & CORTE 3 ALTA \\
\hline 0075 & 7053.75 & 38 & $<=8 \%$ & $D E 20 \mathrm{~A}<30 \mathrm{KM}$ & CORTE 3 ALTA \\
\hline 0076 & 1742.4 & 38 & $<=8 \%$ & $D E 30 \mathrm{~A}<40 \mathrm{KM}$ & CORTE 3 ALTA \\
\hline 0077 & 1450.35 & 38 & $<=8 \%$ & $D E 40 \mathrm{~A}<50 \mathrm{KM}$ & CORTE 3 ALTA \\
\hline 0079 & 2011.35 & & $>8 \% A<=13 \%$ & $D E 00 A<10 \mathrm{KM}$ & CORTE 3 ALTA \\
\hline 0080 & 235015 & & $>8 \% A<=13 \%$ & $D E 10 A<20 \mathrm{KM}$ & CORTE 3 ALTA \\
\hline 0081 & 783.75 & & $>8 \% A<=13 \%$ & $D E 20 A<30 \mathrm{KM}$ & CORTE 3 ALTA \\
\hline 0082 & 193.6 & & $>8 \% \mathrm{~A}<=13 \%$ & DE $30 \mathrm{~A}<40 \mathrm{KM}$ & CORTE 3 ALTA \\
\hline 0083 & 161.15 & & $>8 \% A<=13 \%$ & $D E 40 A<50 \mathrm{kM}$ & CORTE 3 ALTA \\
\hline 0085 & 201135 & & $>13 \% A<=20 \%$ & $D E 00 A<10 \mathrm{KM}$ & CORTE 3 ALTA \\
\hline 0086 & 2350.15 & & $>13 \% A<=20 \%$ & $D E 10 A<20 \mathrm{kM}$ & CORTE 3 ALTA \\
\hline 0087 & 783.75 & & $>13 \% A<=20 \%$ & $\mathrm{DE} 20 \mathrm{~A}<30 \mathrm{KM}$ & CORTE 3 ALTA \\
\hline 0088 & 193.6 & & $>13 \% A<=20 \%$ & DE $30 \mathrm{~A}<40 \mathrm{KM}$ & CORTE 3 ALTA \\
\hline 0089 & 161.15 & & $>13 \% \mathrm{~A}<=20 \%$ & $D E 40 A<50 \mathrm{KM}$ & CORTE 3 ALTA \\
\hline 0091 & 1508.51 & & $>20 \%$ & $D E 00 A<10 \mathrm{KM}$ & CORTE 3 ALTA \\
\hline 0092 & 176261 & & $>20 \%$ & $D E 10 A<20 \mathrm{kM}$ & CORTE 3 ALTA \\
\hline 0093 & 58781 & & $>20 \%$ & $D E 20 \mathrm{~A}<30 \mathrm{KM}$ & CORTE 3 ALTA \\
\hline 0094 & 1452 & & $>20 \%$ & $D E 30 \mathrm{~A}<40 \mathrm{KM}$ & CORTE 3 ALTA \\
\hline 0095 & 120.86 & & $>20 \%$ & $D E 40 \mathrm{~A}<50 \mathrm{KM}$ & CORTE 3 ALTA \\
\hline
\end{tabular}


Tabela 12 (cont.): Divisão da área com cana de açúcar no Estado de São Paulo em blocos de acordo com a expectativa de fertilidade, declividade, distância e estágio de corte distância e estágio de corte.

\begin{tabular}{|c|c|c|c|c|c|}
\hline BLOCO & ÁREA & $\% M E C A N$ & DECLIVIDADE & DISTÂNCIA & ESTÁGIO FERTILID \\
\hline 0097 & 18102.15 & 38 & $<=8 \%$ & $D E 00 A<10 \mathrm{kM}$ & CORTE 4 ALTA \\
\hline 0098 & 21151.35 & 38 & $<=8 \%$ & $D E 10 \mathrm{~A}<20 \mathrm{KM}$ & CORTE 4 ALTA \\
\hline 0099 & 7053.75 & 38 & $<=8 \%$ & $\mathrm{DE} 20 \mathrm{~A}<30 \mathrm{KM}$ & CORTE 4 ALTA \\
\hline 0100 & 17424 & 38 & $<=8 \%$ & $\mathrm{DE} 30 \mathrm{~A}<40 \mathrm{KM}$ & CORTE 4 ALTA \\
\hline 0101 & 1450.35 & 38 & $<=8 \%$ & $D E 40 \mathrm{~A}<50 \mathrm{KM}$ & CORTE 4 ALTA \\
\hline 0103 & 2011.35 & & $>8 \% A<=13 \%$ & $D E 00 A<10 \mathrm{KM}$ & CORTE 4 ALTA \\
\hline 0104 & 2350.15 & & $>8 \% \mathrm{~A}<=13 \%$ & $D E 10 \mathrm{~A}<20 \mathrm{KM}$ & CORTE 4 ALTA \\
\hline 0105 & 783.75 & & $>8 \% \mathrm{~A}<=13 \%$ & $D E 20 \mathrm{~A}<30 \mathrm{kM}$ & CORTE 4 ALTA \\
\hline 0106 & 193.6 & & $>8 \% A<=13 \%$ & $D E 30 \mathrm{~A}<40 \mathrm{KM}$ & CORTE 4 ALTA \\
\hline 0107 & 16115 & & $>8 \% \mathrm{~A}<=13 \%$ & $D E 40 A<50 \mathrm{KM}$ & CORTE 4 ALTA \\
\hline 0109 & 201135 & & $>13 \% A<=20 \%$ & $D E 00 \mathrm{~A}<10 \mathrm{KM}$ & CORTE 4 ALTA \\
\hline 0110 & 2350.15 & & $>13 \% A<=20 \%$ & $D E 10 \mathrm{~A}<20 \mathrm{KM}$ & CORTE 4 ALTA \\
\hline 0111 & 783.75 & & $>13 \% A<=20 \%$ & $D E 20 \mathrm{~A}<30 \mathrm{KM}$ & CORTE 4 ALTA \\
\hline 0112 & 193.6 & & $>13 \% A<=20 \%$ & $D E 30 \mathrm{~A}<40 \mathrm{KM}$ & CORTE 4 ALTA \\
\hline 0113 & 161.15 & & $>13 \% A<=20 \%$ & $\mathrm{DE} 40 \mathrm{~A}<50 \mathrm{KM}$ & CORTE 4 ALTA \\
\hline 0115 & 1508.51 & & $>20 \%$ & $D E 00 A<10 \mathrm{KM}$ & CORTE 4 ALTA \\
\hline 0116 & 1762.61 & & $>20 \%$ & $D E 10 A<20 \mathrm{kM}$ & CORTE 4 ALTA \\
\hline 0117 & 58781 & & $>20 \%$ & $\mathrm{DE} 20 \mathrm{~A}<30 \mathrm{kM}$ & CORTE 4 ALTA \\
\hline 0118 & 145.2 & & $>20 \%$ & $D E 30 \mathrm{~A}<40 \mathrm{KM}$ & CORTE 4 ALTA \\
\hline 0119 & 120.86 & & $>20 \%$ & $\mathrm{DE} 40 \mathrm{~A}<50 \mathrm{KM}$ & CORTE 4 ALTA \\
\hline 0121 & 18102.15 & 38 & $<=8 \%$ & $D E 00 A<10 \mathrm{KM}$ & CORTE 5 ALTA \\
\hline 0122 & 21151.35 & 38 & $<=8 \%$ & DE $10 \mathrm{~A}<20 \mathrm{KM}$ & CORTE 5 ALTA \\
\hline 0123 & 7053.75 & 38 & $<=8 \%$ & $D E 20 A<30 \mathrm{kM}$ & CORTE 5 ALTA \\
\hline 0124 & 1742.4 & 38 & $<=8 \%$ & $\mathrm{DE} 30 \mathrm{~A}<40 \mathrm{kM}$ & CORTE 5 ALTA \\
\hline 0125 & 1450.35 & 38 & $<=8 \%$ & $D E 40 A<50 \mathrm{kM}$ & CORTE 5 ALTA \\
\hline 0127 & 201135 & & $>8 \%$ A $<=13 \%$ & DE $00 \mathrm{~A}<10 \mathrm{KM}$ & CORTE 5 ALTA \\
\hline 0128 & 2350.15 & & $>8 \% A<<=13 \%$ & $D E 10 A<20 \mathrm{KM}$ & CORTE 5 ALTA \\
\hline
\end{tabular}


Tabela 12 (cont.): Divisão da área com cana de açúcar no Estado de São Paulo em blocos de acordo com a expectativa de fertilidade, declividade, distância e estágio de corte distância e estágio de corte.

\begin{tabular}{|c|c|c|c|c|c|}
\hline BLOCO & ÁREA & $\%$ MECAN & DECLIVIDADE & DISTÂNCIA & ESTAGIO FERTILID \\
\hline 0129 & 783.75 & & $>8 \% \mathrm{~A}<=13 \%$ & $D E 20 A<30 \mathrm{KM}$ & CORTE 5 ALTA \\
\hline 0130 & 193.6 & & $>8 \% A<=13 \%$ & $D E 30 \mathrm{~A}<40 \mathrm{KM}$ & CORTE 5 ALTA \\
\hline 0131 & 161.15 & & $>8 \% \mathrm{~A}<=13 \%$ & $D E 40 \mathrm{~A}<50 \mathrm{KM}$ & CORTE 5 ALTA \\
\hline 0133 & 2011.35 & & $>13 \% A<=20 \%$ & $D E 00 A<10 \mathrm{KM}$ & CORTE 5 ALTA \\
\hline 0134 & 2350.15 & & $>13 \% A<=20 \%$ & DE $10 \mathrm{~A}<20 \mathrm{KM}$ & CORTE 5 ALTA \\
\hline 0135 & 783.75 & & $>13 \% A<=20 \%$ & $D E 20 \mathrm{~A}<30 \mathrm{KM}$ & CORTE 5 ALTA \\
\hline 0136 & 193.6 & & $>13 \% A<=20 \%$ & $D E 30 \mathrm{~A}<40 \mathrm{KM}$ & CORTE 5 ALTA \\
\hline 0137 & 161.15 & & $>13 \% A<=20 \%$ & $D E 40 A<50 \mathrm{kM}$ & CORTE 5 ALTA \\
\hline 0139 & 1508.51 & & $>20 \%$ & $D E 00 \mathrm{~A}<10 \mathrm{KM}$ & CORTE 5 ALTA \\
\hline 0140 & 1762.61 & & $>20 \%$ & DE $10 \mathrm{~A}<20 \mathrm{KM}$ & CORTE 5 ALTA \\
\hline 0141 & 587.81 & & $>20 \%$ & $D E 20 A<30 \mathrm{KM}$ & CORTE 5 ALTA \\
\hline 0142 & 1452 & & $>20 \%$ & $D E 30 \mathrm{~A}<40 \mathrm{KM}$ & CORTE 5 ALTA \\
\hline 0143 & 120.86 & & $>20 \%$ & $D E 40 \mathrm{~A}<50 \mathrm{KM}$ & CORTE 5 ALTA \\
\hline 0145 & 18102.15 & 38 & $<=8 \%$ & $D E 00 \mathrm{~A}<10 \mathrm{KM}$ & CORTE 6 ALTA \\
\hline 0146 & 21151.35 & 38 & $<=8 \%$ & $D E 10 \mathrm{~A}<20 \mathrm{KM}$ & CORTE 6 ALTA \\
\hline 0147 & 7053.75 & 38 & $<=8 \%$ & $D E 20 A<30 \mathrm{KM}$ & CORTE 6 ALTA \\
\hline 0148 & 1742.4 & 38 & $<=8 \%$ & $D E 30 A<40 \mathrm{KM}$ & CORTE 6 ALTA \\
\hline 0149 & 1450.35 & 38 & $<=8 \%$ & $D E 40 A<50 \mathrm{KM}$ & CORTE 6 ALTA \\
\hline 0151 & 201135 & & $>8 \% A<=13 \%$ & $D E 00 A<10 \mathrm{kM}$ & CORTE 6 ALTA \\
\hline 0152 & 235015 & & $>8 \%$ A $<=13 \%$ & $D E 10 A<20 \mathrm{KM}$ & CORTE 6 ALTA \\
\hline 0153 & 783.75 & & $>8 \% \mathrm{~A}<=13 \%$ & $D E 20 \mathrm{~A}<30 \mathrm{kM}$ & CORTE 6 ALTA \\
\hline 0154 & 1936 & & $>8 \% A<=13 \%$ & $\mathrm{DE} 30 \mathrm{~A}<40 \mathrm{KM}$ & CORTE 6 ALTA \\
\hline 0155 & 16115 & & $>8 \% A<=13 \%$ & $D E 40 A<50 \mathrm{KM}$ & CORTE 6 ALTA \\
\hline 0157 & 2011.35 & & $>13 \% A<=20 \%$ & $\mathrm{DE} 00 \mathrm{~A}<10 \mathrm{KM}$ & CORTE 6 ALTA \\
\hline 0158 & 2350.15 & & $>13 \% A<=20 \%$ & $\mathrm{DE} 10 \mathrm{~A}<20 \mathrm{kM}$ & CORTE 6 ALTA \\
\hline 0159 & 783.75 & & $>13 \% A<=20 \%$ & $D E 20 A<30 \mathrm{KM}$ & CORTE 6 ALTA \\
\hline 0160 & 193.6 & & $>13 \% \mathrm{~A} \quad<=20 \%$ & $\mathrm{DE} 30 \mathrm{~A}<40 \mathrm{KM}$ & CORTE 6 ALTA \\
\hline
\end{tabular}


Tabela 12 (cont.): Divisão da área com cana de açúcar no Estado de São Paulo em blocos de acordo com a expectativa de fertilidade, declividade, distância e estágio de corte distância e estágío de corte.

\begin{tabular}{|c|c|c|c|c|c|}
\hline BLOCO & ÁREA & $\%$ MECAN. & DECLIVIDADE & DISTÂNCIA & ESTÁGIO FERTILID \\
\hline 0161 & 161.15 & & $>13 \% A<=20 \%$ & $D E 40 \mathrm{~A}<50 \mathrm{KM}$ & CORTE 6 ALTA \\
\hline 0163 & 1508.51 & & $>20 \%$ & $D E 00 A<10 \mathrm{KM}$ & CORTE 6 ALTA \\
\hline 0164 & 1762.61 & & $>20 \%$ & $D E 10 A<20 \mathrm{KM}$ & CORTE 6 ALTA \\
\hline 0165 & 587.81 & & $>20 \%$ & $D E 20 A<30 \mathrm{KM}$ & CORTE 6 ALTA \\
\hline 0166 & 145.2 & & $>20 \%$ & $D E 30 \mathrm{~A}<40 \mathrm{KM}$ & CORTE 6 ALTA \\
\hline 0167 & 120.86 & & $>20 \%$ & $D E 40 \mathrm{~A}<50 \mathrm{KM}$ & CORTE 6 ALTA \\
\hline 0169 & 18102.15 & 38 & $<=8 \%$ & $D E 00 A<10 \mathrm{KM}$ & CORTE 7 ALTA \\
\hline 0170 & 21151.35 & 38 & $<=8 \%$ & $D E 10 \mathrm{~A}<20 \mathrm{KM}$ & CORTE 7 ALTA \\
\hline 0171 & 7053.75 & 38 & $<=8 \%$ & $D E 20 A<30 \mathrm{kM}$ & CORTE 7 ALTA \\
\hline 0172 & 1742.4 & 38 & $<=8 \%$ & $D E 30 \mathrm{~A}<40 \mathrm{KM}$ & CORTE 7 ALTA \\
\hline 0173 & 1450.35 & 38 & $<=8 \%$ & $D E 40 \mathrm{~A}<50 \mathrm{KM}$ & CORTE 7 ALTA \\
\hline 0175 & 2011.35 & & $>8 \% A<=13 \%$ & $D E 00 \mathrm{~A}<10 \mathrm{KM}$ & CORTE 7 ALTA \\
\hline 0176 & 2350.15 & & $>8 \% A<=13 \%$ & $D E 10 \mathrm{~A}<20 \mathrm{kM}$ & CORTE 7 ALTA \\
\hline 0177 & 783.75 & & $>8 \% A<=13 \%$ & $D E 20 A<30 \mathrm{kM}$ & CORTE 7 ALTA \\
\hline 0178 & 193.6 & & $>8 \% \mathrm{~A}<=13 \%$ & $D E 30 A<40 \mathrm{KM}$ & CORTE 7 ALTA \\
\hline 0179 & 161.15 & & $>8 \% A<=13 \%$ & $D E 40 A<50 \mathrm{KM}$ & CORTE 7 ALTA \\
\hline 0181 & 201135 & & $>13 \% A<=20 \%$ & $D E 00 A<10 \mathrm{KM}$ & CORTE 7 ALTA \\
\hline 0182 & 2350.15 & & $>13 \% A<=20 \%$ & $\mathrm{DE} 10 \mathrm{~A}<20 \mathrm{KM}$ & CORTE 7 ALTA \\
\hline 0183 & 783.75 & & $>13 \% A<=20 \%$ & $D E 20 A<30 \mathrm{KM}$ & CORTE 7 ALTA \\
\hline 0184 & 193.6 & & $>13 \% A<=20 \%$ & $D E 30 A<40 \mathrm{KM}$ & CORTE 7 ALTA \\
\hline 0185 & 161.15 & & $>13 \% A<=20 \%$ & $\mathrm{DE} 40 \mathrm{~A}<50 \mathrm{KM}$ & CORTE 7 ALTA \\
\hline 0187 & 1508.51 & & $>20 \%$ & $D E 00 A<10 \mathrm{kM}$ & CORTE 7 ALTA \\
\hline 0188 & 1762.61 & & $>20 \%$ & $D E 10 A<20 \mathrm{KM}$ & CORTE 7 ALTA \\
\hline 0189 & 587.81 & & $>20 \%$ & $D E 20 A<30 \mathrm{KM}$ & CORTE 7 ALTA \\
\hline 0190 & 145.2 & & $>20 \%$ & $D E 30 \mathrm{~A}<40 \mathrm{KM}$ & CORTE 7 ALTA \\
\hline 0191 & 120.86 & & $>20 \%$ & $D E 40 A<50 \mathrm{KM}$ & CORTE 7 ALTA \\
\hline 0193 & 27160.47 & 38 & $<=8 \%$ & $D E 00 A<10 \mathrm{KM}$ & PLANTIO MÉDIA \\
\hline
\end{tabular}


Tabela 12 (cont.): Divisão da área com cana de açúcar no Estado de São Paulo em blocos de acordo com a expectativa de fertilidade, declividade, distância e estágio de corte distância e estágio de corte.

\begin{tabular}{|c|c|c|c|c|c|c|}
\hline$B L O C O$ & AREA & $\%$ MECAN & DECLIVIDADE & DISTÂNCIA & ESTAGIO & FERTILID. \\
\hline 0194 & 24433.93 & 38 & $<=8 \%$ & DE $10 \mathrm{~A}<20 \mathrm{KM}$ & PLANTIO & MÉDIA \\
\hline 0195 & 180774 & 38 & $<=8 \%$ & $D E 20 A<30 \mathrm{kM}$ & PLANTIO & MÉDIA \\
\hline 0196 & 5493.4 & 38 & $<=8 \%$ & $D E 30 \mathrm{~A}<40 \mathrm{KM}$ & PLANTIO & MÉDIA \\
\hline 0197 & 4662.53 & 38 & $<=8 \%$ & $D E 40 \mathrm{~A}<50 \mathrm{KM}$ & PLANTIO & MEDDIA \\
\hline 0198 & 838.93 & 38 & $<=8 \%$ & $>50 \mathrm{KM}$ & PLANTIO & MÉDIA \\
\hline 0199 & 18518.5 & & $>8 \% A<=13 \%$ & $D E 00 A<10 \mathrm{KM}$ & PLANTIO & MÉDIA \\
\hline 0200 & 16659.5 & & $>8 \% A<=13 \%$ & $D E 10 A<20 \mathrm{kM}$ & PLANTIO & MÉDIA \\
\hline 0201 & 12325.5 & & $>8 \% \mathrm{~A}<=13 \%$ & DE $20 \mathrm{~A}<30 \mathrm{KM}$ & PLANTIO & MEDIA \\
\hline 0202 & 3745.5 & & $>8 \% A<-13 \%$ & DE $30 \mathrm{~A}<40 \mathrm{KM}$ & PLANTIO & MEDIA \\
\hline 0203 & 3179 & & $>8 \% \mathrm{~A}<=13 \%$ & $D E 40 A<50 \mathrm{KM}$ & PLANTIO & MÉDIA \\
\hline 0204 & 572 & & $>8 \% A<<=13 \%$ & $>50 \mathrm{kM}$ & PLANTIO & MÉDIA \\
\hline 0205 & 3703.7 & & $>13 \% A<=20 \%$ & $D E 00 A<10 \mathrm{KM}$ & PLANTIO & MÉDIA \\
\hline 0206 & 3331.9 & & $>13 \% A<=20 \%$ & $D E 10 \mathrm{~A}<20 \mathrm{KM}$ & PLANTIO & MÉDIA \\
\hline 0207 & 2465.1 & & $>13 \% A<=20 \%$ & $D E 20 \mathrm{~A}<30 \mathrm{KM}$ & PLANTIO & MÉDIA \\
\hline 0208 & 749.1 & & $>13 \% A<=20 \%$ & $D E 30 \mathrm{~A}<40 \mathrm{KM}$ & PLANTIO & MEDIA \\
\hline 0209 & 635.8 & & $>13 \% A<=20 \%$ & $D E 40 \mathrm{~A}<50 \mathrm{kM}$ & PLANTIO & MÉDIA \\
\hline 0210 & 114.4 & & $>13 \% A<=20 \%$ & $>50 \mathrm{KM}$ & PLANTIO & MÉDIA \\
\hline 0211 & 61728 & & $>20 \%$ & $D E 00 A<10 \mathrm{KM}$ & PLANTIO & MÉDIA \\
\hline 0212 & 555.32 & & $>20 \%$ & $D E 10 A<20 \mathrm{kM}$ & PLANTIO & MÉDIA \\
\hline 0213 & 41085 & & $>20 \%$ & $\mathrm{DE} 20 \mathrm{~A}<30 \mathrm{KM}$ & PLANTIO & MÉDIA \\
\hline 0214 & 124.85 & & $>20 \%$ & $D E 30 A<40 \mathrm{KM}$ & PLANTIO & MEDDIA \\
\hline 0215 & 125.03 & & $>20 \%$ & $D E 40 A<50 \mathrm{KM}$ & PLANTIO & MÉDIA \\
\hline 0217 & 27160.47 & 38 & $<=8 \%$ & $D E 00 A<10 \mathrm{kM}$ & CORTE 1 & MÉDIA \\
\hline 0218 & 24433.93 & 38 & $<=8 \%$ & DE $10 \mathrm{~A}<20 \mathrm{KM}$ & CORTE 1 & MEDIA \\
\hline 0219 & 180774 & 38 & $<=8 \%$ & $D E 20 A<30 \mathrm{kM}$ & CORTE 1 & MÉDIA \\
\hline 0220 & 5493.4 & 38 & $<=8 \%$ & DE $30 \mathrm{~A}<40 \mathrm{KM}$ & CORTE 1 & MÉDIA \\
\hline 0221 & 4662.53 & 38 & $<=8 \%$ & $D E 40 \mathrm{~A}<50 \mathrm{kM}$ & CORTE 1 & MEDIA \\
\hline
\end{tabular}


Tabela 12 (cont.): Divisão da área com cana de açúcar no Estado de São Paulo em blocos de acordo com a expectativa de fertilidade, declividade, distância e estágio de corte distância e estágio de corte.

\begin{tabular}{|c|c|c|c|c|c|}
\hline BLOCO & AREA & $\%$ MECAN. & DECLIVIDADE & DISTÂNCIA & ESTÁGIO FERTILID \\
\hline 0222 & 838.93 & 38 & $<=8 \%$ & $>50 \mathrm{KM}$ & CORTE 1 MÉDIA \\
\hline 0223 & 18518.5 & & $>8 \% \mathrm{~A}<=13 \%$ & $D E 00 A<10 \mathrm{KM}$ & CORTE 1 MÉDIA \\
\hline 0224 & 16659.5 & & $>8 \% \mathrm{~A}<=13 \%$ & $D E 10 A<20 \mathrm{KM}$ & CORTE 1 MEDIA \\
\hline 0225 & 12325.5 & & $>8 \% \mathrm{~A}<=13 \%$ & DE $20 \mathrm{~A}<30 \mathrm{KM}$ & CORTE 1 MÉDIA \\
\hline 0226 & 3745.5 & & $>8 \% \mathrm{~A}<=13 \%$ & DE $30 \mathrm{~A}<40 \mathrm{KM}$ & CORTE 1 MEDIA \\
\hline 0227 & 3179 & & $>8 \% A<=13 \%$ & $D E 40 A<50 \mathrm{KM}$ & CORTE 1 MEDIA \\
\hline 0228 & 572 & & $>8 \% A<=13 \%$ & $>50 \mathrm{KM}$ & CORTE 1 MÉDIA \\
\hline 0229 & 3703.7 & & $>13 \% A<=20 \%$ & $D E 00 \mathrm{~A}<10 \mathrm{KM}$ & CORTE 1 MEDIA \\
\hline 0230 & 3331.9 & & $>13 \% A<=20 \%$ & $D E 10 \mathrm{~A}<20 \mathrm{kM}$ & CORTE 1 MÉDIA \\
\hline 0231 & 24651 & & $>13 \% A<=20 \%$ & DE $20 \mathrm{~A}<30 \mathrm{kM}$ & CORTE 1 MÉDIA \\
\hline 0232 & 749.1 & & $>13 \% \mathrm{~A}<=20 \%$ & DE $30 \mathrm{~A}<40 \mathrm{KM}$ & CORTE 1 MÉDIA \\
\hline 0233 & 635.8 & & $>13 \% \mathrm{~A}<=20 \%$ & $D E 40 \mathrm{~A}<50 \mathrm{kM}$ & CORTE 1 MÉDIA \\
\hline 0234 & 114.4 & & $>13 \% \mathrm{~A}<=20 \%$ & $>50 \mathrm{KM}$ & CORTE 1 MEDIA \\
\hline 0235 & 61728 & & $>20 \%$ & $D E 00 A<10 \mathrm{KM}$ & CORTE 1 MÉDIA \\
\hline 0236 & 555.32 & & $>20 \%$ & $D E 10 \mathrm{~A}<20 \mathrm{KM}$ & CORTE 1 MÉDIA \\
\hline 0237 & 410.85 & & $>20 \%$ & $D E 20 A<30 \mathrm{KM}$ & CORTE 1 MÉDIA \\
\hline 0238 & 124.85 & & $>20 \%$ & $D E 30 \mathrm{~A}<40 \mathrm{KM}$ & CORTE 1 MÉDIA \\
\hline 0239 & 125.03 & & $>20 \%$ & $D E 40 A<50 \mathrm{kM}$ & CORTE 1 MÉDIA \\
\hline 0241 & 27160.47 & 38 & $<=8 \%$ & DE $00 \mathrm{~A}<10 \mathrm{KM}$ & CORTE 2 MÉDIA \\
\hline 0242 & 24433.93 & 38 & $<=8 \%$ & $D E 10 A<20 \mathrm{kM}$ & CORTE 2 MÉDIA \\
\hline 0243 & 180774 & 38 & $<=8 \%$ & $D E 20 A<30 \mathrm{KM}$ & CORTE 2 MEDIA \\
\hline 0244 & 5493.4 & 38 & $<=8 \%$ & $D E 30 \mathrm{~A}<40 \mathrm{KM}$ & CORTE 2 MEDIA \\
\hline 0245 & 4662.53 & 38 & $<=8 \%$ & $D E 40 \mathrm{~A}<50 \mathrm{KM}$ & CORTE 2 MEDIA \\
\hline 0246 & 838.93 & 38 & $<=8 \%$ & $>50 \mathrm{KM}$ & CORTE 2 MÉDIA \\
\hline 0247 & 18518.5 & & $>8 \% \mathrm{~A}<=13 \%$ & $D E 00 A<10 \mathrm{KM}$ & CORTE 2 MEDIA \\
\hline 0248 & 16659.5 & & $>8 \% A<=13 \%$ & $\mathrm{DE} 10 \mathrm{~A}<20 \mathrm{KM}$ & CORTE 2 MÉDIA \\
\hline 0249 & 12325.5 & & $>8 \% A<=13 \%$ & $D E 20 A<30 \mathrm{KM}$ & CORTE 2 MEDIA \\
\hline
\end{tabular}


Tabela 12 (cont.): Divisão da área com cana de açúcar no Estado de São Paulo em blocos de acordo com a expectativa de fertilidade, declividade, distância e estágio de corte distância e estágio de corte.

\begin{tabular}{|c|c|c|c|c|c|}
\hline BLOCO & AREA & $\% M E C A N$ & DECLIVIDADE & DISTANACIA & ESTAGIO FERTILID \\
\hline 0250 & 3745.5 & & $>8 \% \mathrm{~A}<=13 \%$ & $\mathrm{DE} 30 \mathrm{~A}<40 \mathrm{KM}$ & CORTE 2 MÉDIA \\
\hline 0251 & 3179 & & $>8 \% A<=13 \%$ & DE $40 \mathrm{~A}<50 \mathrm{KM}$ & CORTE 2 MÉDIA \\
\hline 0252 & 572 & & $>8 \% \mathrm{~A}<=13 \%$ & $>50 \mathrm{kM}$ & CORTE 2 MÉDIA \\
\hline 0253 & 37037 & & $>13 \% \mathrm{~A}<=20 \%$ & $D E 00 A<10 \mathrm{KM}$ & CORTE 2 MÉDIA \\
\hline 0254 & 3331.9 & & $>13 \% A<=20 \%$ & $D E 10 A<20 \mathrm{kM}$ & CORTE 2 MÉDIA \\
\hline 0255 & 2465.1 & & $>13 \% A<=20 \%$ & $D E 20 A<30 \mathrm{KM}$ & CORTE 2 MÉDIA \\
\hline 0256 & 749.1 & & $>13 \% \mathrm{~A}<=20 \%$ & $D E 30 A<40 \mathrm{KM}$ & CORTE 2 MÉDIA \\
\hline 0257 & 635.8 & & $>13 \% A<=20 \%$ & $\mathrm{DE} 40 \mathrm{~A}<50 \mathrm{KM}$ & CORTE 2 MÉDIA \\
\hline 0258 & 114.4 & & $>13 \% A<=20 \%$ & $>50 \mathrm{KM}$ & CORTE 2 MÉDIA \\
\hline 0259 & 61728 & & $>20 \%$ & $D E 00 \mathrm{~A}<10 \mathrm{KM}$ & CORTE 2 MÉDIA \\
\hline 0260 & 555.32 & & $>20 \%$ & $D E 10 \mathrm{~A}<20 \mathrm{KM}$ & CORTE 2 MÉDIA \\
\hline 0261 & 410.85 & & $>20 \%$ & $D E 20 A<30 \mathrm{kM}$ & CORTE 2 MEDIA \\
\hline 0262 & 124.85 & & $>20 \%$ & $D E 30 \mathrm{~A}<40 \mathrm{KM}$ & CORTE 2 MÉDIA \\
\hline 0263 & 125.03 & & $>20 \%$ & DE $40 \mathrm{~A}<50 \mathrm{KM}$ & CORTE 2 MÉDIA \\
\hline 0265 & 27160.47 & 38 & $<=8 \%$ & $D E 00 \mathrm{~A}<10 \mathrm{KM}$ & CORTE 3 MEDIA \\
\hline 0266 & 24433.93 & 38 & $<=8 \%$ & $D E 10 \mathrm{~A}<20 \mathrm{KM}$ & CORTE 3 MÉDIA \\
\hline 0267 & 18077.4 & 38 & $<=8 \%$ & $\mathrm{DE} 20 \mathrm{~A}<30 \mathrm{KM}$ & CORTE 3 MÉDIA \\
\hline 0268 & 5493.4 & 38 & $<=8 \%$ & $D E 30 A<40 \mathrm{KM}$ & CORTE 3 MÉDIA \\
\hline 0269 & 4662.53 & 38 & $<=8 \%$ & $\mathrm{DE} 40 \mathrm{~A}<50 \mathrm{KM}$ & CORTE 3 MÉDIA \\
\hline 0270 & 838.93 & 38 & $<=8 \%$ & $>50 \mathrm{KM}$ & CORTE 3 MEDIA \\
\hline 0271 & 18518.5 & & $>8 \% A<=13 \%$ & $\mathrm{DE} 00 \mathrm{~A}<10 \mathrm{KM}$ & CORTE 3 MÉDIA \\
\hline 0272 & 166595 & & $>8 \% A<=13 \%$ & DE $10 \mathrm{~A}<20 \mathrm{KM}$ & CORTE 3 MEDIA \\
\hline 0273 & 12325.5 & & $>8 \% A<=13 \%$ & $D E 20 A<30 \mathrm{kM}$ & CORTE 3 MEDIA \\
\hline 0274 & 3745.5 & & $>8 \% A<=13 \%$ & $\mathrm{DE} 30 \mathrm{~A}<40 \mathrm{KM}$ & CORTE 3 MÉDIA \\
\hline 0275 & 3179 & & $>8 \% A<=13 \%$ & $D E 40 A<50 \mathrm{KM}$ & CORTE 3 MÉDIA \\
\hline 0276 & 572 & & $>8 \%$ A $<=13 \%$ & $>50 \mathrm{KM}$ & CORTE 3 MEDIA \\
\hline 0277 & 3703.7 & & $>13 \% A<=20 \%$ & DE $00 \mathrm{~A}<10 \mathrm{KM}$ & CORTE 3 MEDIA \\
\hline
\end{tabular}


Tabela 12 (cont.): Divisão da área com cana de açúcar no Estado de São Paulo em blocos de acordo com a expectativa de fertilidade, declividade, distância e estágio de corte distância e estágio de corte.

\begin{tabular}{|c|c|c|c|c|c|}
\hline BLOCO & ÁREA & $\% M E C A N$ & DECLIVIDADE & DISTÂNCIA & ESTAGIO FERTILID. \\
\hline 0278 & 3331.9 & & $>13 \% \mathrm{~A}<=20 \%$ & $D E 10 A<20 \mathrm{KM}$ & CORTE 3 MEDIA \\
\hline 0279 & 2465.1 & & $>13 \% A<=20 \%$ & DE $20 \mathrm{~A}<30 \mathrm{kM}$ & CORTE 3 MÉDIA \\
\hline 0280 & 749.1 & & $>13 \% A<=20 \%$ & $D E 30 \mathrm{~A}<40 \mathrm{KM}$ & CORTE 3 MEDIA \\
\hline 0281 & 635.8 & & $>13 \% A<=20 \%$ & DE $40 \mathrm{~A}<50 \mathrm{KM}$ & CORTE 3 MÉDIA \\
\hline 0282 & 114.4 & & $>13 \% A<=20 \%$ & $>50 \mathrm{KM}$ & CORTE 3 MEDIA \\
\hline 0283 & 617.28 & & $>20 \%$ & DE $00 \mathrm{~A}<10 \mathrm{KM}$ & CORTE 3 MEDIA \\
\hline 0284 & 555.32 & & $>20 \%$ & $D E 10 \mathrm{~A}<20 \mathrm{kM}$ & CORTE 3 MÉDIA \\
\hline 0285 & 410.85 & & $>20 \%$ & $D E 20 A<30 \mathrm{kM}$ & CORTE 3 MEDIA \\
\hline 0286 & 12485 & & $>20 \%$ & $\mathrm{DE} 30 \mathrm{~A}<40 \mathrm{kM}$ & CORTE 3 MÉDIA \\
\hline 0287 & 125.03 & & $>20 \%$ & DE $40 \mathrm{~A}<50 \mathrm{KM}$ & CORTE 3 MEDIA \\
\hline 0289 & 27160.47 & 38 & $<=8 \%$ & $D E 00 A<10 \mathrm{KM}$ & CORTE 4 MEDIA \\
\hline 0290 & 24433.93 & 38 & $<=8 \%$ & DE $10 \mathrm{~A}<20 \mathrm{KM}$ & CORTE 4 MEDIA \\
\hline 0291 & 180774 & 38 & $<=8 \%$ & $D E 20 A<30 \mathrm{KM}$ & CORTE 4 MÉDIA \\
\hline 0292 & 5493.4 & 38 & $<=8 \%$ & DE $30 \mathrm{~A}<40 \mathrm{KM}$ & CORTE 4 MÉDIA \\
\hline 0293 & 4662.53 & 38 & $<=8 \%$ & $D E 40 \mathrm{~A}<50 \mathrm{kM}$ & CORTE 4 MÉDIA \\
\hline 0294 & 838.93 & 38 & $<=8 \%$ & $>50 \mathrm{KM}$ & CORTE 4 MEDIA \\
\hline 0295 & 18518.5 & & $>8 \% A<=13 \%$ & $D E 00 A<10 \mathrm{KM}$ & CORTE 4 MEDIA \\
\hline 0296 & 16659.5 & & $>8 \% A<=13 \%$ & $D E 10 \mathrm{~A}<20 \mathrm{kM}$ & CORTE 4 MEDIA \\
\hline 0297 & 12325.5 & & $>8 \% A<=13 \%$ & $D E 20 A<30 \mathrm{kM}$ & CORTE 4 MEDIA \\
\hline 0298 & 3745.5 & & $>8 \%, A<=13 \%$ & $\mathrm{DE} 30 \mathrm{~A}<40 \mathrm{KM}$ & CORTE 4 MEDIA \\
\hline 0299 & 3179 & & $>8 \% A<=13 \%$ & $D E 40 \mathrm{~A}<50 \mathrm{KM}$ & CORTE 4 MEDIA \\
\hline 0300 & 572 & & $>8 \% \mathrm{~A}<=13 \%$ & $>50 \mathrm{kM}$ & CORTE 4 MEDIA \\
\hline 0301 & 3703.7 & & $>13 \% A<=20 \%$ & $D E 00 \mathrm{~A}<10 \mathrm{KM}$ & CORTE 4 MÉDIA \\
\hline 0302 & 33319 & & $>13 \% A<=20 \%$ & $D E 10 \mathrm{~A}<20 \mathrm{KM}$ & CORTE 4 MEDIA \\
\hline 0303 & 24651 & & $>13 \% A<=20 \%$ & DE $20 A<30 \mathrm{KM}$ & CORTE 4 MÉDIA \\
\hline 0304 & 749.1 & & $>13 \% \mathrm{~A}<=20 \%$ & DE $30 \mathrm{~A}<40 \mathrm{KM}$ & CORTE 4 MÉDIA \\
\hline 0305 & 6358 & & $>13 \% A<=20 \%$ & DE $40 \mathrm{~A}<50 \mathrm{kM}$ & CORTE 4 MEDIA \\
\hline
\end{tabular}


Tabela 12 (cont.): Divisão da área com cana de açúcar no Estado de São Paulo em blocos de acordo com a expectativa de fertilidade, declividade, distância e estágio de corte distância e estágio de corte.

\begin{tabular}{|c|c|c|c|c|c|}
\hline BLOCO & ÁREA & $\%$ MECAN. & DECLIVIDADE & DISTÂNCIA & ESTAGIO FERTILID \\
\hline 0306 & 114.4 & & $>13 \% \mathrm{~A}<=20 \%$ & $>50 \mathrm{KM}$ & CORTE 4 MÉDIA \\
\hline 0307 & 617.28 & & $>20 \%$ & $D E 00 \mathrm{~A}<10 \mathrm{KM}$ & CORTE 4 MÉDIA \\
\hline 0308 & 555.32 & & $>20 \%$ & $D E 10 \mathrm{~A}<20 \mathrm{kM}$ & CORTE 4 MÉDIA \\
\hline 0309 & 410.85 & & $>20 \%$ & $D E 20 \mathrm{~A}<30 \mathrm{KM}$ & CORTE 4 MÉDIA \\
\hline 0310 & 124.85 & & $>20 \%$ & $D E 30 \mathrm{~A}<40 \mathrm{KM}$ & CORTE 4 MÉDIA \\
\hline 0311 & 125.03 & & $>20 \%$ & $D E 40 \mathrm{~A}<50 \mathrm{KM}$ & CORTE 4 MÉDIA \\
\hline 0313 & 27160.47 & 38 & $<=8 \%$ & $D E 00 \mathrm{~A}<10 \mathrm{KM}$ & CORTE 5 MÉDIA \\
\hline 0314 & 24433.93 & 38 & $<=8 \%$ & $D E 10 \mathrm{~A}<20 \mathrm{KM}$ & CORTE 5 MEDIA \\
\hline 0315 & 18077.4 & 38 & $<=8 \%$ & $D E 20 A<30 \mathrm{KM}$ & CORTE 5 MÉDIA \\
\hline 0316 & 5493.4 & 38 & $<=8 \%$ & DE $30 \mathrm{~A}<40 \mathrm{KM}$ & CORTE 5 MÉDIA \\
\hline 0317 & 4662.53 & 38 & $<=8 \%$ & $D E 40 \mathrm{~A}<50 \mathrm{KM}$ & CORTE 5 MÉDIA \\
\hline 0318 & 838.93 & 38 & $<=8 \%$ & $>50 \mathrm{KM}$ & CORTE 5 MÉDIA \\
\hline 0319 & 18518.5 & & $>8 \% A<=13 \%$ & DE $00 \mathrm{~A}<10 \mathrm{KM}$ & CORTE 5 MÉDIA \\
\hline 0320 & 16659.5 & & $>8 \% \mathrm{~A}<=13 \%$ & $D E 10 \mathrm{~A}<20 \mathrm{KM}$ & CORTE 5 MÉDIA \\
\hline 0321 & 12325.5 & & $>8 \% A<=13 \%$ & $D E 20 A<30 \mathrm{KM}$ & CORTE 5 MEDIA \\
\hline 0322 & 3745.5 & & $>8 \% \mathrm{~A}<=13 \%$ & DE $30 \mathrm{~A}<40 \mathrm{KM}$ & CORTE 5 MEDIA \\
\hline 0323 & 3179 & & $>8 \% \mathrm{~A}<=13 \%$ & $D E 40 A<50 \mathrm{KM}$ & CORTE 5 MEDIA \\
\hline 0324 & 572 & & $>8 \% \mathrm{~A}<=13 \%$ & $>50 \mathrm{kM}$ & CORTE 5 MÉDIA \\
\hline 0325 & 3703.7 & & $>13 \% \mathrm{~A}<=20 \%$ & $D E 00 A<10 \mathrm{KM}$ & CORTE 5 MEDIA \\
\hline 0326 & 3331.9 & & $>13 \% A<=20 \%$ & $D E 10 \mathrm{~A}<20 \mathrm{KM}$ & CORTE 5 MÉDIA \\
\hline 0327 & 2465.1 & & $>13 \% A<=20 \%$ & $D E 20 \mathrm{~A}<30 \mathrm{KM}$ & CORTE 5 MÉDIA \\
\hline 0328 & 749.1 & & $>13 \% \mathrm{~A}<=20 \%$ & $D E 30 A<40 \mathrm{kM}$ & CORTE 5 MÉDIA \\
\hline 0329 & 6358 & & $>13 \% A<=20 \%$ & $D E 40 A<50 \mathrm{KM}$ & CORTE 5 MEDIA \\
\hline 0330 & 114.4 & & $>13 \% A<=20 \%$ & $>50 \mathrm{kM}$ & CORTE 5 MÉDIA \\
\hline 0331 & 61728 & & $>20 \%$ & $D E 00 A<10 \mathrm{KM}$ & CORTE 5 MÉDIA \\
\hline 0332 & $555: 32$ & & $>20 \%$ & $D E 10 \mathrm{~A}<20 \mathrm{KM}$ & CORTE 5 MÉDIA \\
\hline 0333 & 410.85 & & $>20 \%$ & $D E 20 A<30 \mathrm{KM}$ & CORTE 5 MÉDIA \\
\hline
\end{tabular}


Tabela 12 (cont.): Divisão da área com cana de açúcar no Estado de São Paulo em blocos de acordo com a expectativa de fertilidade, declividade, distância e estágio de corte distância e estágio de corte.

\begin{tabular}{|c|c|c|c|c|c|c|}
\hline BLOCO & AREA & $\%$ MECAN & DECLIVIDADE & DISTÂNCIA & ESTÄGIO & FERTILID \\
\hline 0334 & 124.85 & & $>20 \%$ & $D E 30 A<40 \mathrm{KM}$ & CORTE 5 & MÉDIA \\
\hline 0335 & 125.03 & & $>20 \%$ & $D E 40 \mathrm{~A}<50 \mathrm{KM}$ & CORTE 5 & MÉDIA \\
\hline 0337 & 136752 & 38 & $<=8 \%$ & $D E 00 A<10 \mathrm{KM}$ & PLANTIO & $B A I X A$ \\
\hline 0338 & 19675.04 & 38 & $<=8 \%$ & $D E 10 \mathrm{~A}<20 \mathrm{KM}$ & PLANTIO & BAIXA \\
\hline 0339 & 103796 & 38 & $<=8 \%$ & $D E 20 A<30 \mathrm{KM}$ & PLANTIO & BAIXA \\
\hline 0340 & 4847.92 & 38 & $<=8 \%$ & $D E 30 A<40 \mathrm{KM}$ & PLANTIO & BAIXA \\
\hline 0341 & 10336.48 & 38 & $<=8 \%$ & $D E 40 \mathrm{~A}<50 \mathrm{KM}$ & PLANTIO & $\mathrm{BAIXA}$ \\
\hline 0342 & 268576 & 38 & $<=8 \%$ & $>50 \mathrm{KM}$ & PLANTIO & BAIXA \\
\hline 0343 & 2930.4 & & $>8 \% A<=13 \%$ & $D E 00 A<10 \mathrm{KM}$ & PLANTIO & BAIXA \\
\hline 0344 & 4216.08 & & $>8 \% \mathrm{~A}<=13 \%$ & $D E 10 \mathrm{~A}<20 \mathrm{kM}$ & PLANTIO & BAIXA \\
\hline 0345 & 2224.2 & & $>8 \% A<=13 \%$ & $D E 20 A<30 \mathrm{KM}$ & PLANTIO & BAIXA \\
\hline 0346 & 103884 & & $>8 \% A<=13 \%$ & $D E 30 \mathrm{~A}<40 \mathrm{KM}$ & PLANTIO & BAIXA \\
\hline 0347 & 2214.96 & & $>8 \% A<=13 \%$ & $D E 40 A<50 \mathrm{kM}$ & PLANTIO & BAIXA \\
\hline 0348 & 575.52 & & $>8 \% A<=13 \%$ & $>50 \mathrm{KM}$ & PLANTIO & BAIXA \\
\hline 0349 & 10744.8 & & $>13 \% A<=20 \%$ & $D E 00 A<10 \mathrm{kM}$ & PLANTIO & BAIXA \\
\hline 0350 & 15458.96 & & $>13 \% A<=20 \%$ & $D E 10 A<20 \mathrm{kM}$ & PLANTIO & BAIXA \\
\hline 0351 & 8155.4 & & $>13 \% A<=20 \%$ & $D E 20 A<30 \mathrm{kM}$ & PLANTIO & BAIXA \\
\hline 0352 & 3809.08 & & $>13 \% A<=20 \%$ & $D E 30 A<40 \mathrm{KM}$ & PLANTIO & BAIXA \\
\hline 0353 & 8121.52 & & $>13 \% A<=20 \%$ & DE $40 \mathrm{~A}<50 \mathrm{KM}$ & PLANTIO & BAIXA \\
\hline 0354 & 2110.24 & & $>13 \% A<=20 \%$ & $>50 \mathrm{KM}$ & PLANTIO & BAIXA \\
\hline 0355 & 7814.4 & & $>20 \%$ & $D E 00 A<10 \mathrm{KM}$ & PLANTIO & BAIXA \\
\hline 0356 & 11242.88 & & $>20 \%$ & $D E 10 A<20 \mathrm{kM}$ & PLANTIO & BAIXA \\
\hline 0357 & 59312 & & $>20 \%$ & $D E 20 A<30 \mathrm{KM}$ & PLANTIO & BAIXA \\
\hline 0358 & 2770.24 & & $>20 \%$ & $D E 30 \mathrm{~A}<40 \mathrm{KM}$ & PLANTIO & BAIXA \\
\hline 0359 & 5906.56 & & $>20 \%$ & $\mathrm{DE} 40 \mathrm{~A}<50 \mathrm{KM}$ & PLANTIO & BAIXA \\
\hline 0360 & 1534.72 & & $>20 \%$ & $>50 \mathrm{kM}$ & PLANTIO & BAIXA \\
\hline 0361 & 13675.2 & 38 & $<=8 \%$ & $D E 00 \mathrm{~A}<10 \mathrm{KM}$ & CORTE 1 & BAIXA \\
\hline
\end{tabular}


Tabela 12 (cont.): Divisão da área com cana de açúcar no Estado de São Paulo em blocos de acordo com a expectativa de fertilidade, declividade, distância e estágio de corte distância e estágio de corte.

\begin{tabular}{|c|c|c|c|c|c|}
\hline$B L O C O$ & ÁREA & $\%$ MECAN. & DECLIVIDADE & DISTANNCIA & ESTÁGIO FERTILID \\
\hline 0362 & 19675.04 & 38 & $<=8 \%$ & $D E 10 A<20 \mathrm{KM}$ & CORTE 1 BAIXA \\
\hline 0363 & 10379.6 & 38 & $<=8 \%$ & $D E 20 A<30 \mathrm{KM}$ & CORTE 1 BAIXA \\
\hline 0364 & 484792 & 38 & $<=8 \%$ & DE $30 \mathrm{~A}<40 \mathrm{KM}$ & CORTE 1 BAIXA \\
\hline 0365 & 10336.48 & 38 & $<=8 \%$ & DE $40 \mathrm{~A}<50 \mathrm{KM}$ & CORTE 1 BAIXA \\
\hline 0366 & 2685.76 & 38 & $<=8 \%$ & $>50 \mathrm{KM}$ & CORTE 1 BAIXA \\
\hline 0367 & 2930.4 & & $>8 \% A<=13 \%$ & $D E 00 A<10 \mathrm{KM}$ & CORTE 1 BAIXA \\
\hline 0368 & 4216.08 & & $>8 \% \mathrm{~A}<=13 \%$ & $D E 10 A<20 \mathrm{KM}$ & CORTE 1 BAIXA \\
\hline 0369 & 2224.2 & & $>8 \% A<=13 \%$ & $D E 20 A<30 \mathrm{kM}$ & CORTE 1 BAIXA \\
\hline 0370 & 1038.84 & & $>8 \% \mathrm{~A}<=13 \%$ & $D E 30 \mathrm{~A}<40 \mathrm{KM}$ & CORTE 1 BAIXA \\
\hline 0371 & 2214.96 & & $>8 \% A<=13 \%$ & $D E 40 A<50 \mathrm{KM}$ & CORTE 1 BAIXA \\
\hline 0372 & 575.52 & & $>8 \% \mathrm{~A}<=13 \%$ & $>50 \mathrm{KM}$ & CORTE 1 BAIXA \\
\hline 0373 & 10744.8 & & $>13 \% A<=20 \%$ & $D E 00 A<10 \mathrm{kM}$ & CORTE 1 BAIXA \\
\hline 0374 & 15458.96 & & $>13 \% A<=20 \%$ & $D E 10 \mathrm{~A}<20 \mathrm{KM}$ & CORTE 1 BAIXA \\
\hline 0375 & 8155.4 & & $>13 \% A<=20 \%$ & $D E 20 A<30 \mathrm{KM}$ & CORTE 1 BAIXA \\
\hline 0376 & 3809.08 & & $>13 \% \mathrm{~A}<=20 \%$ & DE $30 \mathrm{~A}<40 \mathrm{KM}$ & CORTE 1 BAIXA \\
\hline 0377 & 8121.52 & & $>13 \% A<=20 \%$ & $D E 40 A<50 \mathrm{KM}$ & CORTE 1 BAIXA \\
\hline 0378 & 2110.24 & & $>13 \% A<=20 \%$ & $>50 \mathrm{KM}$ & CORTE 1 BAIXA \\
\hline 0379 & 7814.4 & & $>20 \%$ & $D E 00 A<10 \mathrm{KM}$ & CORTE 1 BAIXA \\
\hline 0380 & 11242.88 & & $>20 \%$ & DE $10 \mathrm{~A}<20 \mathrm{KM}$ & CORTE 1 BAIXA \\
\hline 0381 & 5931.2 & & $>20 \%$ & $D E 20 A<30 \mathrm{KM}$ & CORTE 1 BAIXA \\
\hline 0382 & 2770.24 & & $>20 \%$ & $D E 30 \mathrm{~A}<40 \mathrm{KM}$ & CORTE 1 BAIXA \\
\hline 0383 & 5906.56 & & $>20 \%$ & $D E 40 \mathrm{~A}<50 \mathrm{KM}$ & CORTE 1 BAIXA \\
\hline 0384 & 153472 & & $>20 \%$ & $>50 \mathrm{KM}$ & CORTE 1 BAIXA \\
\hline 0385 & 13675.2 & 38 & $<=8 \%$ & $D E 00 A<10 \mathrm{KM}$ & CORTE 2 BAIXA \\
\hline 0386 & 19675.04 & 38 & $<=8 \%$ & $\mathrm{DE} 10 \mathrm{~A}<20 \mathrm{KM}$ & CORTE 2 BAIXA \\
\hline 0387 & 10379.6 & 38 & $<=8 \%$ & $D E 20 \mathrm{~A}<30 \mathrm{kM}$ & CORTE 2 BAIXA \\
\hline 0388 & 4847.92 & 38 & $<=8 \%$ & $D E 30 \mathrm{~A}<40 \mathrm{KM}$ & CORTE 2 BAIXA \\
\hline
\end{tabular}


Tabela 12 (cont.): Divisão da área com cana de açúcar no Estado de São Paulo em blocos de acordo com a expectativa de fertilidade, declividade, distância e estágio de corte distância e estágio de corte.

\begin{tabular}{|c|c|c|c|c|c|}
\hline$B L O C O$ & AREA & $\% M E C A N$ & DECLIVIDADE & DISTANNCIA & ESTÁGIO FERTILID. \\
\hline 0389 & 10336.48 & 38 & $<=8 \%$ & $D E 40 A<50 \mathrm{KM}$ & CORTE 2 BAIXA \\
\hline 0390 & 2685.76 & 38 & $<=8 \%$ & $>50 \mathrm{KM}$ & CORTE 2 BAIXA \\
\hline 0391 & 29304 & & $>8 \%$ A $<=13 \%$ & $D E 00 A<10 \mathrm{KM}$ & CORTE 2 BAIXA \\
\hline 0392 & 4216.08 & & $>8 \% A<=13 \%$ & $D E 10 \mathrm{~A}<20 \mathrm{kM}$ & CORTE 2 BAIXA \\
\hline 0393 & 2224.2 & & $>8 \% A<=13 \%$ & $D E 20 \mathrm{~A}<30 \mathrm{KM}$ & CORTE 2 BAIXA \\
\hline 0394 & 1038.84 & & $>8 \% A<=13 \%$ & DE $30 \mathrm{~A}<40 \mathrm{KM}$ & CORTE 2 BAIXA \\
\hline 0395 & 2214.96 & & $>8 \% A<=13 \%$ & DE $40 \mathrm{~A}<50 \mathrm{KM}$ & CORTE 2 BAIXA \\
\hline 0396 & 575.52 & & $>8 \% A<=13 \%$ & $>50 \mathrm{KM}$ & CORTE 2 BAIXA \\
\hline 0397 & 107448 & & $>13 \% A<=20 \%$ & DE $00 \mathrm{~A}<10 \mathrm{kM}$ & CORTE 2 BAIXA \\
\hline 0398 & 15458.96 & & $>13 \% A<=20 \%$ & DE $10 \mathrm{~A}<20 \mathrm{KM}$ & CORTE 2 BAIXA \\
\hline 0399 & 8155.4 & & $>13 \% \mathrm{~A}<=20 \%$ & $D E 20 A<30 \mathrm{KM}$ & CORTE 2 BAIXA \\
\hline 0400 & 3809.08 & & $>13 \% A<=20 \%$ & $D E 30 \mathrm{~A}<40 \mathrm{KM}$ & CORTE 2 BAIXA \\
\hline 0401 & 8121.52 & & $>13 \% A<=20 \%$ & $D E 40 A<50 \mathrm{KM}$ & CORTE 2 BAIXA \\
\hline 0402 & 2110.24 & & $>13 \% A<=20 \%$ & $>50 \mathrm{KM}$ & CORTE 2 BAIXA \\
\hline 0403 & 7814,4 & & $>20 \%$ & $D E 00 \mathrm{~A}<10 \mathrm{kM}$ & CORTE 2 BAIXA \\
\hline 0404 & 11242.88 & & $>20 \%$ & $D E 10 A<20 \mathrm{KM}$ & CORTE 2 BAIXA \\
\hline 0405 & 5931.2 & & $>20 \%$ & $D E 20 \mathrm{~A}<30 \mathrm{kM}$ & CORTE 2 BAIXA \\
\hline 0406 & 2770.24 & & $>20 \%$ & $D E 30 \mathrm{~A}<40 \mathrm{KM}$ & CORTE 2 BAIXA \\
\hline 0407 & 5906.56 & & $>20 \%$ & $D E 40 \mathrm{~A}<50 \mathrm{KM}$ & CORTE 2 BAIXA \\
\hline 0408 & 153472 & & $>20 \%$ & $>50 \mathrm{KM}$ & CORTE 2 BAIXA \\
\hline 0409 & 13675.2 & 38 & $<=8 \%$ & $D E 00 \mathrm{~A}<10 \mathrm{KM}$ & CORTE 3 BAIXA \\
\hline 0410 & 19675.04 & 38 & $<=8 \%$ & $D E 10 A<20 \mathrm{kM}$ & CORTE 3 BAIXA \\
\hline 0411 & 10379.6 & 38 & $<=8 \%$ & $\mathrm{DE} 20 \mathrm{~A}<30 \mathrm{KM}$ & CORTE 3 BAIXA \\
\hline 0412 & 4847.92 & 38 & $<=8 \%$ & $\mathrm{DE} 30 \mathrm{~A}<40 \mathrm{KM}$ & CORTE 3 BAIXA \\
\hline 0413 & 1033648 & 38 & $<=8 \%$ & $D E 40 \mathrm{~A}<50 \mathrm{KM}$ & CORTE 3 BAIXA \\
\hline 0414 & 268576 & 38 & $<=8 \%$ & $>50 \mathrm{kM}$ & CORTE 3 BAIXA \\
\hline 0415 & 2930.4 & & $>8 \% A<=13 \%$ & $D E 00 \mathrm{~A}<10 \mathrm{KM}$ & CORTE 3 BAIXA \\
\hline
\end{tabular}


Tabela 12 (cont.): Divisão da área com cana de açúcar no Estado de São Paulo em blocos de acordo com a expectativa de fertilidade, declividade, distância e estágio de corte distância e estágio de corte.

\begin{tabular}{|c|c|c|c|c|c|}
\hline BLOCO & ÁREA & $\% M E C A N$ & DECLIVIDADE & DISTANNCIA & ESTAGIO FERTILID \\
\hline 0416 & 4216.08 & & $>8 \% \mathrm{~A}<=13 \%$ & $D E 10 \mathrm{~A}<20 \mathrm{KM}$ & CORTE 3 BAIXA \\
\hline 0417 & 22242 & & $>8 \% A<=13 \%$ & $D E 20 A<30 \mathrm{KM}$ & CORTE 3 BAIXA \\
\hline 0418 & 1038.84 & & $>8 \% A<=13 \%$ & $D E 30 \mathrm{~A}<40 \mathrm{KM}$ & CORTE 3 BAIXA \\
\hline 0419 & 2214.96 & & $>8 \% A<=13 \%$ & $D E 40 A<50 \mathrm{KM}$ & CORTE 3 BAIXA \\
\hline 0420 & 575.52 & & $>8 \% A<=13 \%$ & $>50 \mathrm{kM}$ & CORTE 3 BAIXA \\
\hline 0421 & 10744.8 & & $>13 \% A<=20 \%$ & $D E 00 A<10 \mathrm{KM}$ & CORTE 3 BAIXA \\
\hline 0422 & 15458.96 & & $>13 \% A<=20 \%$ & $D E 10 A<20 \mathrm{kM}$ & CORTE 3 BAIXA \\
\hline 0423 & 8155.4 & & $>13 \% A<=20 \%$ & $\mathrm{DE} 20 \mathrm{~A}<30 \mathrm{kM}$ & CORTE 3 BAIXA \\
\hline 0424 & 3809.08 & & $>13 \% A<=20 \%$ & $D E 30 A<40 \mathrm{KM}$ & CORTE 3 BAIXA \\
\hline 0425 & 8121.52 & & $>13 \% A<=20 \%$ & $\mathrm{DE} 40 \mathrm{~A}<50 \mathrm{KM}$ & CORTE 3 BAIXA \\
\hline 0426 & 211024 & & $>13 \% A<=20 \%$ & $>50 \mathrm{KM}$ & CORTE 3 BAIXA \\
\hline 0427 & 7814.4 & & $>20 \%$ & DE $00 \mathrm{~A}<10 \mathrm{KM}$ & CORTE 3 BAIXA \\
\hline 0428 & 1124288 & & $>20 \%$ & $D E 10 A<20 \mathrm{KM}$ & CORTE 3 BAIXA \\
\hline 0429 & 5931.2 & & $>20 \%$ & $D E 20 \mathrm{~A}<30 \mathrm{KM}$ & CORTE 3 BAIXA \\
\hline 0430 & 2770.24 & & $>20 \%$ & $\mathrm{DE} 30 \mathrm{~A}<40 \mathrm{kM}$ & CORTE 3 BAIXA \\
\hline 0431 & 5906.56 & & $>20 \%$ & $D E 40 A<50 \mathrm{KM}$ & CORTE 3 BAIXA \\
\hline 0432 & 153472 & & $>20 \%$ & $>50 \mathrm{KM}$ & CORTE 3 BAIXA \\
\hline 0433 & 13675.2 & 38 & $<=8 \%$ & $D E 00 A<10 \mathrm{KM}$ & CORTE 4 BAIXA \\
\hline 0434 & 19675.04 & 38 & $<=8 \%$ & $D E 10 \mathrm{~A}<20 \mathrm{kM}$ & CORTE 4 BAIXA \\
\hline 0435 & 10379.6 & 38 & $<=8 \%$ & $\mathrm{DE} 20 \mathrm{~A}<30 \mathrm{kM}$ & CORTE 4 BAIXA \\
\hline 0436 & 484792 & 38 & $<=8 \%$ & $D E 30 A<40 \mathrm{KM}$ & CORTE 4 BAIXA \\
\hline 0437 & 10336.48 & 38 & $<=8 \%$ & DE $40 \mathrm{~A}<50 \mathrm{KM}$ & CORTE 4 BAIXA \\
\hline 0438 & 2685.76 & 38 & $<=8 \%$ & $>50 \mathrm{KM}$ & CORTE 4 BAIXA \\
\hline 0439 & 2930.4 & & $>8 \% A<=13 \%$ & $D E 00 A<10 \mathrm{KM}$ & CORTE 4 BAIXA \\
\hline 0440 & 4216.08 & & $>8 \% A<=13 \%$ & $D E 10 A<20 \mathrm{KM}$ & CORTE 4 BAIXA \\
\hline 0441 & 22242 & & $>8 \% A<=13 \%$ & DE $20 \mathrm{~A}<30 \mathrm{KM}$ & CORTE 4 BAIXA \\
\hline 0442 & 1038.84 & & $>8 \% A<=13 \%$ & $D E 30 \mathrm{~A}<40 \mathrm{kM}$ & CORTE 4 BAIXA \\
\hline
\end{tabular}


Tabela 12 (cont.): Divisão da área com cana de açúcar no Estado de São Paulo em blocos de acordo com a expectativa de fertilidade, declividade, distância e estágio de corte distância e estágio de corte.

\begin{tabular}{|c|c|c|c|c|c|}
\hline BLOCO & ÁREA & $\% M E C A N$ & DECLIVIDADE & DISTÂNCIA & ESTAGIO FERTILID \\
\hline 0443 & 2214.96 & & $>8 \% A<=13 \%$ & $D E 40 \mathrm{~A}<50 \mathrm{KM}$ & CORTE 4 BAIXA \\
\hline 0444 & 575.52 & & $>8 \% A<=13 \%$ & $>50 \mathrm{KM}$ & CORTE 4 BAIXA \\
\hline 0445 & 107448 & & $>13 \% A<=20 \%$ & $D E 00 A<10 \mathrm{kM}$ & CORTE 4 BAIXA \\
\hline 0446 & 15458.96 & & $>13 \% A<=20 \%$ & $D E 10 \mathrm{~A}<20 \mathrm{kM}$ & CORTE 4 BAIXA \\
\hline 0447 & 8155.4 & & $>13 \% A<=20 \%$ & $\mathrm{DE} 20 \mathrm{~A}<30 \mathrm{KM}$ & CORTE 4 BAIXA \\
\hline 0448 & 3809.08 & & $>13 \% A<=20 \%$ & $D E 30 \mathrm{~A}<40 \mathrm{KM}$ & CORTE 4 BAIXA \\
\hline 0449 & 8121.52 & & $>13 \% A<=20 \%$ & $D E 40 A<50 \mathrm{KM}$ & CORTE 4 BAIXA \\
\hline 0450 & 2110.24 & & $>13 \% \mathrm{~A}<=20 \%$ & $>50 \mathrm{KM}$ & CORTE 4 BAIXA \\
\hline 0451 & 7814.4 & & $>20 \%$ & $D E 00 A<10 \mathrm{KM}$ & CORTE 4 BAIXA \\
\hline 0452 & 11242.88 & & $>20 \%$ & $\mathrm{DE} 10 \mathrm{~A}<20 \mathrm{KM}$ & CORTE 4 BAIXA \\
\hline 0453 & 59312 & & $>20 \%$ & DE $20 \mathrm{~A}<30 \mathrm{KM}$ & CORTE 4 BAIXA \\
\hline 0454 & 2770.24 & & $>20 \%$ & $D E 30 \mathrm{~A}<40 \mathrm{KM}$ & CORTE 4 BAIXA \\
\hline 0455 & 5906.56 & & $>20 \%$ & $D E 40 \mathrm{~A}<50 \mathrm{KM}$ & CORTE 4 BAIXA \\
\hline 0456 & 1534.72 & & $>20 \%$ & $>50 \mathrm{KM}$ & CORTE 4 BAIXA \\
\hline
\end{tabular}




\section{RESULTADOS E DISCUSSÃO}

\subsection{Resultados}

A simulação realizada para validar o modelo matemático acima descrito apresentou os resultados descritos a seguir.

Durante todo o horizonte de planejamento ( 16 anos) somente 3 das 14 politicas disponiveis foram utilizadas. As politicas utilizadas foram:

- Plantio manual sem incorporação de palha;

- Colheita manual de cana queimada;

- Colheita mecânica de cana queimada.

Pode-se perceber que nenhuma das atividades relacionadas com o corte de cana crua foi ativada durante o horizonte de planejamento. Houve nos quatro primeiros anos compra de colhedoras de cana queimada num total de 200 máquinas adicionais perfazendo um total de 400 colhedoras de cana queimada disponíveis a partir do ano 4 . Os resultados mostram que para as faixas de declividade acima de $8 \%$ somente duas politicas foram adotadas, uma para plantio e outra para corte. Os resultados para estas faixas de declividade são mostrado na Tabela 13. 
Tabela 13: Área alocada pelo modelo para cada política adotada nos locais com declividade acima de $8 \%$.

\begin{tabular}{|c|c|c|c|}
\hline Ano & Política & $\begin{array}{l}\text { Área } \\
\text { (mil ha) }\end{array}$ & $\%$ da área \\
\hline 1 & Plantio Manual & 180 & $18 \%$ \\
\hline 1 & Corte Manual & 832 & $82 \%$ \\
\hline 2 & Plantio Manual & 180 & $18 \%$ \\
\hline 2 & Corte Manual & 832 & $82 \%$ \\
\hline 3 & Plantio Manual & 180 & $18 \%$ \\
\hline 3 & Corte Manual & 832 & $82 \%$ \\
\hline 4 & Plantio Manual & 180 & $18 \%$ \\
\hline 4 & Corte Manual & 832 & $82 \%$ \\
\hline 5 & Plantio Manual & 180 & $18 \%$ \\
\hline 5 & Corte Manual & 832 & $82 \%$ \\
\hline 6 & Plantio Manual & 180 & $18 \%$ \\
\hline 6 & Corte Manual & 832 & $82 \%$ \\
\hline 7 & Plantio Manual & 180 & $18 \%$ \\
\hline 7 & Corte Manual & 832 & $82 \%$ \\
\hline 8 & Plantio Manual & 180 & $18 \%$ \\
\hline 8 & Corte Manual & 832 & $82 \%$ \\
\hline 9 & Plantio Manual & 180 & $18 \%$ \\
\hline 9 & Corte Manual & 832 & $82 \%$ \\
\hline 10 & Plantio Manual & 180 & $18 \%$ \\
\hline 10 & Corte Manual & 832 & $82 \%$ \\
\hline 11 & Plantio Manual & 180 & $18 \%$ \\
\hline 11 & Corte Manual & 832 & $82 \%$ \\
\hline 12 & Plantio Manual & 180 & $18 \%$ \\
\hline
\end{tabular}


Tabela 13 (cont.): Área alocada pelo modelo para cada política adotada nos locais com declividade acima de $8 \%$.

\begin{tabular}{llll}
\hline Ano & Política & Área & $\%$ da área \\
\hline & & (mil ha) & \\
\hline 12 & Corte Manual & 832 & $82 \%$ \\
13 & Plantio Manual & 180 & $18 \%$ \\
13 & Corte Manual & 832 & $82 \%$ \\
14 & Plantio Manual & 180 & $18 \%$ \\
14 & Corte Manual & 832 & $82 \%$ \\
15 & Plantio Manual & 180 & $18 \%$ \\
15 & Corte Manual & 832 & $82 \%$ \\
16 & Plantio Manual & 180 & $18 \%$ \\
16 & Corte Manual & 832 & $82 \%$ \\
\hline
\end{tabular}

Para a faixa de declividade menor ou igual a $8 \%$ as duas politicas de corte foram utilizadas, em proporções diferentes, ao longo do horizonte de planejamento. Inicialmente houve uma ampliação da área de corte mecanizada e, a partir do ano 5 , uma estabilização desta área. A Tabela 14 mostra os resultados obtidos nos 16 anos para as áreas com declividade menor que $8 \%$. 
Tabela 14 : Área alocada pelo modelo para cada uma das políticas adotadas para os locais com declividade menor ou igual a $8 \%$.

\begin{tabular}{|c|c|c|c|}
\hline Ano & Politica & $\begin{array}{l}\text { Área } \\
\text { (mil ha) }\end{array}$ & $\%$ da área \\
\hline 1 & Plantio Manual & 192 & $16 \%$ \\
\hline 1 & Corte Manual & 523 & $44 \%$ \\
\hline 1 & Corte Mecânico & 473 & $40 \%$ \\
\hline 2 & Plantio Manual & 192 & $16 \%$ \\
\hline 2 & Corte Manual & 444 & $37 \%$ \\
\hline 2 & Corte Mecânico & 473 & $47 \%$ \\
\hline 3 & Plantio Manual & 192 & $16 \%$ \\
\hline 3 & Corte Manual & 379 & $32 \%$ \\
\hline 3 & Corte Mecânico & 618 & $52 \%$ \\
\hline 4 & Plantio Manual & 192 & $16 \%$ \\
\hline 4 & Corte Manual & 310 & $26 \%$ \\
\hline 4 & Corte Mecânico & 687 & $58 \%$ \\
\hline 5 & Plantio Manual & 192 & $16 \%$ \\
\hline 5 & Corte Manual & 310 & $26 \%$ \\
\hline 5 & Corte Mecânico & 687 & $58 \%$ \\
\hline 6 & Plantio Manual & 192 & $16 \%$ \\
\hline 6 & Corte Manual & 310 & $26 \%$ \\
\hline 6 & Corte Mecânico & 687 & $58 \%$ \\
\hline 7 & Plantio Manual & 192 & $16 \%$ \\
\hline 7 & Corte Manual & 310 & $26 \%$ \\
\hline 7 & Corte Mecânico & 687 & $58 \%$ \\
\hline 8 & Plantio Manual & 192 & $16 \%$ \\
\hline 8 & Corte Manual & 310 & $26 \%$ \\
\hline
\end{tabular}


Tabela 14 (cont.): Área alocada pelo modelo para cada uma das políticas adotadas para os locais com declividade menor ou igual a $8 \%$.

\begin{tabular}{|c|c|c|c|}
\hline Ano & Politica & $\begin{array}{l}\text { Área } \\
\text { (mil ha) }\end{array}$ & $\%$ da área \\
\hline 8 & Corte Mecânico & 687 & $58 \%$ \\
\hline 9 & Plantio Manual & 192 & $16 \%$ \\
\hline 9 & Corte Manual & 310 & $26 \%$ \\
\hline 9 & Corte Mecânico & 687 & $58 \%$ \\
\hline 10 & Plantio Manual & 192 & $16 \%$ \\
\hline 10 & Corte Manual & 310 & $26 \%$ \\
\hline 10 & Corte Mecânico & 687 & $58 \%$ \\
\hline 11 & Plantio Manual & 192 & $16 \%$ \\
\hline 11 & Corte Manual & 310 & $26 \%$ \\
\hline 11 & Corte Mecânico & 687 & $58 \%$ \\
\hline 12 & Plantio Manual & 192 & $16 \%$ \\
\hline 12 & Corte Manual & 310 & $26 \%$ \\
\hline 12 & Corte Mecânico & 687 & $58 \%$ \\
\hline 13 & Plantio Manual & 192 & $16 \%$ \\
\hline 13 & Corte Manual & 310 & $26 \%$ \\
\hline 13 & Corte Mecânico & 687 & $58 \%$ \\
\hline 14 & Plantio Manual & 192 & $16 \%$ \\
\hline 14 & Corte Manual & 310 & $26 \%$ \\
\hline 14 & Corte Mecânico & 687 & $58 \%$ \\
\hline 15 & Plantio Manual & 192 & $16 \%$ \\
\hline 15 & Corte Manual & 310 & $26 \%$ \\
\hline 15 & Corte Mecânico & 687 & $58 \%$ \\
\hline 16 & Plantio Manual & 192 & $16 \%$ \\
\hline
\end{tabular}


Tabela 14 (cont.): Área alocada pelo modelo para cada uma das políticas adotadas para os locais com declividade menor ou igual a $8 \%$.

\begin{tabular}{llll}
\hline Ano Política & $\begin{array}{c}\text { Area } \\
\text { (mil ha) }\end{array}$ \\
\hline 16 & Corte Manual & 310 & $26 \%$ \\
16 & Corte Mecânico & 687 & $58 \%$ \\
\hline
\end{tabular}

Visando avaliar melhor a introdução do corte mecânico foram analisados os resultados das áreas com declividade menor que $8 \%$ para cada uma das faixas de distância. Os resultados obtidos mostram que para as áreas com uma distância menor que $10 \mathrm{~km}$ toda a área foi alocada para corte mecânico já a partir do primeiro ano. Para a faixa de distância de 10 a $20 \mathrm{~km}$, houve uma expansão da área colhida até o quarto ano e a partir daí toda a área passou a ser colhida mecanicamente. Na terceira faixa de distância adotada, de 20 a $30 \mathrm{~km}$, somente o corte manual era praticado até o terceiro ano sendo introduzido a partir do quarto ano o corte mecânico em $\%$ da área, porcentagem esta que não se alterou até o último ano do planejamento. O resumo destes resultados são apresentados na Tabela 15, Tabela 16 e Tabela 17

Finalmente, a Tabela 18 mostra os resultados obtidos nas áreas com distância superior a $30 \mathrm{~km}$, onde somente o corte manual foi adotado. 
Tabela 15 : Área alocada pelo modelo para cada uma das políticas adotadas para os locais com declividade menor ou igual a $8 \%$ e distância menor ou igual a $10 \mathrm{~km}$.

\begin{tabular}{|c|c|c|c|}
\hline Ano & Política & $\begin{array}{l}\text { Área } \\
\text { (mil ha) }\end{array}$ & $\%$ da área \\
\hline 1 & Plantio Manual & 59 & $16 \%$ \\
\hline 1 & Corte Mecânico & 317 & $82 \%$ \\
\hline 2 & Plantio Manual & 59 & $16 \%$ \\
\hline 2 & Corte Mecânico & 317 & $82 \%$ \\
\hline 3 & Plantio Manual & 59 & $16 \%$ \\
\hline 3 & Corte Mecânico & 317 & $82 \%$ \\
\hline 4 & Plantio Manual & 59 & $16 \%$ \\
\hline 4 & Corte Mecânico & 317 & $82 \%$ \\
\hline 5 & Plantio Manual & 59 & $16 \%$ \\
\hline 5 & Corte Mecânico & 317 & $82 \%$ \\
\hline 6 & Plantio Manual & 59 & $16 \%$ \\
\hline 6 & Corte Mecânico & 317 & $82 \%$ \\
\hline 7 & Plantio Manual & 59 & $16 \%$ \\
\hline 7 & Corte Mecânico & 317 & $84 \%$ \\
\hline 8 & Plantio Manual & 59 & $16 \%$ \\
\hline 8 & Corte Mecânico & 317 & $84 \%$ \\
\hline 9 & Plantio Manual & 59 & $16 \%$ \\
\hline 9 & Corte Mecânico & 317 & $84 \%$ \\
\hline 10 & Plantio Manual & 59 & $16 \%$ \\
\hline 10 & Corte Mecânico & 317 & $84 \%$ \\
\hline 11 & Plantio Manual & 59 & $16 \%$ \\
\hline 11 & Corte Mecânico & 317 & $84 \%$ \\
\hline 12 & Plantio Manual & 59 & $16 \%$ \\
\hline
\end{tabular}


Tabela 15 (cont.): Área alocada pelo modelo para cada uma das politicas adotadas para os locais com declividade menor ou igual a $8 \%$ e distância menor ou igual a $10 \mathrm{~km}$.

\begin{tabular}{|c|c|c|c|}
\hline Ano & Politica & $\begin{array}{l}\text { Área } \\
\text { (mil ha) }\end{array}$ & $\%$ da área \\
\hline 12 & Corte Mecânico & 317 & $84 \%$ \\
\hline 13 & Plantio Manual & 59 & $16 \%$ \\
\hline 13 & Corte Mecânico & 317 & $84 \%$ \\
\hline 14 & Plantio Manual & 59 & $16 \%$ \\
\hline 14 & Corte Mecânico & 317 & $84 \%$ \\
\hline 15 & Plantio Manual & 59 & $16 \%$ \\
\hline 15 & Corte Mecânico & 317 & $84 \%$ \\
\hline 16 & Plantio Manual & 59 & $16 \%$ \\
\hline 16 & Corte Mecânico & 317 & $84 \%$ \\
\hline
\end{tabular}

Tabela 16 : Área alocada pelo modelo para cada uma das políticas adotadas para os locais com declividade menor ou igual a $8 \%$ e distância maior que $10 \mathrm{~km}$ e menor ou igual a 20 km.

\begin{tabular}{|c|c|c|c|}
\hline Ano & Politica & $\begin{array}{l}\text { Área } \\
\text { (mil ha) }\end{array}$ & $\%$ da área \\
\hline 1 & Plantio Manual & 65 & $16 \%$ \\
\hline 1 & Corte Manual & 193 & $47 \%$ \\
\hline 1 & Corte Mecânico & 156 & $37 \%$ \\
\hline 2 & Plantio Manual & 65 & $16 \%$ \\
\hline 2 & Corte Manual & 113 & $27 \%$ \\
\hline
\end{tabular}


Tabela 16 (cont.): Área alocada pelo modelo para cada uma das políticas adotadas para os locais com declividade menor ou igual a $8 \%$ e distância maior que $10 \mathrm{~km} \mathrm{e}$ menor ou igual a $20 \mathrm{~km}$.

\begin{tabular}{|c|c|c|c|}
\hline Ano & Política & $\begin{array}{l}\text { Área } \\
\text { (mil ha) }\end{array}$ & $\%$ da área \\
\hline 2 & Corte Mecânico & 236 & $57 \%$ \\
\hline 3 & Plantio Manual & 65 & $16 \%$ \\
\hline 3 & Corte Manual & 48 & $12 \%$ \\
\hline 3 & Corte Mecânico & 301 & $72 \%$ \\
\hline 4 & Plantio Manual & 65 & $16 \%$ \\
\hline 4 & Corte Mecânico & 349 & $84 \%$ \\
\hline 5 & Plantio Manual & 65 & $16 \%$ \\
\hline 5 & Corte Mecânico & 349 & $84 \%$ \\
\hline 6 & Plantio Manual & 65 & $16 \%$ \\
\hline 6 & Corte Mecânico & 349 & $84 \%$ \\
\hline 7 & Plantio Manual & 65 & $16 \%$ \\
\hline 7 & Corte Mecânico & 349 & $84 \%$ \\
\hline 8 & Plantio Manual & 65 & $16 \%$ \\
\hline 8 & Corte Mecânico & 349 & $84 \%$ \\
\hline 9 & Plantio Manual & 65 & $16 \%$ \\
\hline 9 & Corte Mecânico & 349 & $84 \%$ \\
\hline 10 & Plantio Manual & 65 & $16 \%$ \\
\hline 10 & Corte Mecânico & 349 & $84 \%$ \\
\hline 11 & Plantio Manual & 65 & $16 \%$ \\
\hline 11 & Corte Mecânico & 349 & $84 \%$ \\
\hline 12 & Plantio Manual & 65 & $16 \%$ \\
\hline 12 & Corte Mecânico & 349 & $84 \%$ \\
\hline
\end{tabular}


Tabela 16 (cont.): Área alocada pelo modelo para cada uma das políticas adotadas para os locais com declividade menor ou igual a $8 \%$ e distância maior que $10 \mathrm{~km} \mathrm{e}$ menor ou igual a $20 \mathrm{~km}$.

\begin{tabular}{|c|c|c|c|}
\hline Ano & Política & $\begin{array}{l}\text { Área } \\
\text { (mil ha) }\end{array}$ & $\%$ da área \\
\hline 13 & Plantio Manual & 65 & $16 \%$ \\
\hline 13 & Corte Mecânico & 349 & $84 \%$ \\
\hline 14 & Plantio Manual & 65 & $16 \%$ \\
\hline 14 & Corte Mecânico & 349 & $84 \%$ \\
\hline 15 & Plantio Manual & 65 & $16 \%$ \\
\hline 15 & Corte Mecânico & 349 & $84 \%$ \\
\hline 16 & Plantio Manual & 65 & $16 \%$ \\
\hline 16 & Corte Mecânico & 349 & $84 \%$ \\
\hline
\end{tabular}

Tabela 17 : Área alocada pelo modelo para cada uma das políticas adotadas para os locais com declividade menor ou igual a $8 \%$ e distância maior que $20 \mathrm{~km}$ e menor ou igual a 30 km.

\begin{tabular}{llll}
\hline Ano & Política & Área & $\%$ da área \\
\hline & & (mil ha) & \\
\hline 1 & Plantio Manual & 36 & $17 \%$ \\
\hline 1 & Corte Manual & 181 & $83 \%$ \\
\hline 2 & Plantio Manual & 36 & $17 \%$ \\
\hline 2 & Corte Manual & 181 & $83 \%$ \\
\hline 3 & Plantio Manual & 36 & $17 \%$ \\
3 & Corte Manual & 181 & $83 \%$ \\
\hline
\end{tabular}


Tabela 17 (cont.): Área alocada pelo modelo para cada uma das políticas adotadas para os locais com declividade menor ou igual a $8 \%$ e distância maior que $20 \mathrm{~km} \mathrm{e}$ menor ou igual a $30 \mathrm{~km}$.

\begin{tabular}{|c|c|c|c|}
\hline Ano & Política & $\begin{array}{l}\text { Área } \\
\text { (mil ha) }\end{array}$ & $\%$ da área \\
\hline 4 & Plantio Manual & 36 & $17 \%$ \\
\hline 4 & Corte Manual & 161 & $73 \%$ \\
\hline 4 & Corte Mecânico & 20 & $10 \%$ \\
\hline 5 & Plantio Manual & 36 & $17 \%$ \\
\hline 5 & Corte Manual & 160 & $73 \%$ \\
\hline 5 & Corte Mecânico & 21 & $10 \%$ \\
\hline 6 & Plantio Manual & 36 & $17 \%$ \\
\hline 6 & Corte Manual & 160 & $73 \%$ \\
\hline 6 & Corte Mecânico & 21 & $10 \%$ \\
\hline 7 & Plantio Manual & 36 & $17 \%$ \\
\hline 7 & Corte Manual & 160 & $73 \%$ \\
\hline 7 & Corte Mecânico & 21 & $10 \%$ \\
\hline 8 & Plantio Manual & 36 & $17 \%$ \\
\hline 8 & Corte Manual & 160 & $73 \%$ \\
\hline 8 & Corte Mecânico & 21 & $10 \%$ \\
\hline 9 & Plantio Manual & 36 & $17 \%$ \\
\hline 9 & Corte Manual & 160 & $73 \%$ \\
\hline 9 & Corte Mecânico & 21 & $10 \%$ \\
\hline 10 & Plantio Manual & 36 & $17 \%$ \\
\hline 10 & Corte Manual & 160 & $73 \%$ \\
\hline 10 & Corte Mecânico & 21 & $10 \%$ \\
\hline 11 & Plantio Manual & 36 & $17 \%$ \\
\hline
\end{tabular}


Tabela 17 (cont.): Área alocada pelo modelo para cada uma das políticas adotadas para os locais com declividade menor ou igual a $8 \%$ e distância maior que $20 \mathrm{~km}$ e menor ou igual a $30 \mathrm{~km}$.

\begin{tabular}{|c|c|c|c|}
\hline Ano & Política & $\begin{array}{l}\text { Área } \\
\text { (mil ha) }\end{array}$ & $\%$ da área \\
\hline 11 & Corte Manual & 160 & $73 \%$ \\
\hline 11 & Corte Mecânico & 21 & $10 \%$ \\
\hline 12 & Plantio Manual & 36 & $17 \%$ \\
\hline 12 & Corte Manual & 160 & $73 \%$ \\
\hline 12 & Corte Mecânico & 21 & $10 \%$ \\
\hline 13 & Plantio Manual & 36 & $17 \%$ \\
\hline 13 & Corte Manual & 160 & $73 \%$ \\
\hline 13 & Corte Mecânico & 21 & $10 \%$ \\
\hline 14 & Plantio Manual & 36 & $17 \%$ \\
\hline 14 & Corte Manual & 160 & $73 \%$ \\
\hline 14 & Corte Mecânico & 21 & $10 \%$ \\
\hline 15 & Plantio Manual & 36 & $17 \%$ \\
\hline 15 & Corte Manual & 160 & $73 \%$ \\
\hline 15 & Corte Mecânico & 21 & $10 \%$ \\
\hline 16 & Plantio Manual & 36 & $17 \%$ \\
\hline 16 & Corte Manual & 160 & $73 \%$ \\
\hline 16 & Corte Mecânico & 21 & $10 \%$ \\
\hline
\end{tabular}


Tabela 18 : Área alocada pelo modelo para cada uma das políticas adotadas para os locais com declividade menor ou igual a $8 \%$ e distância maior que $30 \mathrm{~km}$.

\begin{tabular}{|c|c|c|c|}
\hline Ano & Politica & $\begin{array}{l}\text { Área } \\
\text { (mil ha) }\end{array}$ & $\%$ da área \\
\hline 1 & Plantio Manual & 32 & $18 \%$ \\
\hline 1 & Corte Manual & 149 & $82 \%$ \\
\hline 2 & Plantio Manual & 32 & $18 \%$ \\
\hline 2 & Corte Manual & 149 & $82 \%$ \\
\hline 3 & Plantio Manual & 32 & $18 \%$ \\
\hline 3 & Corte Manual & 149 & $82 \%$ \\
\hline 4 & Plantio Manual & 32 & $18 \%$ \\
\hline 4 & Corte Manual & 149 & $82 \%$ \\
\hline 5 & Plantio Manual & 32 & $18 \%$ \\
\hline 5 & Corte Manual & 149 & $82 \%$ \\
\hline 6 & Plantio Manual & 32 & $18 \%$ \\
\hline 6 & Corte Manual & 149 & $82 \%$ \\
\hline 7 & Plantio Manual & 32 & $18 \%$ \\
\hline 7 & Corte Manual & 149 & $82 \%$ \\
\hline 8 & Plantio Manual & 32 & $18 \%$ \\
\hline 8 & Corte Manual & 149 & $82 \%$ \\
\hline 9 & Plantio Manual & 32 & $18 \%$ \\
\hline 9 & Corte Manual & 149 & $82 \%$ \\
\hline 10 & Plantio Manual & 32 & $18 \%$ \\
\hline 10 & Corte Manual & 149 & $82 \%$ \\
\hline 11 & Plantio Manual & 32 & $18 \%$ \\
\hline 11 & Corte Manual & 149 & $82 \%$ \\
\hline 12 & Plantio Manual & 32 & $18 \%$ \\
\hline
\end{tabular}


Tabela 18 (cont.): Área alocada pelo modelo para cada uma das políticas adotadas para os locais com declividade menor ou igual a $8 \%$ e distância maior que $30 \mathrm{~km}$.

\begin{tabular}{|c|c|c|c|}
\hline Ano & Política & $\begin{array}{l}\text { Area } \\
\text { (mil ha) }\end{array}$ & $\%$ da área \\
\hline 12 & Corte Manual & 149 & $82 \%$ \\
\hline 13 & Plantio Manual & 32 & $18 \%$ \\
\hline 13 & Corte Manual & 149 & $82 \%$ \\
\hline 14 & Plantio Manual & 32 & $18 \%$ \\
\hline 14 & Corte Manual & 149 & $82 \%$ \\
\hline 15 & Plantio Manual & 32 & $18 \%$ \\
\hline 15 & Corte Manual & 149 & $82 \%$ \\
\hline 16 & Plantio Manual & 32 & $18 \%$ \\
\hline 16 & Corte Manual & 149 & $82 \%$ \\
\hline
\end{tabular}

Durante o horizonte de planejamento em estudo, o aumento da mecanização do corte de cana provocou uma diminuição na utilização da mão-de-obra na época de safra. A Tabela 19 mostra a evolução da utilização de mão-de-obra no período de safra.

Tabela 19: Uso de mão de obra durante o horizonte de planejamento.

\begin{tabular}{cccc}
\hline Ano Homens & $\begin{array}{c}\text { t.cana colhidas } \\
\text { manualmente do total } \\
\text { (milhões ton.) }\end{array}$ \\
\hline 1 & 46072 & 103.7 & $73 \%$ \\
\hline 2 & 43597 & 98.1 & $69 \%$ \\
\hline 3 & 41122 & 92.5 & $65 \%$ \\
\hline 4 & 38647 & 87.0 & $61 \%$ \\
\hline
\end{tabular}


Tabela 19 (cont.): Uso de mão de obra durante o horizonte de planejamento.

\begin{tabular}{|c|c|c|c|}
\hline Ano & Homens & $\begin{array}{l}\text { t.cana colhidas } \\
\text { manualmente } \\
\text { (milhões ton.) }\end{array}$ & $\begin{array}{l}\% \text { do total } \\
\text { de cana }\end{array}$ \\
\hline 5 & 38647 & 87.0 & $61 \%$ \\
\hline 6 & 38647 & 87.0 & $61 \%$ \\
\hline 7 & 38647 & 87.0 & $61 \%$ \\
\hline 8 & 38647 & 87.0 & $61 \%$ \\
\hline 9 & 38647 & 87.0 & $61 \%$ \\
\hline 10 & 38647 & 87.0 & $61 \%$ \\
\hline 11 & 38647 & 87.0 & $61 \%$ \\
\hline 12 & 38647 & 87.0 & $61 \%$ \\
\hline 13 & 38647 & 87.0 & $61 \%$ \\
\hline 14 & 38647 & 87.0 & $61 \%$ \\
\hline 15 & 38647 & 87.0 & $61 \%$ \\
\hline 16 & 38647 & 87.0 & $61 \%$ \\
\hline
\end{tabular}




\subsection{Discussão dos resultados}

Os resultados apresentados pela simulação são bastante coerentes com o que era esperado dado as informações iniciais fornecidas ao sistema. $O$ fato de somente 3 politicas serem utilizadas pode ser facilmente explicado.

Inicialmente, das 4 atividades criadas para plantio de cana, duas previam plantio mecanizado. Como este é um projeto em desenvolvimento, ou seja não existem plantadoras disponiveis, nenhuma destas políticas poderia ser acionada. A terceira alternativa para plantio era de plantio manual com incorporação de palha, o que pressupōe haver um corte de cana crua anteriormente à reforma. Como nenhuma alternativa de cana crua foi acionada não poderia ser utilizada nenhuma politica com incorporação de palha. Portanto, para o plantio, restou somente uma alternativa: plantio manual sem incorporação de palha. Esta foi a alternativa adotada pelo modelo para todo o horizonte de planejamento.

A análise da resposta obtida para as áreas em estágio de corte é um pouco mais complexa. Os dados utilizados mostram um custo de corte, carregamento e transporte para a cana crua bastante superiores ao da cana queimada. Apesar de terem sido utilizados valores de produtividade e qualidade tecnológica superiores para a cana crua, este aumento na receita 
não foi suficiente para tornar o corte de cana crua uma atividade interessante para o modelo. Além disso, a palha não estaria gerando nenhuma renda adicional pois o custo de recolhimento da palha com a tecnologia disponivel atualmente foi maior do que a receita produzida pela energia elétrica que seria fornecida para a rede ou pelo bagaço hidrolisado que seria produzido se a palha fosse levada para a indústria. Estes motivos explicam o porque de nenhuma política relacionada com corte de cana crua ter sido adotada pelo modelo ao longo do horizonte de planejamento.

A introdução do corte mecanizado pode ser explicado pelo fato de o custo operacional utilizado para o corte mecânico de cana queimada ser menor do que o de corte manual de cana queimada. Nas áreas com declividade acima de $8 \%$ o corte mecânico não foi acionado pois este limite foi imposto como declividade máxima para a mecanização do corte com os equipamentos disponiveis hoje no mercado. O resultado mais interessante sobre este aspecto foi a não utlização do corte mecânico em toda a área com declividade menor do que $8 \%$. Este fato pode ser explicado pelo custo de transporte. O custo de transporte de cana colhida mecanicamente foi considerado mais alto pelo fato da capacidade de carga dos caminhões ser menor quando em comparação com o corte manual de cana. Com isto, o modelo optou por alocar o corte mecânico somente nas áreas mais 
próximas às usinas, permanecendo com o corte manual nas áreas mais distantes.

Finalmente, a diminuição da utilização de mão-de-obra é um fator de grande preocupação pois, mesmo sem a introdução de nenhuma das diversas novas tecnologias em desenvolvimento nesta área, a utilização de mão-de-obra deve cair em cerca de $16 \%$ Isto representa uma disponibilização de cerca de 7500 pessoas. Deve-se destacar que as tecnologias em desenvolvimento visam permitir o corte mecânico em áreas com declividade maior, o que deverá atender à pressão ecológica para a introdução rápida do corte de cana crua, que tende a ser viável somente com o corte mecânico. 


\section{CONCLUSÕES E SUGESTÕES}

\subsection{CONCLUSÕES}

O presente trabalho permite concluir que o modelo adotado conseguiu representar o sistema produtivo agroindustrial da cana-de-açúcar e possibilita a avaliação do efeito causado pela introdução de tecnologias relativas à eliminação ou redução da queima de palha de cana bem como de fatores externos como a disponibilidade de mão-de-obra. A simulação realizada forneceu resultados coerentes com a expectativa existente em relação às informações fornecidas.

De um modo geral, o modelo é especialmente indicado para avaliar a variação de custos de produção, uso de mão-de-obra, destino da palha de cana que deixa de ser queimada (assim como dos preços dos produtos originados), evolução da produtividade agrícola e características tecnológicas da matéria-prima provocadas pela introdução de tecnologias. 0 horizonte de 16 anos garante que todas as tecnologias tenham tempo hábil para serem introduzidas.

\subsection{SUGESTÕES}

Para a continuação das pesquisas pode-se sugerir: 
a) a utilização de diferentes coeficientes de preços dos produtos gerados pela palha de cana assim como dos seus custos de produção;

b) uma análise de sensibilidade sobre a eficiência dos equipamentos em estudo visando obter os valores onde a pesquisa agrícola necessitaria chegar para tornar esta tecnologia viável;

c) a incorporação de outras tecnologias como por exemplo a inclusão de diferentes sistemas de transporte; 


\section{BIBLIOGRAFIA}

AGUILAR, Antonio et alii. La combustión de los residuos agrícolas de la caña de azúcar. Parte 1. Caracteristicas combustibles. Cuba Azucar. 40-47, Ene./Mar. 1989.

ATCHISON, Joseph $H$. Making bagasse avaialable for pulp, paper, paperboard, fibreboard, particleboard, and other industrial products at what price equivalent fuel values of bagasse and other fibrous raw materials as compared to fossil fuels. In: INTERNATIONAL SOCIETY OF SUGAR CANE TECHNOLOGISTS, 16., São Paulo, Sep. 9-20, 1977. Procedings. São Paulo, 1978 p. 3129-3144.

AYER, H.W. e SCHUH, G.E. Taxa de retorno social e outros aspectos da pesquisa agrícola: o caso da pesquisa do algodão em São Paulo, Brasil. In: ARAÚJJ, P.F.C de . Desenvolvimento da agricultura, educação, pesquisa e assistência técnica. Editora Pioneira, 1975, 238 p.-pg 117-137.

AYALA, H.G. Experiencia argentina en el uso alternativo de la caña de azúcar para energia y alimento. México, GEPLACEA, 1987. p. 57-63. (Coleccion GEPLACEA, Serie Diversificacion).

BASSINELLO, A.L. Implicações agricolas e industriais da colheita de cana crua. Araras. IAA/PLANALSUCAR.COSUL. 1988 55p.

CETESB. Cálculo preliminar da energia liberada anualmente na queima dos canaviais brasileiros. São Paulo, 1985.

DEGASPARI, N et alli. A queima de cana-de-açúcar, os efeitos sobre a população da broca. Diatraea saccharalis (Fabr. 1794), seus predadores e parasitos. STAB, Piracicaba, 1(5):35-40, maio/jun. 1983.

EILAND, B.R. \& CLAYTON J.E. Perfomance and energy considerations in mechanical sugar cane harvesting without preharvest burning: Florida progress report. Journal American Sugar Cane Tecnologists. Baton Rouge, 1:15-9. July 1982. 
EILAND, B.R. \& CLAYTON, J.E. Collection of sugarcane crop residue for energy. In: AMERICAN SOCIETY OF AGRICULTURAL ENGINEERS, Chicago, Dec. 14-17, 1987. Winter meeting. St. Joseph, 1982. 6p. (Paper 82-3586).

EVENSON, R.E. Economic aspects of the organization of agricultural Research. In: Resource allocation in agricultural Research. Edited by Walter L. Fishel, 1971. University of Minnesota. 391 p. - p.163-182.

FERNANDES, A.C. Qualidade tecnológica da cana de açúcar. Relatório técnico COPERSUCAR, 1988.

FISHEL,W.L. The Minnesota agricultural Research resource allocation information system and experiment. In. Resource allocation in agricultural Research. Edited by Walter L. Fishel, 1971. University of Minnesota. 391 p. - p.344-382.

FOSTER, D.H. \& IVIN, P.C. Losses of sugar cana and water from canes in fires. In: CONFERENCE OF THE AUSTRALIAN SOCIETY OF SUGAR CANE TECHNOLOGISTS. Burdaberg, 1981. Proceedings, p.13-20.

FOSTER, D.H. et alli. Estudoss en el deterior de la caña de azúcar en Australia. Tecnologia GEPLACEA, México (16):111-28, 1980.

FURLANI NETO, V.L. et alii. Effects of green and burned cane on cane quality, cane losses, crop residues and chopper harvester performance. In: INTERNATIONAL SOCIETY OF SUGAR CANE TECHNOLOGISTS, 20., São Paulo, Oct. 12-21, 1989. Proceedings. São Paulo, 1989. p. $1043-1048$.

GASCHO, G.J. et alli. Sugarcane deterioration during storage as affected by chopping, delay in milling, and burning. In: MEETINGS OF THE AMERICAN SOCIETY OF SUGAR CANE TECHONOLOGISTS, 2. Flórida, 1972. Proceedings. p.168-74.

GRILICHES, Z. Despesas em pesquisa e educação na função de produção agricola agregada. In: Uso alternativo de la caña de azucar para energia y alimento. México, GEPLACEA, 1987. p. 57-63. (Coleccion GEPLACEA, Serie Diversificacion).p.101-115. 
HALL, D.O., MYNICK, H.E e WILLIAMS, R.H., 1990. Carbon sequestration versus fossil fuel substitution - PO/CEES Report 255, Princeton University.

HAYAMI, Y e RUTTAN, V.W. Preços dos fatores e mudânça técnica no desenvolvimento da agricultura: Estados Unidos e Japão 1880-1960 In: Uso alternativo de la caña de azucar para energia y alimento. México, GEPLACEA, 1987. p. 57-63. (Coleccion GEPLACEA, Serie Diversificacion).p.53-76.

HEADY, E.O. Welfare implications of agricultural Research. In: Resource allocation in agricultural Research. Edited by Walter L. Fishel, 1971. University of Minnesota. 391 p. - p.121-137.

KALDOR, D.R. Social returns to research and objectives of public research. In. Resource allocation in agricultural Research. Edited by Walter $L$. Fishel, 1971. University of Minnesota. 391 p. - p.62-79.

KIRCHHOFF, V. e SAHAI, Y, 1985. Medidas de ozônio a bordo do avião Bandeirante do Inpe, Revista Brasileira de Geofísica, V.4, 21-26.

KIRCHHOFF, V. et alli, 1991. Enhancements of $\mathrm{CO}$ and $\mathrm{O}_{3}$ from burnings in sugar cane fields, Journal of Atmospheric Chemestry, 12, 87-102.

LOPEZ, Pedro A. Recolección de barbojo como fuente energética en el Central Romana. In: Uso alternativo de la caña de azucar para energia y alimento. México, GEPLACEA, 1987. p. 57-63. (Coleccion GEPLACEA, Serie Diversificacion).

MACEDO, I.C. Agroindústria da cana-de-açúcar: Participação na redução da taxa de carbono atmosférico no Brasil, Relatório Técnico COPERSUCAR, 1991.

MACEDO, I.C. e NOGUEIRA, L.A.H., Balanço de Energia na Produção de Cana-de-Açúcar e Álcool nas Usinas Cooperadas, Boletim Técnico Copersucar, 31/85: 22-23. 
MAHLSTEDE, J.P. Long-range planning at the lowa Agricultural and Home Economics Experiment Station. In. Resource allocation in agricultural Research. Edited by Walter L. Fishel, 1971. University of Minnesota. 391 p. - p.326-343.

MATHUR, P,S. E SAKSENA, M.M. On the utility of trash mulch in sugar cane ratoons. 1965, Indian Sugarcane Journal, 10(1).p.24-27.

MOLINA JR., Walter Francisco et alii. Estudo preliminar sobre enfardamento de residuos de colheita de cana-de-açúcar (Saccharum spp.). 18 p.Dep. Eng. Rural, ESALQ, USP - Piracicaba, 1991.

NICKELL, L.G., 1970. Comparisons of burning Vs. now-burning of cane I field, Annual Confrence Hawaiian Sugar Technologists, 29. Reports, 101-110.

ORSENIGO, J.R. A harvest comparison of green and burned sugarcane. Technical Bulletin 794, Institute of Food and Agricultural Sciences, California, Abril 1978, 30p.

PAULSEN, A.A. The pricing of Research output. In: Resource allocation in agricultural Research. Edited by Walter L. Fishel, 1971. University of Minnesota. 391 p. - p.80-89.

PETERSON, H.L. The returns to investment in Agricultural Research in the United States. In: Resource allocation in agricultural Research. Edited by Walter L. Fishel, 1971. University of Minnesota. 391 p - p.139-162.

PIZYSIEZNIG FILHO, J. Um modelo de avaliação de novas tecnologias: o caso do aproveitamento dos subprodutos do cacau. Dissertação de Mestrado em Economia Agrária pela ESALQ-USP. Piracicaba. 1987.

PUTERBAUGH, H.L. An application of Planning-ProgrammingBudgeting(PPB) in the Agricultural Research Service. In: Resource allocation in agricultural Research. Edited by Walter L. Fishel, 1971. University of Minnesota. 391 p. - p.316-315.

REDMAN, E.H. Deterioro de cana quemada. El Cañero, Santo Domingo, 6(8):6-7, ago. 1977. 
RIPOLI, T.C. Do facão a mecanização, a colheita da cana-de-açúcar. Agricultura de Hoje, Rio de Janeiro, 4(44):32-5, dez. 1978

RIPOLI, T.C. et alli. Critério para avaliação de estado de canaviais visando a colheita. Brasil Açucareiro, Rio de Janeiro, 4(44):32-5, dez. 1978.

RIPOLI, T.C.C. et alii. Equivalente energético do palhiço da cana-de-açúcar. Piracicaba, ESALQ/USP. 14 p. 1990

RIPOLI, Tomaz Caetano \& MOLINA JR., Walter F. Cultura canavieira: um desperdicio energético. Maquinaria Agrícola, 6 (1): 2-3, Jan. 1991.

RIPOLI, Tomaz Caetano; MIALHE, Ruiz Geraldo \& BRITO, José Otávio. Queima de canavial: o desperdicio não mais admissivel. Álcool \& Açúcar, 10 (54): 18-23, Jul./Ago. 1990.

SALLAWAY, M.M. Trash retention as a soil conservation technique. Proceedings of Australian Society of Sugar Cane Technologists. 1979. p.133-137.

TOLEDO, P.E.N., YOSHII, R.J., OTANI, M.N. Avaliação do potencial de uso de colheitadeiras de cana-de-açúcar no Estado de São Paulo. Informações Econômicas 21(6). Junho, 1991.

TURNER, A.W. El deterioro de la caña de azúcar después de su corte. In: Proceedings do $V$ Conferencia del Instituto Tecnologico Azucarero Veracruz. Cordoba, 1961. p.455-475.

TICHENOR, P.J. e RUTTAN, V.W. Problems and issues in Resource allocation for Agricultural Research. In. Resource allocation in agricultural Research. Edited by Walter L. Fishel, 1971. University of Minnesota. 391 p. - p.3-22.

WOOD, R.A \& TOIT, J.L. Deterioration losses in whole stalk sugarcane. In: ANNUAL CONGRESS OF THE SOUTH AFRICAN SUGAR TECHNOLOGISTS ASSOCIATION, 46. Mount Edgecombe, 1972. Proceedings, p.151-7. 
WOOD, R.A. Varietal diferences in rate deterioration of whole stalk sugarcane. IN: ANNUAL CONGRESS OF THE SOUTH AFRICAN SUGAR TECHNOLOGISTS ASSOCIATION, 47. Mout Edgecombe, 1973. Proceedings. p.133-9.

YOUNG, H.E. Deterioration of burnt standing cane and burnt cut cane. In: CONGRESS OF THE ISSCT, 11, Maurititiu, 1962. Proceedings. Amsterdam, Elsevier, 1983 p.307-18. 